Critical Recognition of the Experiences of Therapeutic Behavioral Strategists in Addressing Student Trauma

\title{
Critical Recognition of the Experiences of Therapeutic Behavioral Strategists in Addressing Student Trauma
}

A Dissertation Submitted to the School of Education at the University of Redlands in Partial

Fulfillment of the Requirements for the Degree of Doctor of Education in Leadership for

\author{
Educational Justice \\ Nathan Ambrosio \\ University of Redlands \\ Dissertation Committee \\ Dr. Jose Lalas Ph.D., Chair \\ Dr. Annie Blankenship Knox, J.D. Ph.D., Member \\ Dr. Mikela Bjork Ph.D., Member
}




\section{RlRedlands \\ SchoOl OF Education}

We hereby approve the dissertation of

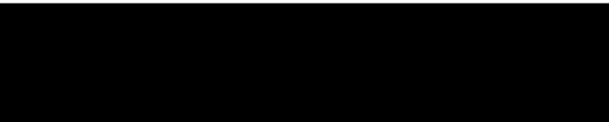

Candidate for the degree of Doctor of Education
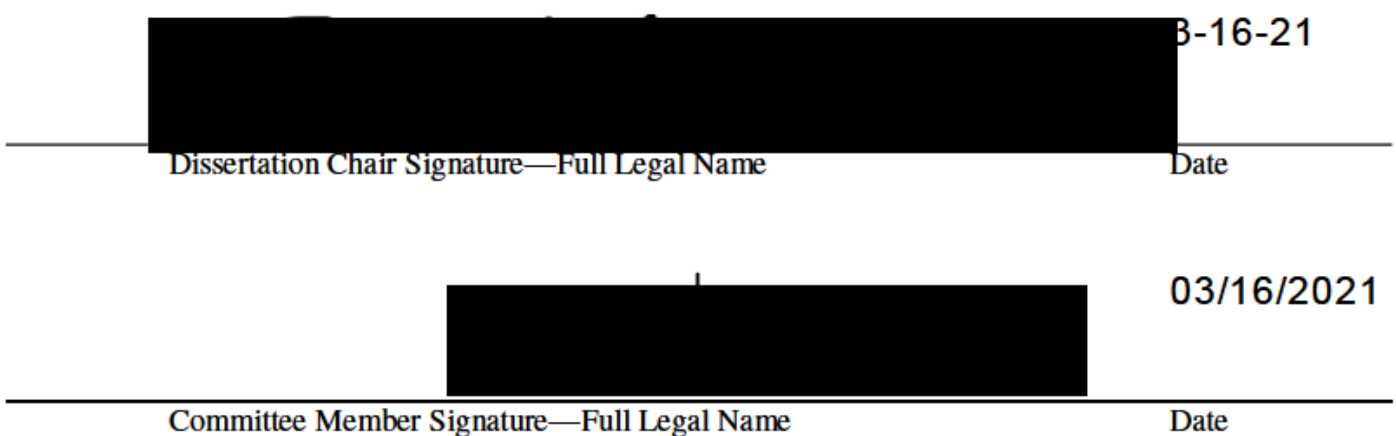

Committee Member Signature-Full Legal Name

Date

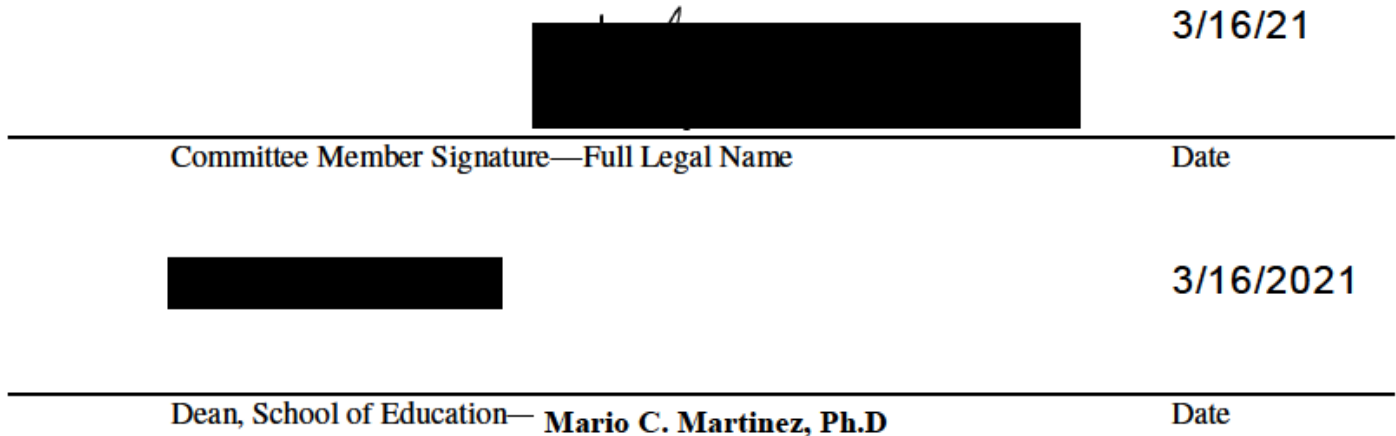


Critical Recognition of the Experiences of Therapeutic Behavioral Strategists in Addressing Student Trauma
Abstract
Using narrative inquiry, this study aims to examine the role of therapeutic behavioral strategists (TBS) in addressing the impact of trauma to students who are in the primary and secondary levels of public education. This dissertation studies and amplifies the experiences of the participating therapeutic behavioral strategists (TBS) in the Rialto Unified School District. Six (6) therapeutic behavioral strategists are interviewed and the narrative data analyzed through the constructed lenses of critical consciousness, recognition and redistribution, and transformative learning theory. The paradigm shift from the traditional approach to trauma- informed care highlights the framework of best professional practices in appropriately responding to students experiencing trauma. 
Critical Recognition of the Experiences of Therapeutic Behavioral Strategists in Addressing Student Trauma

\section{Dedication}

First and foremost, I want to say thank you to my lord and savior Jesus Christ. With God by my side, I know all things are possible. A heartfelt thanks to my family, especially my wife, Nicole, who has been my biggest cheerleader throughout this process. Thank you for always believing in me. Thank you also for understanding when I have not been as available while investing in this doctoral program. Most importantly, thank you for all the sacrifices that you have made to help me fulfill my goals. Words cannot describe how grateful I am to have you as my wife. Thank you to my son,, for always providing me with the inspiration and motivation to move forward through times of adversity. I hope to make both of you proud.

A special thank you to my mother, sister, and brother. Through this research, I have realized that I am drawn to the topic of trauma because of the circumstances we encountered together as a family. I admire all three of you for persevering each and every day and now realize how much strength it took to support each other while facing difficult times.

Also, thank you to my friend for your words of encouragement throughout this entire process. I really appreciate all your support.

"With man this is impossible, but with God all things are possible." Matthew 19:26 NIV 
Critical Recognition of the Experiences of Therapeutic Behavioral Strategists in Addressing Student Trauma

\section{Acknowledgements}

Dr. Jose Lalas, you have been so supportive of me throughout this entire process, and I just want to sincerely thank you for all of your significant contributions as a scholar. Dr. Lalas, this project would not have been completed without your expertise, steadfast guidance, and belief in me. Dr. Annie Blankenship Knox \& Dr. Mikela Bjork, though we have not known each other long, I truly appreciate your feedback and support throughout my dissertation process. I have benefited from the guidance by becoming a stronger scholar because of my interactions with the both of you. Finally, Dr. Heidi Strikwerda...-words cannot describe how inspirational your presence was for me throughout this difficult process. As I faced adversity, it was you who instilled hope by providing words of encouragement to keep moving forward. The hope and guidance you have provided through my educational journey propelled me to heights I did not think were possible. I sincerely appreciate all that you have done for me.

Thank you all for everything along this journey! 
Critical Recognition of the Experiences of Therapeutic Behavioral Strategists in Addressing Student Trauma

Table of Contents

Chapter One: Introduction....................................................... 11

Problem Statement............................................................ 11

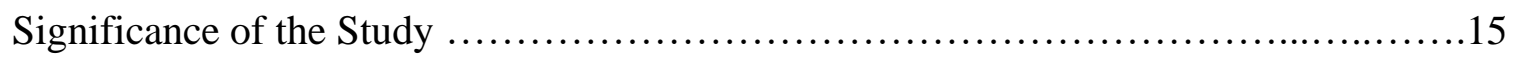

Purpose of Study ........................................................... 16

Conceptual Framework....................................................... 17

Research Questions......................................................22

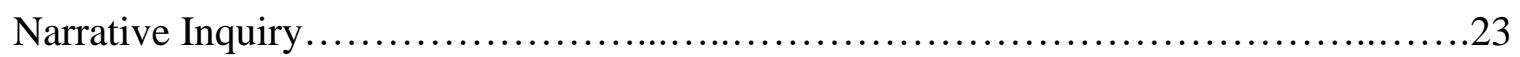

Definition of Key terms................................................... 24

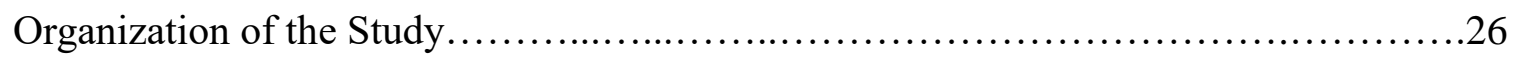

Chapter Two: Literature Review...................................................28

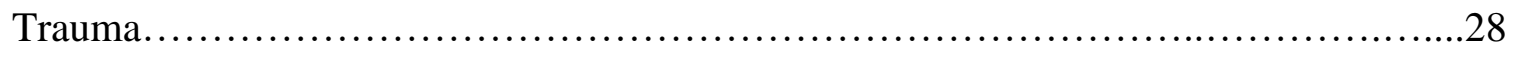

Forms of Trauma...........................................................

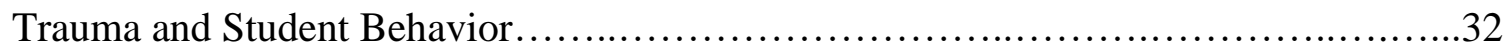

Impact of Trauma on Student Learning .......................................... 34

Impact of Trauma on the Brain........................................... 35

IQ and Academic Achievement............................................ 37 
Critical Recognition of the Experiences of Therapeutic Behavioral Strategists in Addressing Student Trauma

Trauma and The Importance of Relationships

Critical Consciousness

Transformative Learning Theory....

Importance of TIC

Critical Examination.

Professional Development in The Area of Trauma.................................46

Level of Cognitive Development for Transformative Learning to Occur. .48

Significance of Professional Development.

Paradigm Shift.

Trauma Informed Care .56

Shifting Perspectives

Self-Care for Educators .59

Trauma Informed Care Schools and Trauma. .60

Safe Calm Supportive and Healing Environment 66

Chapter Three: Methodology .69

Research Design. .70

Why Narrative Inquiry and Why is it used. .70 
Critical Recognition of the Experiences of Therapeutic Behavioral Strategists in Addressing Student Trauma

Narrative Inquiry.

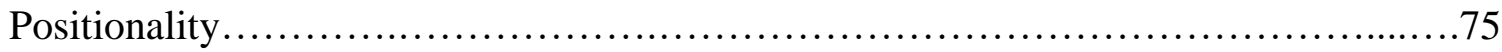

Acknowledging Potential Bias............................................. 78

Population and Sample..................................................... 81

Protection of Participants..................................................... 81

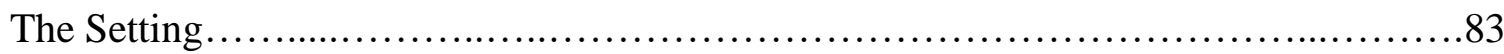

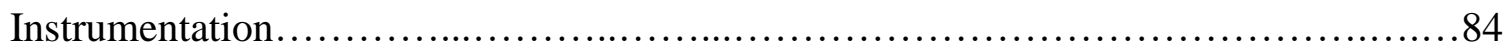

Data Collection and Analysis................................................84

Summary.............................................................. 87

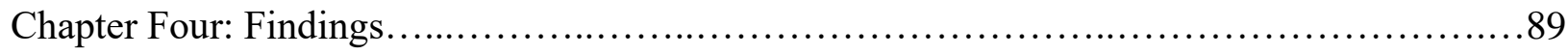

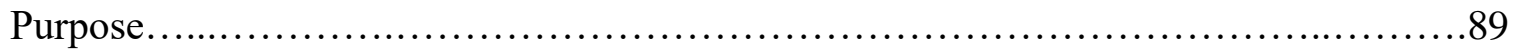

Participants............................................................. 89

Narratives...............................................................92

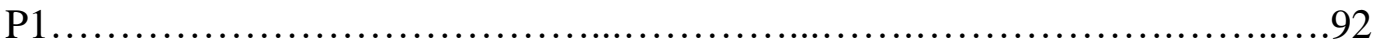

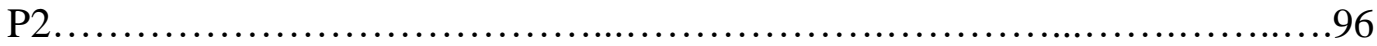

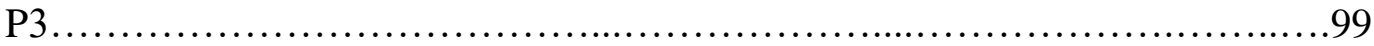

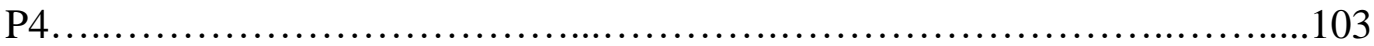


Critical Recognition of the Experiences of Therapeutic Behavioral Strategists in Addressing Student Trauma

P6

Data Analysis.

Findings

Themes and Categories.

Making Meaning of Emerging Themes

Chapter Five: Conclusion.

Summary of the Study.

Research Questions Discussion.

New Take-Aways From Interview Process

Implications.

Conclusion 140

Limitations. .141

Future Research. 142

References

Appendix A: Gatekeeper Letter. 157

Appendix B: Interview Protocol. 158 
Critical Recognition of the Experiences of Therapeutic Behavioral Strategists in Addressing Student Trauma

Appendix C: Consent Form............................................. 160 
Critical Recognition of the Experiences of Therapeutic Behavioral Strategists in Addressing Student Trauma

\section{List of Figures}

Figure 1: Cycle of Trauma.........................................................

Figure 2: Paradigm Shift from Traditional Practices to Trauma Informed Care Practices........17

Figure 3: Conceptual Framework................................................22

Figure 4: Tables Describing Forms of Trauma........................................... 31

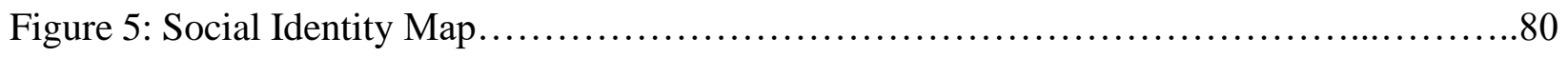

Figure 6: Table Describing Length of Time for each Participant Interview...................85

Figure 7: Emerge Theme- Empathy \& Compassion.................................. 121

Figure 8: Emerging Theme- Reflection \& Awareness.................................122

Figure 9: Emerging Theme- Building Trust \& Relationships........................... 123

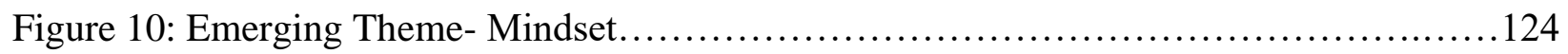

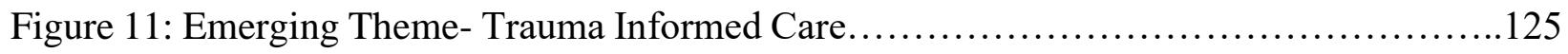


Critical Recognition of the Experiences of Therapeutic Behavioral Strategists in Addressing Student Trauma

\section{Chapter 1: Introduction}

\section{Statement of Problem}

Students in American public schools often experience trauma that can shape their lives indefinitely (Gubi, 2019). Although there is not much reliable data to measure the problem of trauma in our schools, there is a general sense among educators, communicated through their associations, that trauma and trauma-related behavior issues have reached crisis levels in classrooms across the country. New research has shed light on how trauma affects the developing brain. Those findings, paired with behaviors observed in schools, are increasing the urgency within the education profession to find practical approaches that can help classrooms and communities (Gubi, 2019).

Trauma is a term used to explain a student's response to a negative external event or series of events which render a child "temporarily helpless" and surpass the child's ordinary coping and defensive operations (McInerney \& McKlindon, 2014). A plethora of different experiences can result in childhood trauma, and a child's response to these potentially traumatizing events will vary depending on the characteristics of the child (e.g., age, stage of development, personality, intelligence, and prior history of trauma) environment (e.g., school and family supports), and experience (e.g., relationship to perpetrator) (McInerney \& McKlindon, 2014). The Diagnostic and Statistical Manual of Mental Disorders (DSM-IV-TR) defines traumatic events as those in which an individual experiences, witnesses, or is confronted with actual or threatened death or serious injury, or threatened physical integrity of self or others. It is critical to understand that the event need not be violent and need not be directed at the child who experiences trauma (McInerney \& McKlindon, 2014). One well-known study describes 
Critical Recognition of the Experiences of Therapeutic Behavioral Strategists in Addressing Student Trauma traumatic experiences in childhood as Adverse Childhood Experiences (ACEs), which may include physical, psychological, or sexual abuse; violence against one's mother; or living with household members who are mentally ill, suicidal, substance abusers, or were ever incarcerated (McInerney \& McKlindon, 2014). This study linked ACEs to many common adult psychological problems. In response to a traumatic event, a person may feel intense fear, horror, or helplessness, and in response, a child may display disorganized or agitated behavior (McInerney \& McKlindon, 2014).

A large body of research going back more than two decades has established that children who experience trauma not only are more likely to exhibit negative behaviors at school, but are more likely to develop risky behaviors and face a host of negative health consequences over their lifetimes. Data from the 2016 National Survey of Children's Health (NSCH) showed that 46 percent of America's children had experienced at least one traumatic event with the number rising to 55 percent for children aged 12 to 17 (Ghandour, 2018). One in five U.S. children had two or more traumatic events (Ghandour, 2018). Non-Hispanic black children and youth are more likely than their non-Hispanic white and Hispanic peers to have had three or more adverse experiences (17 percent, compared to ten and 11 percent, respectively, in 2016). Non-Hispanic white children and youth are the most likely to have had no adverse experiences (59 percent), followed by Hispanic children and youth (48 percent) and non-Hispanic black children and youth (Ghandour, 2018).

Academic and behavioral expectations can be challenging to meet for students in school, and those expectations become nearly impossible to meet for students who have suffered from trauma. Trauma-informed teaching is not usually fostered in schools, and most public schools are not trauma-informed. An instructor may see a "problem student" intentionally breaking rules and 
Critical Recognition of the Experiences of Therapeutic Behavioral Strategists in Addressing Student Trauma believe that student needs discipline in the form of suspension or even expulsion. However, an instructor who is trauma-informed may see that same student as a person that is having difficulties self-regulating and managing their emotions, and realize that the student needs extra support. There are a plethora of complex layers to the issues of childhood trauma. Different indicators of trauma lead to unsuitable, unsuccessful interventions.

When trauma causes emotional or psychological damage to children, children are at higher risk of adopting sets of behaviors or patterns of thinking that place them on a path for further trauma (McInerney \& McKlindon, 2014). Either directly through their own repeated actions (e.g., they are quicker to resort to violence) or as a result of consequences for their actions that do not fit within societal rules and norms (e.g., punitive measures after violation of rules/laws), children may become re-traumatized, and then their problems are only compounded. We need to understand the "cycle of trauma" (see figure below) which is particularly important to keep in mind in the school environment, where students may display problem behaviors related to past trauma and then become re-traumatized through punishment for those behaviors embedding the trauma further and continuing the cycle of behavioral problems rather than decreasing them. 
Critical Recognition of the Experiences of Therapeutic Behavioral Strategists in Addressing Student Trauma

Figure 1: McInerney, M., \& McKlindon, A. (2014).

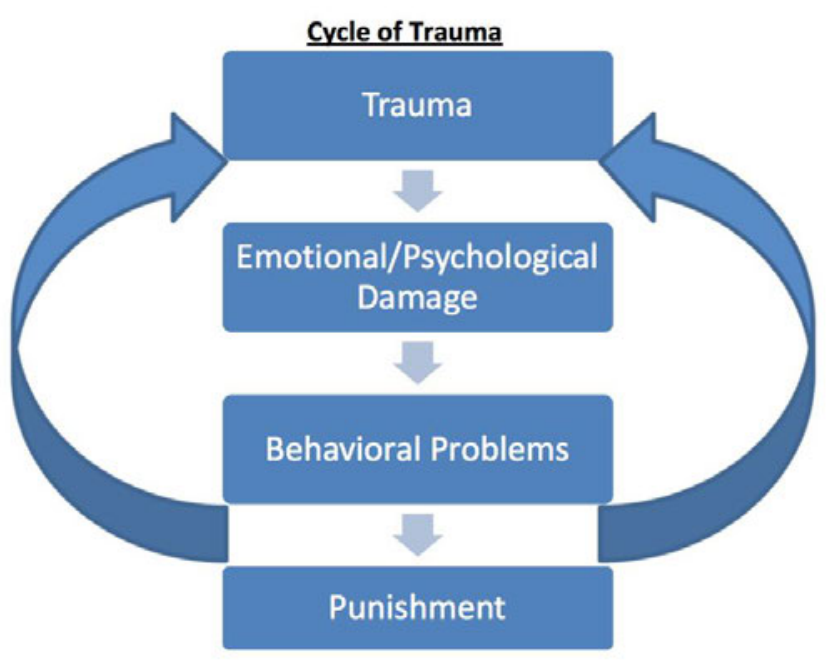

Therapeutic Behavioral Strategists (TBS) at the elementary, middle, and high school level recognize additional issues when dealing with students possessing trauma. According to Rialto unified school district, a TBS facilitator has experience working with children who have behavioral challenges, and has possession of a Master's Degree in social work, marriage/family therapy, or any related behavioral science field. Therapeutic behavioral strategists provide comprehensive behavioral support services to students, school staff, and parents, to address mental health-related behavioral challenges that limit a student from receiving the full benefit of their educational experience. Therapeutic behavioral strategists' manage a caseload assigned by the Lead Student Services Agent and provide direct behavior intervention services, and linkage to tiered level support. A TBS facilitator also provides psychoeducation in a group or individual setting, particularly for students who have experienced trauma. Through psychoeducation TBS facilitator's conduct lessons on the different elements of social emotional learning. Those elements are anger management, grief/loss, self-empowerment, self-regulation, and social skills. TBS facilitators deliver services that integrate and synergize psychotherapeutic and educational 
Critical Recognition of the Experiences of Therapeutic Behavioral Strategists in Addressing Student Trauma

interventions. The goal of TBS facilitators is to shift the paradigm to a more holistic and competence-based approach, stressing health, collaboration, coping, and empowerment (Dixon, 1999; Marsh, 1992). TBS facilitators assist students to remove barriers to comprehending and digesting complex and emotionally loaded information and to develop strategies to use the information in a proactive fashion (Lukens \& McFarlane, 2004).

Studies highlight that students of color, specifically students of color with low socioeconomic status, are at higher risks of exposure to trauma (Crosby, 2015). Trauma significantly impacts brain chemistry and creates learning difficulties (Fox et al., 2015). Two to five hours of mental health training for every five years is the only requirement public school teachers need in order to work with students (Lahey et al., 2015). This requirement does not even include education on trauma, and schools are not likely to require training in trauma-informed care practices (Lahey et al., 2015). The requirement on educating teachers on trauma is ineffective, especially when $47.9 \%$ of students in American public schools experience a potentially traumatic event at age 16 (National Child Traumatic Stress Network, 2017).

\section{Significance of Study}

Now that we understand that children who have experienced trauma have higher chances of struggling in school academically, behaviorally, and socially (Merritt \& Klein, 2014), evidence-based practice supports paying particular attention to the therapeutic relationship when working with survivors of childhood trauma (Berg, 2017). Creating relationships with students that have experienced trauma can be especially challenging, because children with histories of trauma can have difficulty forming trusting relationships as well as difficulty/inability regulating their emotions (Gurwitch, 2016). Often, educators risk re-traumatizing students by exposing 
Critical Recognition of the Experiences of Therapeutic Behavioral Strategists in Addressing Student Trauma

them to well-meaning but uninformed practitioners who are more likely to expose traumatized students to secondary trauma (de Zulueta, 2014). Unfortunately, there is not enough research highlighting information on the challenges faced when serving students with trauma history, and how to best overcome those challenges.

\section{Purpose of Study}

Children who have experienced trauma encounter a variety of possible challenges which could include learning deficits, emotional regulation problems, and inter-personal issue with teachers, other staff, and peers. The purpose of this study is to create a paradigm shift in the way we work with traumatized students in the school setting. A paradigm frames and directs the types of research inquires generated from within that theoretical orientation, and it provides the fundamental basis for evaluating the results of the generated research (Thomas, 1962). A paradigm shift provides the questions for: what should be asked, what phenomena should be observed, and how should the observations be interpreted (Thomas, 1962). A paradigm shift reflects a consensus view of a particular scientific community, bought into expression by the members of that community, either by being consciously articulated or, more likely, simply assumed and not intentionally acknowledged (Thomas, 1962). 
Critical Recognition of the Experiences of Therapeutic Behavioral Strategists in Addressing Student Trauma

\section{PURPOSE}

\section{Traditional Practices}

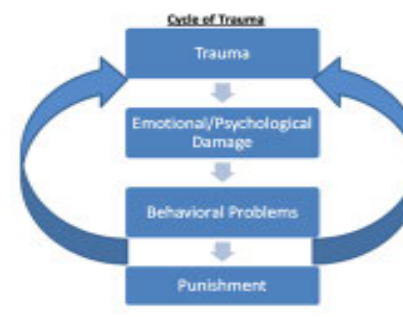

Paradigm Shift
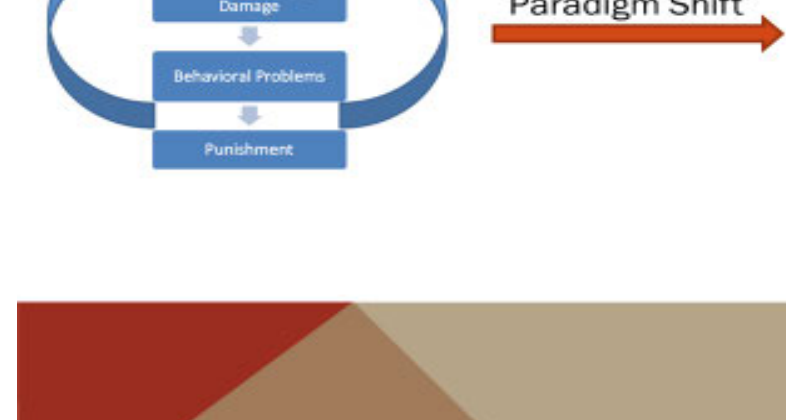

Figure: 2

7
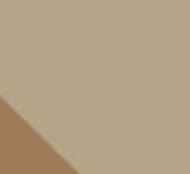

.

\section{Trauma Informed Care Practices}

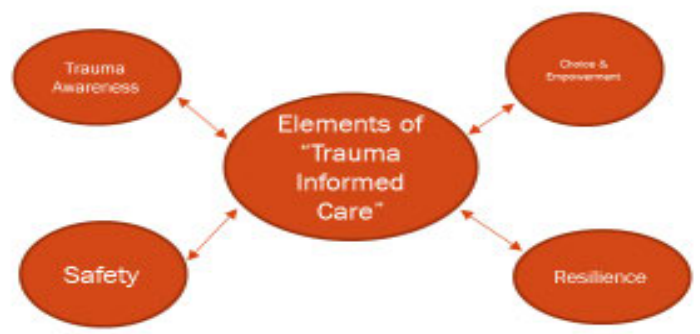

By highlighting the challenges that therapeutic behavioral strategists encounter when working with students who experience trauma and examining the need for additional support of traumatized students, we can develop a better understanding of how to work with them appropriately in the school setting.

\section{Conceptual Framework}

As this study focuses on the issue of trauma in schools, this dissertation will utilize critical consciousness theory, transformative learning theory, paradigm shift theory, and elements of trauma-informed care (TIC). Critical consciousness involves the ability to reflect on one's personal biases in working collaboratively with individuals and community stakeholders to take action and transform existing obstacles to a satisfactory quality of life (Freire, 2000). Critical consciousness has been used in educational training programs and community 
Critical Recognition of the Experiences of Therapeutic Behavioral Strategists in Addressing Student Trauma

development initiatives to foster awareness, empowerment, and social justice ideals (Goodman, 2009). This praxis-oriented perspective establishes individuals (such as therapeutic behavioral strategists) as critical co-investigators with the community they are serving (Nelson \& Neufeldt, 1998). Thus, critical consciousness can serve as a vehicle for the development of empowerment and cultural competence. Infusing the principles of critical consciousness into professional development training for trauma responses prepares school sites for current and future trauma informed practices.

The process of becoming critically conscious begins with reflection and the development of awareness (Goodman, 2009). During this process, awareness of personal biases and a deeper understanding of complex social issues develop (Goodman, 2009). This awareness engenders transformation in interpersonal relationships whereby individuals seek more collaborative and empowering relationships with students they serve (Goodman, 2009). The development of critical consciousness may also allow individuals to work collectively with colleagues, thereby transforming the experience of working in a group into one of reciprocity, engagement, and growth (Goodman, 2009).

The theory of critical consciousness has been used in the mental health profession and in other professions as a tool for the development of cultural competence and social justice ideals (Goodman, 2009). The process of increasing awareness through reflection is critical in the development of cultural competence because it can liberate individuals from socially embedded and often unconscious hegemonic views (Goodman, 2009). Freire's (2000) theory has been used to facilitate critical thinking and to engender a greater understanding of oppression, leading to action orientated to social justice (Watts et al., 1999). 
Critical Recognition of the Experiences of Therapeutic Behavioral Strategists in Addressing Student Trauma

As the reality of traumas faced by students becomes evident, educators must evaluate their former perceptions and dispositions toward traumatized students and how they may need to change in the future. Some challenges or dilemmas, such as managing the behaviors of traumatized students, cannot be solved by continuing to use past practices or by learning more; school staff must challenge old assumptions and grow (Mezirow, 1978). Transformational learning theory is utilized when there is a change in a point of view, or belief, or the habit of mind (Merriam et al., 2013). According to Merriam et al. (2013), Mezirow's theory of transformational learning can be broken down into four parts: 1 . An experience that does not align to the learner's existing meaning perspective, prompting a disorienting dilemma: 2. Critical reflection on how one's assumptions and beliefs interpreted the experience, causing emotions such as guilt or embarrassment (i.e. awareness of a discrepancy between what was perceived as true and the new information): 3. Reflective discourse with co-workers regarding the mismatch of assumptions to come to a consensus of understanding and investigation of possible actions: 4 . Implementing behaviors and plans for action, culminating in the integration of new knowledge into a fresh perspective.

Transformative learning theory addresses self-worth, as individuals may question their self-concept upon the realization of past perceptions and behaviors toward students, motivating staff to do more and be more than they thought possible, to achieve the extraordinary without using power or extrinsic rewards (Bass, 2010). Transformative learning theory can be used to make staff aware of the importance of the problem, the desired outcomes of the professional development and how to reach the goal of a fully embedded trauma-informed care framework within the school district culture (Barbuto, 1997). Leaders must motivate their staff to forgo selfinterests (i.e., maintaining old world-views as a means of self-protection) for the best interest of 
Critical Recognition of the Experiences of Therapeutic Behavioral Strategists in Addressing Student Trauma

the district and well-being of students, and advance employees on Maslow's hierarchy of needs from one of safety to self-actualization (Barbuto, 1997). According to Bass (2010),

transformative learners act as visionaries, intellectually engaging employees to foster autonomy and elevate employee morality about what is truly important, modeling expectations and behaviors, setting high standards for employees to follow, demonstrating respect and confidence for school staff. Transformative learning theory questions old perceptions and reframe challenges (Bass, 2010), such as the old ways of viewing student misbehaviors and lack of academic progress, to uncover solutions. Transformative learning is crucial, as you cannot offer incentives or coerce adults into genuinely caring for and empathizing with traumatized students or improving their interpersonal relationships.

According to Thomas Kuhn (1962), a paradigm shift occurs when the methods legitimized by the paradigm go wrong, becoming counter to what was expected to happen. These contradictory occurrences are defined as a crisis that is contrary to the established order that results and persists as a historical event, resulting in a redirection of research, and creating a means for a new paradigm (Thomas, 1962). A paradigm shift begins, as a solution to the new crisis is needed, resulting in an extraordinary amount of new research where new ideas arise, with new methods, a new theory, and a new worldview which creates a revolution. The revolution encompasses a paradigm shift that formulates a new world order with words that express the changed thoughts, the different view of the world, the different feelings for how it works, the different phenomena and puzzling of difficulties, and the new ways of interacting (Thomas, 1962). As a result of the revolution, there is a change in meaning within the researchers themselves, which is demonstrated, by a change in theory. 
Critical Recognition of the Experiences of Therapeutic Behavioral Strategists in Addressing Student Trauma

Trauma-informed care (TIC) is a strength-based framework that is grounded in an understanding of and responsiveness to the impact of trauma, that emphasizes physical, psychological, and emotional safety for both providers and survivors, and that creates opportunities for survivors to rebuild a sense of control and empowerment (Hopper et al., 2010). There are four main elements that make up the TIC framework. The first element is trauma awareness. Trauma awareness is being able to understand the prevalence and impact of trauma among students and within other educational professionals in the workforce. The second element is safety. Policy and practice should reflect a commitment to provide physical and emotional safety for students who have been exposed to trauma. The third element is choice and empowerment. Choice and empowerment should help facilitate healing and avoid retraumatization. Choice and empowerment are part of trauma-informed service delivery, for both service recipients and staff. Lastly, the fourth element is the strength based approach. The strength-based element focuses on strength and resilience, service recipients build skills that will help them move in a positive direction (Hopper et al., 2010). Professionals in education who are not trained in trauma or TIC are unlikely to understand the benefits of models such as these. Teachers or staff members exercising authority and control over the class are usually using traditional practices in public schools. These traditional practices would be counter-productive for children who have experienced trauma and may be defiant toward authority, as those students may already be feeling oppressed (Crosby, 2015). 
Critical Recognition of the Experiences of Therapeutic Behavioral Strategists in Addressing Student Trauma

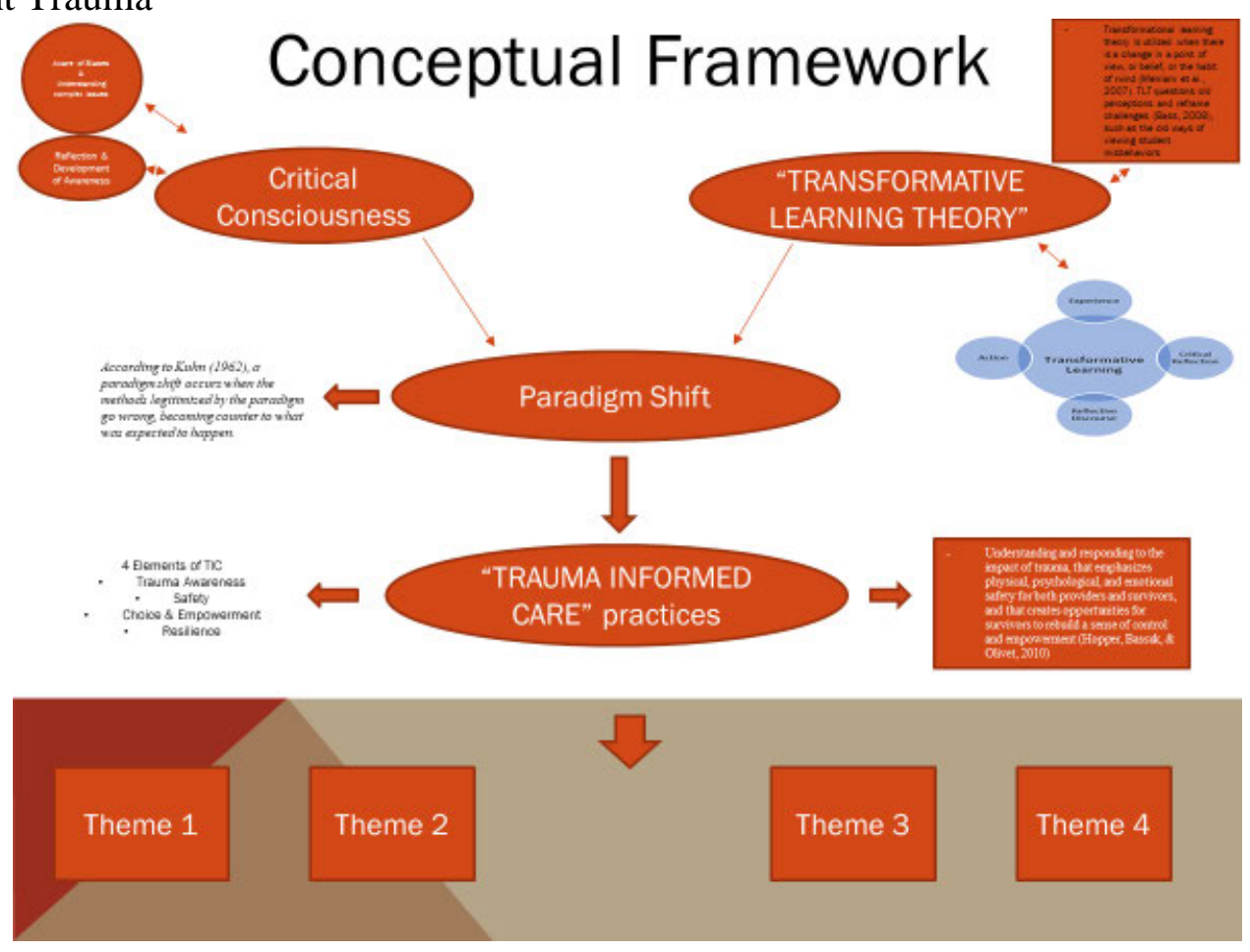

Figure: 3

\section{Research Questions}

The conceptual framework above is used as a guide in seeking answers to the following research questions: How does TBS work with students who have experienced trauma? What do TBS's view as challenges in the school setting for children who have experienced trauma? What recommendations can TBS provide in order to help school sites better serve students who have experienced trauma?

The first question helps highlight how therapeutic behavioral strategists work with students who have a history of trauma. This question is important to answer because it helps the reader understand how therapeutic behavioral strategists work with students, and how their professional experience working with traumatized students will help other professional educators understand how to best serve students that have dealt with trauma in a classroom setting. The 
Critical Recognition of the Experiences of Therapeutic Behavioral Strategists in Addressing Student Trauma data gathered from this question may provide insight into how TBS works with students dealing with trauma and the significance of utilizing a TIC lens.

The second question is investigating the types of challenges TBS facilitators encounter while working in a school setting. This question is important to answer because it will highlight the different challenges that TBS experience when collaborating with school staff while working with students experiencing trauma. The data gathered from TBS participants will help explain the types of challenges that TBS faces when working with school sites that possess students experiencing trauma.

The third question helps highlight the steps that are needed to help school sites better serve students who have experienced trauma. This question is important to answer because it helps readers understand how TBS are able to help school sites through a critical consciousness, transformative learning, paradigm shift and trauma-informed care framework. The data gathered from this question will help school teachers and administrators collaborate with TBS effectively in order to appropriately work with students experiencing trauma.

\section{Narrative Inquiry}

The method of inquiry that amplified the voices of participating therapeutic behavioral strategists was a narrative inquiry approach. I dialogued with study participants in the Freirean sense and worked to objectively record and consequently communicate their perspective every step along the way. Humans learn better through the power of story when compared to recitation and memorization of facts and figures (Hsiao et al., 2013). Furthermore, Conle (2001) emphasizes that a narrative inquiry approach focuses on the study of a lived experience. Conle (2001) also states that narrative inquiry is a rhetorical exercise based on the art of persuasion best served to study personal experiences rooted in practice and not easily named. Finally, Connelly 
Critical Recognition of the Experiences of Therapeutic Behavioral Strategists in Addressing Student Trauma

and Clandinin (1990) discuss that narrative inquiry is a method to study human experience that is powerful because humans are storytelling organisms who individually and socially lead storied lives. This lived experience and what was learned from the powerful story that resulted were the underlying purposes of this inquiry. I worked diligently to craft a powerful story from the data gathered through dialogue and the resultant themes obtained in this study. Using this powerful story, I endeavored to persuade action toward improving the way schools work with traumatized students so that future generations can experience the same amount of support as the population being studied in this work.

\section{Definitions of Key Terms}

Several terms and phrases utilized within the education and mental health fields are necessary to define for this study:

- Adverse Childhood Experiences: Abuse, neglect, dysfunctions in the home, and exposure to other traumatic stressors during childhood (Centers for Disease Control and Prevention [CDC], 2016)

- Amygdala: A component of the limbic system responsible for interpreting sensory information and recognizing potential threats (Willis, 2006).

- Child Protective Services Agency: CPS is an official state agency responsible for receiving and responding to reported cases of suspected child abuse and neglect. The agency determines the validity of the reports and provides protective services to the children and their families (Centers for Disease Control and Prevention. (2018). 
Critical Recognition of the Experiences of Therapeutic Behavioral Strategists in Addressing Student Trauma

- Complex Trauma: Gabowitz et al. (2008) define complex trauma as chronic exposure to traumatizing life events, often caused by caregivers, which therefore may be interpersonal in nature, impacting adolescents' development and long-term physical and mental health.

- Confidentiality: A term used in schools to explain the type of information that school counselors are required by law to keep private or report to parents, CPS or the police (i.e., harm to self or others, and abuse or neglect) (Elkovitch \& Hansen, 2009). Due to the professional 24 promise to respect the student's right to privacy, sensitive information regarding trauma may not be shared with employees in the building.

- Empathy: The emotional response to another person's emotions and behaviors; how one interprets their emotional response and perspective-taking; and the conscious decision to utilize empathetic behaviors (Gerdes et al., 2011).

- Executive Functioning: The capabilities a person possesses to control their behavior and successfully participate in independent, purposeful, and goal-oriented activities. Executive functions include self-awareness, regulation, motivation, and the ability to plan, organize, and purposefully carry out action (Gabowitz et al., 2008).

- Mindfulness: Mindfulness is a conscious state of mind in which one is calmly observant and accepting of their thoughts, feelings, and body (Moss et al., 2012).

- Perspective taking: Perspective taking within the framework of empathy, is an action, in which the one member of an interpersonal interaction pays close attention to the other individual's feelings or divulged information. Moreover, research shows that perspective taking, or imagining the other person's perspective, what that person may feel, or putting yourself in their shoes, 
Critical Recognition of the Experiences of Therapeutic Behavioral Strategists in Addressing Student Trauma

results in feelings of empathy and increased positive attitudes toward the other individual

(Madera et al., 2011).

- Stakeholder: Stakeholders include school employees, parents, and students who impact and are impacted by the academic achievement of the school district (LAW Writer: Ohio Laws and Rules, 2015).

- Trauma-Informed Lens: The lens adults' use, filtered by life experiences and beliefs, to interpret student behaviors and inform adult responses (Bloom \& Farragher, 2013).

- Traumatic Stress: Stress caused by traumatic events, resulting in feelings of anxiousness, insecurity, fear, and stress related behaviors (Oehlberg, 2008).

\section{Organization of Study}

This qualitative study is organized into five chapters. Chapter One contains an overview of the impact trauma has on students, the significance of this study, the conceptual framework used to guide the research, the research questions, and recommendations. Chapter Two gets is a detailed literature review on the symptoms of trauma for children in school, the effects that trauma can have while students are in school, and trauma informed care. Chapter Three includes a description of the methodology used for this qualitative study as well as the researcher's positionality, the setting, instrumentation, and descriptors of the six district therapeutic behavioral strategists. Chapter Four includes a discussion of the process of data analysis, the findings from the qualitative data gathered, and contains the six narratives. Finally, Chapter Five includes a summary of the previous chapters, a discussion of the research questions, and 
Critical Recognition of the Experiences of Therapeutic Behavioral Strategists in Addressing Student Trauma

recommendations for $\mathrm{K}-12$ teachers and administrators when dealing with students that have trauma history. 
Critical Recognition of the Experiences of Therapeutic Behavioral Strategists in Addressing Student Trauma

Chapter 2: Literature Review.

This review of literature is organized into an argument that relates to the impact trauma can have on students. The impact of trauma on children is explained in terms of the significance trauma has for them in the school setting, and how educators can better serve students dealing with trauma.

\section{Trauma}

Generally, adults are able to remember an incident or series of related or unrelated incidents that unsettled their life in some fashion as a child. Impact from these incidents can be social, emotional, or physical, and can impact students' success in school preventing them from rising to their full potential. Trauma is the damage spawned by high levels of stress during violent, real, or perceived threats, or any life altering experience (Children's Defense Fund Ohio, 2015; Jaycox et al., 2006) that happens to a person or is witnessed (Rossen \& Cowan, 2013). Trauma results from short term or single, severe incidents (i.e., an acute stressor), or recurrent incidents (i.e., chronic stressor) that spark an ongoing activation of the brain and body's response systems, resulting in overwhelming feelings (Rossen \& Cowan, 2013) and toxic stress (Children's Defense Fund - Ohio, 2015). The National Child Traumatic Stress Network (n.d.) uses the phrase acute traumatic event to describe short-term or single-incident traumas (e.g., severe accidents, gang violence, school shootings, natural disasters, or physical or sexual assault), and the phrase chronic traumatic situations to describe repeated events over a long period of time (e.g., on-going physical or sexual abuse, or domestic or political violence). Results of trauma can impact victims to the point that they feel powerless, helpless, or lacking control (Sitler, 2009), fear, panic, unsafe, unable to cope, disgust, or shame (Rossen \& Cowan, 
Critical Recognition of the Experiences of Therapeutic Behavioral Strategists in Addressing Student Trauma

2013); therefore, trauma is the perception and response to an event, not the event itself (Hertel \& Johnson, 2013; Souers \& Hall, 2016). Fear of the unknown impacts educators as well as students (Souers \& Hall, 2016).

While studies have shown that trauma is prevalent in many of these children's lives, the type and intensity of traumatic incidents differs, as well as how children and adolescents interpret events and cope, generating various symptoms and behavioral outcomes (Bell et al., 2013)). The consequences of traumatic experiences may begin as early as infancy or any stage of development, be instantaneous or delayed (Kasich \& Plouck, 2016), and vary between children, ranging from no effect to devastating consequences, depending on factors such as the environment (e.g., poverty or family dysfunctions), physiology, level of support (Bell et al., 2013), past ACEs, age, mental abilities (Simonich et al., 2015), and resiliency factors (WhiteMcMahon \& Baker, 2019). The aftereffects of traumatic experiences appear to depend on how students manage the outcomes, the student's developmental stage, ethnic or spiritual belief system, and the level of environmental and social supports, rather than the type of trauma itself (Woodbridge et al., 2016). Some students may seem unaffected or recover quickly from traumatic experiences, while others continue to struggle with everyday life. Some may be leaders, have friends, and do well in school, while others lack friends, fail, or bully. In the same household, some children cope, while their siblings struggle (Rossen \& Cowan 2013). Blodgett (2018) confirmed that exposure to traumatic experiences "is a pervasive community problem established early in life and during key developmental stages" (p. 11). The coping skills of a young person, especially if parents or guardians lack coping skills of their own, may become overwhelmed, resulting in trauma related stress. Stress has a detrimental effect on learning and behavior: it results in excessive absences, impairs attention, concentration, and social skills, and 
Critical Recognition of the Experiences of Therapeutic Behavioral Strategists in Addressing Student Trauma

reduces creativity, memory, motivation, and neurogenesis (Jensen \& Lundgren 2009). Fear and

feeling powerless are normal responses to traumatic experiences, regardless of whether the experiences are real or perceived threats to the adolescent's personal safety and well-being, or to that of a loved one (Jensen \& Lundgren 2009).

\section{Forms of Trauma}

Trauma can be grouped into three categories: acute trauma (i.e., a single event), complex trauma (i.e., multiple forms of trauma), and chronic trauma (i.e., on-going exposure to trauma producing events) (Thomas et al., 2015). Complex trauma, such as several exposures to one or more combined forms of traumatic incidents of sexual, physical or emotional abuse, neglect, witnessing domestic violence, or loss of a caregiver impacts children in a multifaceted capacity (Greeson et al., 2011). The 1995 to 1997 ACE study examined forms of trauma such as emotional, physical, or sexual abuse and neglect, and household dysfunctions (e.g., family member imprisoned, mentally ill, suicidal, alcohol or drug user, deceased, separated or divorced family, or witnessing domestic violence) (Felitti \& Anda, 2010). Other forms of trauma include experiencing a natural disaster such as a hurricane, flood or tornado (Perry, 2001), illegal behaviors in the home, or prolonged or life-threatening illness of a family member (Souers \& Hall, 2016). A child whose parent is serving in a war, such as Iraq or Afghanistan, may experience trauma (Sitler, 2009). These various forms of trauma may be organized into four categories: intrapersonal, interpersonal, familial dysfunction, and nondomestic (see Table 1).

\section{Table 1}


Critical Recognition of the Experiences of Therapeutic Behavioral Strategists in Addressing Student Trauma

\begin{tabular}{|c|c|c|c|}
\hline Intrapersonal & Interpersonal & Familial Dysfunction & Nondomestic \\
\hline Feels like a failure $^{a}$ & Bullying $^{\mathrm{a}}$ & Family member ill ${ }^{\text {bdh }}$ & Prejudice $^{\mathrm{c}}$ \\
\hline Feeling labeled $^{\mathrm{a}}$ & Harshly criticized $^{\text {ae }}$ & Abuse of mother ${ }^{\mathrm{e}}$ & War \\
\hline Lonely $^{\mathrm{a}}$ & Kidnapping $^{\mathrm{b}}$ & Divorce or separation $^{\mathrm{e}}$ & Natural disaster $^{\mathrm{d}}$ \\
\hline $\begin{array}{l}\text { Feeling unable to } \\
\text { accomplish like } \\
\text { peers }^{\mathrm{a}}\end{array}$ & $\begin{array}{l}\text { Parent is serving in } \\
\text { the military or war }\end{array}$ & $\begin{array}{l}\text { Family member mentally } \\
\text { ill }^{\mathrm{e}}\end{array}$ & $\begin{array}{l}\text { Terrorism or } \\
\text { political violence }^{\mathrm{d}}\end{array}$ \\
\hline Personal illness ${ }^{b}$ & Emotional neglect $^{\mathrm{e}}$ & Substance abuse $^{\mathrm{e}}$ & School violence $^{\mathrm{d}}$ \\
\hline $\begin{array}{l}\text { Frequent changes to } \\
\text { school enrollment }^{\mathrm{c}}\end{array}$ & Death of a parent ${ }^{\text {bf }}$ & $\begin{array}{l}\text { Domestic violence } \\
\text { witness }^{\text {edf }}\end{array}$ & $\begin{array}{l}\text { Neighborhood } \\
\text { violence }^{\mathrm{d}}\end{array}$ \\
\hline \multirow[t]{5}{*}{ Serious accident $^{\mathrm{bd}}$} & Sexual abuse ${ }^{\text {ef }}$ & Lack of basic resources ${ }^{c}$ & \\
\hline & Emotional abuse $^{\text {ef }}$ & Family member suicidal $^{\mathrm{e}}$ & \\
\hline & Physical abuse $^{c}$ & Relative in jail $^{\mathrm{e}}$ & \\
\hline & Physical neglect $^{\mathrm{e}}$ & Homelessness $^{\mathrm{h}}$ & \\
\hline & & Illegal activity in the home $\mathrm{h}^{\mathrm{h}}$ & \\
\hline
\end{tabular}

${ }^{\mathrm{a}}$ Vicario \& Gentile, 2015; ${ }^{\mathrm{b}}$ Perry, 2001; ${ }^{\mathrm{C}}$ Blaustein, 2013; ${ }^{\mathrm{d}}$ Black, 2015; ${ }_{\mathrm{e}}^{\mathrm{e}}$ Felitti \& Anda, 2010; ${ }^{\mathrm{f}}$ Cook et al., 2005; ${ }^{\mathrm{g}}$ Sitler, 2009; ${ }^{\mathrm{h}}$ Souers \& Hall, 2016

Figure: 4

While poverty may increase the likelihood of trauma, poverty is not a form of trauma (Souers \& Hall, 2016). However, trauma may be caused by experiences that are often linked to poverty, dramatically increasing the stress felt by parents or guardians: lack of food, unemployment, an overextended caregiver, living in crowded or unsafe conditions, eviction, lack of resources to take care of basic needs, exposure to violence, or homelessness (Souers \& Hall, 2016). While poverty may increase the prevalence of trauma (Blitz et al., 2016), the ACE study demonstrated that trauma could occur within any socioeconomic status. Although gender, race, or ethnicity is not a form of trauma, certain individuals may be more likely to experience trauma due to prejudice. A study conducted by Woodbridge et al. (2016) indicated that males, Black, Native American, and Latino students reported significantly higher traumatic experiences than female, White or Asian students. Surprisingly, the study also found that adolescent males who were separated from their caregiver were nearly two times as likely to report high levels of trauma-related stress than females. The predominant predictor of trauma-related stress across 
Critical Recognition of the Experiences of Therapeutic Behavioral Strategists in Addressing Student Trauma

racial groups and gender was separation from a caregiver and the perceived threat of physical violence, not a tangible assault (Woodbridge et al., 2016).

\section{Trauma and Student Behavior}

A report by the U.S. Department of Health and Human Services (2013) defined the behaviors that result from traumatic experiences as "a child's behavior in the school or community that adversely affects socialization, learning, growth, and moral development" (p. 103). Distressed children do not consciously choose the negative behaviors that result from impaired brain functioning. Traumatized individuals are largely unaware of the feelings and motivations behind their destructive behaviors that impact themselves and others; therefore, adults must be curious about the true meaning of the behavior (Bloom \& Farragher, 2013). Life experiences and human interactions shape the developing brain, which alters how events are interpreted and the ensuing behaviors (i.e., a visible reaction to objects and people) (WhiteMcMahon \& Baker, 2016). "All behavior is needs driven," especially when children lack the ability to tell adults what they need or to meet their own needs, triggering stress and defensive behaviors, even if the behaviors are counterproductive and result in consequences (WhiteMcMahon \& Baker, 2016, p. 1).

Educators may use Maslow's hierarchy of needs as a lens to interpret student behaviors. Students must have certain needs met before they can ascertain positive self-esteem, demonstrate respect for self and others, and achieve academic success and self-actualization. Maslow's (1987) hierarchy of needs is aligned to the needs of a trauma victim: physiological (e.g., basic needs such as food or sleep), safety (e.g., physical and psychological), and feeling loved, cared for, or belonging (as cited in Sitler, 2009). Educators need an understanding of how trauma 
Critical Recognition of the Experiences of Therapeutic Behavioral Strategists in Addressing Student Trauma

reveals itself, although not all misbehaviors are a result of trauma (White-McMahon \& Baker, 2016). For example, students may use apathetic behaviors for self-protection or challenge teachers to avoid completing schoolwork (Sitler, 2009). Traumatized students may exhibit impulsive behaviors, have problems sleeping, explosive outbursts, under (hypovigilance) or over (hypervigilance) react to situations such as loud noises or abrupt movements, self-harm or hurt others, emotionally withdraw (Children's Defense Fund - Ohio, 2015), feel apathetic, fail to think about the future, exhibit inattentiveness, verbally or physically act out, use profanity, or skip school (Sitler, 2009).

Other behaviors, such as stealing and storing food or other items may fulfill unmet needs due to neglect, engagement in sexual promiscuity may fulfill the need for care and affection, or the student may overeat to fulfill the need for emotional support (Blaustein, 2013). Furthermore, physically and emotionally neglected students may exhibit attention-seeking behaviors that may be misinterpreted by educators as demanding, difficult, dishonest and manipulative (Rossen \& Cowan, 2013). Traumatized students often fail and are punished in school because their behaviors are misunderstood as laziness, indifference, or purposeful disobediences (Cole et al., 2013). "Blaming a trauma-affected child for having an outburst in class is like blaming a child who has the flu for having a fever" (Rossen \& Cowan, 2013).

According to the 1995 to 1997 Adverse Childhood Experiences (ACE) Study, individuals who experienced four or more traumas in youth were almost twice as likely to smoke cigarettes, four and a half times as likely to use drugs, seven times as likely to be abuse alcohol, eleven times as likely to use intravenous drugs, and nineteen times as likely to have attempted suicide in their life-time (Rossen \& Cowan, 2013). In addition, students naturally relapse into behaviors from an earlier developmental stage in an attempt to feel safe (Rossen \& Cowan, 2013). Jaycox 
Critical Recognition of the Experiences of Therapeutic Behavioral Strategists in Addressing Student Trauma

et al. (2006) noted that the behaviors students exhibit following traumatic experiences vary by age: preschool students may display behaviors of an earlier age, reenact the events during play, have tantrums, or withdrawal behaviors; elementary students may complain of somatic symptoms such as frequent headaches or stomach aches, appear to be short-tempered, may be absent from school or do poorly on school work, lack concentration, or talk incessantly about the trauma; secondary students may have truancy issues and display at-risk behaviors, such as fighting, alcohol or drug use, have difficulties with relationships, and poor performance in school.

When the brain's amygdala is triggered, the body's fight-or-flight reaction causes individuals to contemplate negative outcomes and practice potential responses for events that may or may not ever occur (Newberg \& Waldman, 2012). The emotional center of the brain may replay fearful events, whether fantasy or real, like a runaway train that must be slowed down so that students can access the thinking part of the brain. Students need assistance to evaluate whether the perceived situation is a real threat to their safety, followed by assistance in reframing negative thoughts into positive ones so that the student can regain self-control and feelings of safety (Newberg \& Waldman, 2012). Educators who understand the impact of trauma on the brain and quickly intervene when a traumatized student's amygdala is firing can help students achieve feelings of safety and well-being.

\section{Impact of Trauma on Student Learning}

The impact of complex trauma on adolescents includes "a loss of core capacities for selfregulation and interpersonal relatedness" which "places them at risk for additional trauma 
Critical Recognition of the Experiences of Therapeutic Behavioral Strategists in Addressing Student Trauma

exposure and cumulative impairment (e.g., psychiatric and addictive disorders; chronic medical

illness; legal, vocational, and family problems)” (Cook et al., 2005, p. 390).

\section{Impact of Trauma on the Brain}

Childhood trauma negatively impacts brain architecture during crucial stages of development (Bloom \& Farragher, 2013; Evans \& Coccoma, 2014; Perry, 2001). While genetics determines the number of neurons formed in the brain at birth and the process of pruning in childhood, the child's environment determines the final structure of the brain and strength of the neural connections (Bloom \& Farragher, 2013). The brain's architecture continues to form until late adolescence, thus the brain is more susceptible in childhood to alterations due to trauma's fear response; however, the prefrontal cortex continues to develop into adulthood (Evans \& Coccoma, 2014).

Neuroscience has demonstrated that the brain changes in structure into adulthood as a result of experiences: "Experience gradually modifies the connections between neurons following a 'use it or lose it' rule" (as cited in Zhang \& Lu, 2009, p. 37). Advances in brain research provide educators with valuable information regarding how genetics and the environment impact how students learn, and the importance that emotion and motivation plays in learning (Hinton et al., 2008; Zhang \& Lu, 2009). Although the magnitude of the impact of trauma on the brain is not fully understood, researchers know that trauma has a profound impact on the normal structure (e.g., smaller in volume) and functioning (e.g., impairment of areas responsible for learning and behaviors) of the brain (Hertel \& Johnson, 2013). The impact of traumatic experiences on brain development, including the organizational and functional status of the brain, is dependent on two main forms of abuse (e.g., neglect and traumatic stress); 
Critical Recognition of the Experiences of Therapeutic Behavioral Strategists in Addressing Student Trauma

environmental factors; the nature, pattern (e.g., single event or chronic experience) and duration

of trauma; area of brain undergoing development and rate of the development (i.e., increased rate of development is directly related to level of impact); nature of the child (i.e., age, genetics, gender, history of traumatic experiences); and mitigating factors such as supportive adults; "therefore, adverse events can have a tremendous negative impact on the development of the brain" (Perry, 2001, p. 15). The brain's response to overstimulation is to prompt the body to produce hormones such as adrenaline and cortisol, which are beneficial if there is a need to fight or escape to survive, and detrimental if the experiences are chronic, because brain cells can be destroyed, inhibiting normal development (Hertel \& Johnson, 2013). Individuals differ in whether an event is perceived as traumatic or results in traumatic stress symptoms (Perfect et al., 2016). "Neuroplasticity is the quality that allows region-specific changes to occur in the brain as a result of experience" (Jensen, 2009, p. 47).

Brain abnormalities may be dependent on the area of the brain undergoing development when trauma occurs, negatively impacting the following structures of the brain: brainstem (e.g., altered regulation of core functions such as respiration, cardiovascular, temperature, hyperreactivity, sensory integration difficulties, impaired regulation of sleep, feeding, and selfsoothing); diencephalon (e.g., motor control and secondary sensory processing); limbic system (e.g., memory, emotional regulation, disorganized attachment, and primary sensory integration); and neocortex (e.g., reasoning, problem solving, abstract thinking, and secondary sensory integration) (Perry, 2001). Areas of the brain develop in an ordered pattern beginning with the brainstem in infancy to the neocortex in puberty and adulthood (Perry, 2001).

Disruptions in one part of the brain may negatively impact subsequent areas of development, "each layer organizing at a different time and each layer reflecting the experiences 
Critical Recognition of the Experiences of Therapeutic Behavioral Strategists in Addressing Student Trauma

good and bad of that era in the individual's life. Key insights to understanding human

functioning, then, will come from understanding neurodevelopment” (Perry, 2001, p. 17). Brain

development is altered in response to disruptions of the normal neurochemical release, as a result

of experiences, changing neuron differentiation and functional capacity (i.e., unused neurons will prune), and potentially causing abnormalities or shortfalls in neurodevelopment (Perry, 2001).

Neurons need to connect properly during development in order for the brain to function correctly (Perry, 2001). Traumatic events, whether real or perceived, result in the child's brain mediating the brainstem and di-encephalic stress-related response, resulting in emotional, behavioral, cognitive, and physiological adaptations needed to survive (Perry, 2001).

Our experiences change the brain as neuron connectivity is strengthened, diminished or eliminated (Hinton et al., 2008). Throughout childhood and adolescence, changes in the brain impact cognitive and emotional functioning, self-image, language development, and beliefs (Perry, 2001). "Adverse childhood events, therefore, can alter the organization of developing neural systems in ways that create a lifetime of vulnerability" (Perry, 2001, p. 27). However, the opposite is also true; positive experiences and interactions created by caring educators influence student brain plasticity fueling optimism and the motivation for change (White-McMahon \& Baker, 2019).

\section{IQ and academic achievement.}

A study conducted by Crozier and Barth (2005) determined that maltreated students scored lower on IQ (i.e., 2.13 times more likely to score one SD below the mean) and academic achievement tests (i.e., 1.92 times as likely to score as low on the reading and 2.75 times as likely on the math tests) than peers. In addition, as the number of risk factors increased, the 
Critical Recognition of the Experiences of Therapeutic Behavioral Strategists in Addressing Student Trauma

percentage of students scoring lower on IQ and achievement tests increased. While no significant differences were found on IQ and achievement tests between age groups and gender, students living in poverty were significantly more likely to score below 85 on the IQ, math, and reading tests (Crozier \& Barth, 2005). However, studies on institutionalized, abused and neglected children have shown that IQ scores can improve by 40 to 60 points when children are placed in caring, safe, and predictable environments (Perry, 2001). The older the child and longer the child was exposed to adverse experiences, the more significant the developmental delay and pervasive deficits (Perry, 2001). Impact on brain functioning. As administrators and teachers study how the brain learns, they gain professional skills to implement brain-based learning and teaching strategies (Willis, 2009). Willis (2009), a neurologist, researcher, and teacher, supports the use of positron emission tomography (PET scans), functional magnetic resonance imaging (fMRI), and quantitative electroencephalography brain wave monitoring (qEEG) to view the brain as it learns. Educators now have neuroimaging and brain-mapping studies available to inform effective instruction (Willis, 2009).

According to Willis (2006), stress in the learning environment overstimulates the amygdala in the limbic system. Fear, stress, helplessness and anxiety can overactivate the amygdala and prevent information received by the brain's sensory areas from moving through the amygdala's filters to the part of the brain responsible for memory (Willis, 2009). Brain scans indicate that negative emotional experiences, such as rejection, cause feelings of shame and low self-esteem, activating the same parts of the brain as physical pain (Brendtro \& Longhurst, 2005). In contrast, neuroimaging shows lower levels of amygdala stimulations when students experience positive emotions, causing improved social behaviors, working memory, verbal fluency, and problem solving capabilities (Willis, 2009). Negative words or phrases that trigger 
Critical Recognition of the Experiences of Therapeutic Behavioral Strategists in Addressing Student Trauma

fear, cause noticeable neural changes in the fMRI scans of brains, and overtime may damage portions of the brain that control memory, feelings, and emotions, and disrupt sleep, appetite, and health (Newberg \& Waldman, 2012). The activity in the amygdala increases and the normal functioning of the brain is interrupted due to the release of stress-causing hormones and neurotransmitters (Newberg \& Waldman, 2012). Groundbreaking research by Newberg and Waldman can be used to reflect on the potential impact of trauma, a negative school climate, or poor relationships on students as well as school personnel. Negative thinking and worrying is self-perpetuating, meaning that increased exposure to negativity, whether it is personal or expressed by another, causes the brain to respond by generating more negative thoughts and feelings which can lead to violence (Newberg \& Waldman, 2012).

Moreover, Newberg and Waldman (2012) claimed that verbally expressing negativity prompts a greater release of stress related chemicals in both the speaker's and listener's brains than merely thinking negative thoughts, causing both parties to experience feelings of anxiety and irritability, therefore reducing feelings of trust, cooperation and empathy. The automatic and brain-based contagious nature of emotions within social interactions can be explained by specialized brain cells discovered in the 1990's called mirror neurons (Keysers, 2011). Even witnessing an event involving another person can trigger a biological response; humans have the natural capacity to feel what others feel (Keysers, 2011). The realization that the brain responds in a similar manner in make believe situations, such as watching negative or violent scenes in a movie, is especially important for educators to understand, as research shows that the brain “doesn't distinguish between fantasies and facts when it perceives a negative event. Instead it assumes that a real danger exists in the world" (Newberg \& Waldman, 2012, pp. 24-25). 
Critical Recognition of the Experiences of Therapeutic Behavioral Strategists in Addressing Student Trauma

What matters most during interpersonal conflicts is if the student perceives the threat as

real, not whether the educator perceives the negative words or fearful comments as real threats. This understanding may help educators adjust their dispositional response to traumatized students who are exhibiting behaviors indicative of fear. Interpersonal conflict increases the release of cortisol, a chemical in the body that intensifies stress, leading to brain and cardiovascular system damage. Newberg and Waldman (2012) reported that children who were exposed to hostile language and conflict in the home have difficulty avoiding anxiety, depression, and fear, as hostile language appears to interfere with the genes that produce neurochemicals designed to protect us from physical stress. Furthermore, according to a study conducted by The Ohio State College of Medicine, hostility and anger diminish the body's healing progression (Newberg \& Waldman, 2012). The brain and body continue to respond to traumatic stress, even after the incidents have concluded, due to the "prolonged activation of the body's stress response system," which in turn "can disrupt development of brain architecture, increasing risk for stress-related diseases and cognitive impairment, which can persist into adulthood" (Children's Defense Fund - Ohio, 2015, p. 2).

Complex trauma has a profound impact on the human brain. According to Gabowitz et al. (2008), complex trauma "has been associated with structural and functional alterations in brain development, which in turn can result in cognitive and neuropsychological deficits" (p. 163) including "neurohormonal to neuroanatomical" "psychobiological abnormalities" (p. 164). Neuroimaging studies have identified differences in the brains of complex trauma victims, such as smaller total brain volume, smaller corpus callosum, prefrontal cortex, and cerebrum, and larger lateral ventricles and cerebrospinal fluid volumes in the frontal lobe of the brain that result in a multitude of developmental and cognitive consequences (Gabowitz et al.). Moreover, 
Critical Recognition of the Experiences of Therapeutic Behavioral Strategists in Addressing Student Trauma

neuroimaging studies have shown that dysfunction of mirror neurons in the brain due to trauma or other forms of brain injury can result in attachment problems (i.e., lack of emotional connection with others) (Keysers, 2011). Attachment trauma, caused by a lack of opportunity to build attachments with caring adults in early childhood through perceived rejection or separation from caregivers, may result in a reduced capacity for self-regulation, stress management, empathy or development of the prefrontal cortex (Oehlberg, 2008). Exposure to chronic stress at an early age impacts brain maturation, including the sympathetic nervous system, neurochemical changes (i.e., changes in serotonin levels), the limbic system, neurogenesis, and pruning at critical stages of childhood maturation (Gabowitz et al., 2008). Although the more than 100 billion neurons present at birth are used throughout the lifespan, researchers have recently demonstrated that neurogenesis can occur in the adult brain (Perry, 2001). This finding is significant because it implies hope for injured or traumatized brains to heal.

\section{Trauma and the Importance of Relationships}

One theory about the origin of trauma is that it stems from a disrupted attachment in early childhood (Berg, 2017). Children who have experienced trauma have a very difficult time forming healthy attachments, though these attachments are imperative for effective treatment. Relationships and the therapeutic alliance are extremely important (Berg, 2017). Many medications, apart from stimulants, interfere with oxytocinergenic levels in the brain, which in turn interferes with the individual's ability to form relationships (Foltz, 2008). In a school setting, the child will be more likely to learn if he forms a positive relationship or alliance with the teacher. This can be particularly difficult for a child who has experienced complex trauma because adult caretakers have not been reliable and predictable. Children with these histories often do not know how to use adults in positive ways. A child who has experienced trauma may 
Critical Recognition of the Experiences of Therapeutic Behavioral Strategists in Addressing Student Trauma

present as stubborn, argumentative, and oppositional, but they truthfully may be yearning to feel

some sort of control in a world that feels unpredictable (Fecser, 2015).

\section{Critical Consciousness}

Critical consciousness is a gained awareness of the social and historical problems of the world, as people learn to help themselves though critical confrontation of their problems and become agents of their own liberation. Freire (1974) described a, "consciousness about the world, which implies a consciousness about myself in the world, with it and with others" (p. 11). Thus, without a critical consciousness of the world and their responsibility in the world, men and women are not able to integrate themselves into the struggle in order to gain experiences marked by intense change and active participation (Freire, 1974).

Utilizing criticality means that educators are responsible for making sure students have opportunities to examine and question their current positions, values, or power of themselves involving what Freire (1974) described as the "possibility of knowing" (p. 50). This includes expanding the possibilities of critical thinking through a reading of the world and the word, dialogue, problem-posing education, and fostering curiosity. According to Giroux (2014), "critical thinking represents the ability to step beyond commonsense assumptions and to be able to evaluate them in terms of their genesis, development, and purpose" (p. 40). In this way, criticality is a political act where "human beings must emerge from their own submersion and acquire the ability to intervene in reality as it is unveiled (Giroux, 2014, p. 41). Criticality creates an awareness of the world through linking historical consciousness of how inequities and injustices have been created, maintained, and fought against throughout history. In addition, criticality develops a critical praxis, or a problem posing education that builds curiosity through a 
Critical Recognition of the Experiences of Therapeutic Behavioral Strategists in Addressing Student Trauma

questioning of the world. This replaces what Freire (1974) called the banking education, where information from the educator is deposited into the compliant, submissive student. Instead, the problem-posing educator facilitates learning through real-world experiences and a critical praxis involving dialogue and curiosity. "The role of the educator is to challenge the learner's naïve curiosity in order that they can both share criticalness, affirming itself, and unveiling hidden truths" (Freire, 1964, p. 52). For Freire (1974), criticality is created through dialogue and reflection. "Dialogue is full of curiosity and unrest., ... presupposes maturity, a spirit of adventure, confidence in questioning, and seriousness of providing answers" (p. 5). Dialogue is a critical posture of communication that goes past a scientific position of the world and stimulates curiosity. In addition, reflection is needed to form an understanding of historical criticality. Freire (1974) stated that reflection is a prerequisite, which enables people to "reflect upon themselves, their responsibilities, and their role in the new cultural climate-indeed to reflect on their very power of reflection., ... that would mean an increased capacity for choice” (p. 13). Thus, criticality requires critical thinking skills with a gained awareness in social and historical consciousness through problem posing, dialogue, curiosity, and reflection. Without criticality, students are trained to adapt without protest and to continue the silence, without exposure to the possibility of the negation of social injustices (Giroux, 2011). It is a way of keeping society tamed as "Hope [is] pulverized in the immobility of the crushing present, some sort of final stop beyond which nothing is possible" (Freire, 1974, p. 55). Therefore, educators must gain an understanding of the social and political nature of schooling and the role they play in shaping what knowledge students receive and are exposed to through criticality (Giroux, 2011).

Transformative Learning Theory 
Critical Recognition of the Experiences of Therapeutic Behavioral Strategists in Addressing Student Trauma

"A commitment to change (i.e., reframing beliefs and organizational practices) is essential, to become a learning organization (Giesecke \& McNeil, 2004). The first step is to understand how organizations learn and the motivations for behaviors (Giesecke \& McNeil, 2004). Cranton (2002) explained that a traumatic event or even a provoking question can prompt an individual to become aware of and critically reflect on their limiting perceptions and alternative viewpoints. Past experiences reinforce current perceptions and expectations; habits of mind impact our self-perceptions, interpretation of experiences, beliefs, and work-related knowledge (Cranton, 2002). "It is easier and safer to maintain habits of mind than to change" This means that it is easier and more comfortable to keep the same points of view rather than questioning and examining them. (Cranton, 2002, p. 65). Adults may undergo transformational learning as a result of experiencing a significant event or acquiring new knowledge that prompts critical reflection of whether past beliefs are still valid (Cranton, 2002). On the other hand, learning may happen over time without recognition that transformational learning occurred until later (Cranton, 2002). Through a new awareness, discussing assumptions, beliefs and concepts with others within a supportive and encouraging environment helps the process (Cranton, 2002). When faced with experiences such as those integrated into the TIC PD, participants may experience emotions such as guilt or anxiety, challenging an individual's meaning perspectives, motivating the individual to critically examine the assumptions that formed the foundation of one's selfhood. For example, an educator may interpret experiences with students based on their misbehaviors, labeling students as unmotivated, antagonistic, or bad, when in reality the behaviors were a coping mechanism, a response to trauma (Overstreet \& Chafouleas, 2016). The perceptions of students become embedded into teacher habits of mind, and are reinforced over time (e.g., the student is lazy, does not care, or cannot learn). 
Critical Recognition of the Experiences of Therapeutic Behavioral Strategists in Addressing Student Trauma

Importance of Understanding TIC

In reality, when educators understand the science behind TIC, they realize how trauma impacts the brain, student learning, and behaviors, and therefore understand that fear of failure may underlie what appears to be laziness (Cranton, 2002). Furthermore, a negative experience with a student after gaining TIC knowledge (i.e., a disorienting dilemma that does not align with past assumptions) may cause educators to critically examine past beliefs and behaviors toward students, feeling guilt or shame. Participating in reflective discourse with colleagues to find a new common understanding, forming new points of view or perspectives, enables educators to collectively determine appropriate courses of action to take to better support traumatized students.

Educators must forgive themselves for destructive, stereotypical beliefs and behaviors in order to move past their history toward a more compassionate future (Cranton, 2002). Adult learners look for evidence that supports or negates revisions to new assumptions by engaging in dialogue with others, hence the importance of school administrators developing an open, trusting, and collegial school culture for educators to participate in transformational learning. "Adult educators must be aware that helping adults learn how to move from an argumentative mindset to an empathic understanding of others' views is a priority" (Merriam, 2013).

\section{Critical Examination}

As adults (i.e., educators) develop and face new experiences, the assumptions created by past experiences (i.e., meaning perspectives) prompt an integration or transformation of the new learning into one's personal existence (Mezirow, 1978). When faced with an experience, life crisis, or dilemma that causes anxiety or challenges an individual's meaning perspectives, in 
Critical Recognition of the Experiences of Therapeutic Behavioral Strategists in Addressing Student Trauma

essence forcing a person out of their comfort zone (i.e., managing a traumatized student's

behavior), the individual must critically examine the assumptions that formed the foundation of oneself in a process called "perspective transformation" (Mezirow, 1978, p. 102). Changing one's assumptions may occur when an educator personally experiences trauma, witnesses the profound effect of trauma on students, or faces the truth about their interactions with traumatized students. Transformational learning is different from learning informational text.

Transformational learning involves a root change in how we view ourselves and the world we live in as we develop during adulthood (Merriam et al., 2007). Mezirow (1978) suggested that adults move along a maturation continuum, as allowable by an individual's culture, revising the lens utilized for understanding and creating personal meanings or perspectives. The goal of TIC PD is to persuade adults to utilize a trauma-informed lens to understand students and modify personal dispositions and behaviors. In addition, when current perspectives do not adequately fit or explain new experiences and a person becomes conflicted, transformation may occur by adopting others' perspectives through the conscious recognition that the new viewpoint, or perspective, is more advantageous than the old viewpoint or perspective (Mezirow, 1978).

\section{Professional Development in the area of Trauma}

PD regarding the prevalence of trauma, the multifaceted impact of trauma on students, and the research regarding ability of the brain to heal itself with the support of nurturing adults may create an opportunity for educators to perceive that a TIC approach is more advantageous than former dispositions or behaviors. The new meaning perspective includes "dimensions of thought, feeling and will” (Mezirow, 1978, p. 105), determines how a person views themselves, 
Critical Recognition of the Experiences of Therapeutic Behavioral Strategists in Addressing Student Trauma

their roles and relationships with others, and influences whether action is taken or behavior is

changed. Cranton (2002) noted that there are no specific PD methods that guarantee

transformational learning will occur as each participant will respond to something that speaks to

their individual thoughts or feelings. Transformational learning takes place within an

environment that balances challenging participants with safety, support, participant

empowerment and honoring their feelings and individuality (Cranton, 2002). The

transformational learning PD included activities to meet the needs of diverse learners and to

encourage critical reflection and rational discourse: informative videos, illustrations and

handouts for visual learners; real-world stories of trauma, the iceberg metaphor (i.e., the realities

of a student's existence that is readily hidden from teachers; teachers only see student behaviors), group discussions for auditory learners, and interactive activities with games requiring movement and role plays for kinesthetic learners.

Cranton (2002) noted that videos and stories may serve as the catalyst or activating event, exposing participants to alternative perspectives and new information. Asking participants personal questions about their experiences and analyzing metaphors, modeling self-reflection of perceptions for participants, and openly talking about alternative points of view, requires participants to communicate and ponder the consequences of former assumptions (Cranton, 2002). Bass (2010) wrote that transformational leaders stimulate intellectual reflection through the use of metaphors, potentially revealing hidden beliefs. Roleplays and simulations provide an opportunity for participants to practice new perspectives, behaviors, and interpersonal communication skills within a safe environment to solve a problem, such as an educator response to student misbehavior (Cranton, 2002). Critical reflection, decision-making, and implementing change require conscious thought and cognitive functioning. 
Critical Recognition of the Experiences of Therapeutic Behavioral Strategists in Addressing Student Trauma

Level of Cognitive Development for Transformative Learning to Occur

Unlike Mezirow's theory that utilized cognition during transformation, Merriam noted studies, such as those conducted by Freire, Taylor, McDonald, Kovan and Dirkx, in which people were not aware that they were critically reflecting during the time their perspectives were transformed. This means that you can be unconscious of critically reflecting while still being able to transform your own perspective (Merriam, 2013). The research findings indicate that transformational learning can occur without a specific level of cognitive development, purposeful critical reflection, and awareness that one is undergoing change (Merriam, 2013). In addition to Mezirow's views on individual transformations, Laurent Daloz's psychodevelopmental view of transformational learning encapsulated the importance of storytelling and Robert Boyd's psychoanalytic view (i.e., an emotional and spiritual approach) clarified the value of symbols and the unconscious during the learning process (Merriam, 2007).

While Mezirow's approach to transformative learning was largely based on a cognitive framework, Boyd utilized Jungian theory to understand the affective and spiritual nature of adult learning (Dirkx, 2006). In addition to advancing educator learning, school leaders can use storytelling, metaphors and symbolic language to strum the heartstrings of educators and inspire a shared vision of the future of the school district (Dirkx, 2006). Real world stories of the traumas faced by students shared by a passionate and authentic leader may motivate educators to step out of their comfort zone and collectively experience transformational learning. Dirkx (2006) explored how emotionally provocative images can assist learners in giving a voice to the unconscious conflicts or dilemmas that arise during transformational learning experiences. 
Critical Recognition of the Experiences of Therapeutic Behavioral Strategists in Addressing Student Trauma

Significance of Professional Development

The possession of emotions is a core tenant of humanity (Dirkx, 2006). Trauma informed care professional development (PD) is about "changing the heart" of trainees (C. Blodgett, personal communication, October, 21, 2015). TIC professional development typically includes video reenactments of childhood abuse that depicts the real impact of trauma on childhood emotional regulation and behaviors. The reenactments have the potential to conjure powerful emotional responses in PD participants. Regardless of the importance of emotion to human existence, emotion or affective aspects of learning are often overshadowed in research by the cognitive aspects of learning (Dirkx, 2006). Dirkx (2006) noted the impact emotions have on the process of critical reflection on assumptions described by Mezirow, prompting feelings such as guilt, shame, fear or anxiety. The feelings that surface as educators explore taboo topics such as assumptions about the motives for student behaviors, stereotypes of students who may have experienced trauma, and the impact of reflections on how educators view themselves and their behaviors toward students, are an example of how emotions affect the process of critical reflection during transformational learning.

Mezirow's theory typically applies to individual transformation resulting in some form of personal decision or action, although disorienting dilemmas may prompt social action with the aid of like-minded individuals (Merriam et al., 2007). Maintaining new meaning perspectives and the resulting action requires support from others who share the same perspectives (Mezirow, 1978). The need for close social relationships for the development of perspective taking, introducing action for school improvement, and transformational learning has implications for school leaders charged with the task of helping educators develop professionally. Kouzes and Posner (2012) note the importance of traits such as vulnerability, benevolence, reliability, 
Critical Recognition of the Experiences of Therapeutic Behavioral Strategists in Addressing Student Trauma

competence, honesty, and openness in the development of trust between school leaders and educators.

These leadership traits are vital to creating a school culture conducive to transformative learning as well as developing trusting relationships that supports shared perspectives and yet respect the unique differences of individuals. School leaders must recognize that educators are as uniquely different in personal histories, heredity, cultures, learning styles, and social-emotional competencies as students, and therefore must honor the differences by respecting the wealth of accumulated life experiences and knowledge that educators bring to the PD table. School leaders must be sensitive to the reality that educators, like students, may have experienced trauma.

Assuming that teachers will grow professionally from a traditional "sit and get" type instructional format utilized in the K-12 classroom fails to meet the criteria for transformative learning. School leaders must sustain a safe and trusting climate for educators to embrace a TIC lens and approach, which requires methodical self-awareness of adult dispositions and behaviors toward students. C. Blodgett (personal communication, October 21, 2015) advocates for a "coaching and consultation" model of PD. Adult stakeholders within schools must feel safe to coach and be coached by colleagues following PD to create opportunities for continual transformation learning. The "heart of transformative learning" for educators within the field of education is a type of knowledge defined by Habermas as emancipatory knowledge: "critically questioning and reflecting on what we do, how it works, and why we believe it is important" (Cranton \& King, 2003, pp. 31-32). PD activities may lack transformative learning opportunities for educators by focusing on what Habermas termed technical knowledge (Cranton \& King, 2003). 
Critical Recognition of the Experiences of Therapeutic Behavioral Strategists in Addressing Student Trauma

Transformative learning, rather than acquiring technical knowledge, requires an open, honest, and vulnerable examination of an educator's practice. School leaders must create a safe and trusting atmosphere for educators to risk a critical reflection of their beliefs and behaviors, privately or with their peers, for transformational learning to occur (Cranton \& King, 2003). Genuine PD is more than the acquisition of a set of strategies for the educators' toolbox; "It must involve educators as whole persons- their values, beliefs, and assumptions about teaching and their ways of seeing the world" (Cranton \& King, 2003, p. 33). Teaching must be driven by more than curriculum and resources such as textbooks; teaching must be driven by a teacher's understanding of the moment by moment needs of individual students, and ability to consider the perspective of the student. When a teacher learns to understand their students' understandings, the teacher is better able to accurately diagnose and respond to student's behaviors in the classroom (Rodgers \& RaiderRoth, 2006).

Just as school leaders promote the use of differentiated instruction for students, they must acknowledge and meet the diverse adult learning needs of individual teachers. "When educators are led to examine their practice critically and thereby acquire alternative ways of understanding what they do, transformative learning about teaching takes place" (Cranton \& King, 2003, p. 32). Transformative learning that informs pedagogical change is a key goal for school leaders and educators striving to achieve school improvement. School leaders are charged with the critical task of delivering quality PD to teachers in order to improve the art and science of teaching and subsequently improve student learning (Kose, 2009.) While descriptions of the five PD roles of school leaders (e.g., transformative visionary, transformative learning leader, transformative structural leader, transformative cultural leader, and transformative political 
Critical Recognition of the Experiences of Therapeutic Behavioral Strategists in Addressing Student Trauma

leader) are not critical to the premise of this research, it is important to note the use of the term transformative within the title of each role (Kose, 2009).

Quality and meaningful PD that results in real learning, improving instructional performance and teacher attitudes within the classroom, must counter potential resentment created by mandated PD, inadequate preparation by the administrator, or ineffective presentation strategies utilized by the PD presenter (Beavers, 2009). Wei, Darling-Hammond, Andree, Richardson, and Orphanos (2009) assert that on-going, collaborative PD and job embedded practice increases student learning. Although the literature does not address the need for quality PD for classified staff to improve student learning, school leaders must consider the impact that all adult-student relationships and interactions have on student learning.

To attain continual school improvement, Beavers (2009) noted the benefits of understanding adult learning theory as school leaders attempt to increase the effectiveness of PD. Knowledge of transformative learning is applicable to the examination of the perceived learning outcomes of the faculty workshop presented by a national non-profit organization for certified staff and the PD developed and implemented by a school counselor and administrator for classified employees within this research study. The theory can be used as a framework to examine whether educators perceived a transformation in their knowledge, dispositions, and behaviors toward traumatized students as a result of attending TIC PD.

When faced with interactive experiences such as those integrated into the professional developments, participants may have experienced emotions such as empathy, anxiety, or guilt, challenging an individual's meaning perspectives, motivating the individual to critically examine the assumptions that formed the foundation their sense of self. In addition, participants may have 
Critical Recognition of the Experiences of Therapeutic Behavioral Strategists in Addressing Student Trauma

felt sadness, anxiety, empathy, or even fear, as mirror neurons respond to real-world stories and video-depictions of students experiencing a traumatic event (Keysers, 2011). Deep-seated change in personal beliefs about the nature and impact of trauma on students, as well as colleagues, transforms the lens by which educators view students and colleagues, impacting the quality of collective self-efficacy, and beliefs of individual student's potential to achieve academic success. This is an ideal example of the type of adult transformational learning that has the potential to transform teacher-student relationships.

Furthermore, improved relationships may result in an improved school culture, in which all students feel accepted and all stakeholders perceive that the school district has a safe and caring climate (Harris, 2000). Schools may benefit from providing educators with experiences that transform their foundational beliefs about students' capacity to learn, regardless of trauma, so that all students feel equally accepted, challenged, and justly treated, improving the likelihood of an equitable education for all. The purpose of the Trauma-Informed Care PD, implemented in a manner to promote transformational learning, is to improve educator knowledge of trauma, the impact of trauma on students within the school setting, and educator dispositions toward traumatized students. Heartfelt change is challenging (C. Blodgett, personal communication, October 21, 2015).

Newberg and Waldman (2012) indicated that changing the manner in which adults listen, communicate and behaviorally interact with others is difficult and is often met with resistance because learned behaviors slip into unconscious long-term memory: old behaviors are often the first to emerge even after learning new behaviors that are perceived as more effective. "Change does not occur immediately - time and effort are needed" (Kotsou, Nelis, Gregoire, \& Mikolajczak, 2011, p. 834). People who possess strong beliefs in their capabilities set higher 
Critical Recognition of the Experiences of Therapeutic Behavioral Strategists in Addressing Student Trauma

goals for themselves and persist in their efforts to achieve goals and to overcome challenges

(Bandura, 1989). Self-efficacy, the belief that one is capable of meeting the needs of traumatized students and changing one's behaviors as a result of new knowledge, is vital to the success of PD. Bandura (1989) recognized the distinction between acquiring knowledge and skills and effectively and consistently applying knowledge and skills in various situations.

PD that requires participants to learn new knowledge and skills will produce widespread and enduring effects if the PD enhances participant self-efficacy. School leaders can enhance participant self-efficacy through encouragement and belief in their abilities, successfully modeling skills to overcome challenges, and providing participants with opportunities to successfully practice skills (Bandura, 1989). Alternately, if participants are not convinced that they are capable of successfully implementing the new knowledge and skills they will abandon their efforts if they fail to get results or if it is perceived as too difficult (Bandura, 1989). Employees who participate in TIC PD must believe that they can make a difference in the lives of their students. Teachers are the most significant factor in schools for influencing students' educational outcomes (Hattie, 2012). "It matters what teachers do, but what matters most is having an appropriate mind frame relating to the impact of what they do.

An appropriate mind frame combined with appropriate actions work together to achieve a positive learning effect" (Hattie, 2012, p. 15). Hattie (2012) advocates for educator practice that aligns with evidence-based mind frames, such as believing change is possible, setting high expectations for all students, developing trusting environments, and critically reflecting on one's effect on student learning. Educator perception of their role in student learning is critical: teachers must perceive that they can make a difference and that students can overcome obstacles (Hattie, 2012). In summation, transformative learning theory has evolved since 1978 to 
Critical Recognition of the Experiences of Therapeutic Behavioral Strategists in Addressing Student Trauma

incorporate concepts from multiple theories (e.g., cognition, feminist, critical social, and

postmodern) into a holistic approach to adult learning theory that encompasses storytelling,

emotions, the arts, and relational learning (Taylor \& Cranton, 2012). Transformative learning

theory has altered the landscape of adult learning, endured revisions of additional constructs, has been examined across many disciplines during international conferences, and prompted the publication of hundreds of journal articles, more than a dozen books and 150 doctoral dissertations (Kitchenham, 2008). As a guide to adult learning, this theory can be utilized to revolutionize PD for educators.

\section{Paradigm Shift}

Theorists such as Ptolemy, Copernicus, Galileo, Keplar, and Newton have expounded upon the notion of paradigm in many forms. Foundationally, Kuhn (1962) single handedly changed the meaning of the word paradigm by evolving the connected connotations that were used previously relating to the word, before his time. As a result, the word paradigm continues to evolve. In rhetoric, Aristotle discussed the art of persuasion and used the word paradigm to describe the discussion between two parties, an orator, and an audience, who share a great many beliefs that need to be stated (Kuhn, 1962). Aristotle's use of the word paradigm meant an exemplar of the dispute between the two parties based off of the views and beliefs of those involved in the discussion (Kuhn, 1962). Thus, for Aristotle, the word paradigm evolved into the word exemplar, where a standard model was to be followed for the specific context (Kuhn, 1962). The primary use for the word paradigm was related to grammar and was also used as a metaphor (Kuhn, 1962). In Germany in 1930s, the word paradigm was commonly used in the philosophical writings of the Vienna Circle (Kuhn, 1962, p. xx). It then emerged in America as a philosophy of science and appeared many times in Viennese Ludwig Wittgenstein's (1953 as 
Critical Recognition of the Experiences of Therapeutic Behavioral Strategists in Addressing Student Trauma

cited in Kuhn, 1962) book. Philosophical investigations, in which using the word paradigm related to grammar and language games. Eventually, Kuhn (1962) evolved the word to mean a sharing of intellectual attitudes and problems that is legitimized by what the community does and believes based off of extensive research that was done on the phenomena. In Kuhn's (1962) book. Second thoughts on paradigm, he stated that paradigm refers to "the achievements served as exemplars of what to do, the kinds of questions to ask, successful application, and exemplary observations and experiences" (p. xxii). Thus, paradigms were considered the normalcy that legitimized the problems and puzzles within the scientific community, during that time (Kuhn, 1962). As Kuhn (1962) continued to discover the connotation behind the word paradigm, he discovered a new term, paradigm shift, which is a trendy term commonly used in educational practice. According to Kuhn, a paradigm shift occurs when the methods legitimized by the paradigm go wrong, becoming counter to what was expected to happen. These contradictory occurrences are defined as anomalies, or a crisis that is contrary to the established order that results and persists as a historical event, resulting in a redirection of research, and creating a means for a new paradigm (Kuhn, 1962). A paradigm shift begins as a solution to the new crisis is needed, resulting in an extraordinary amount of new research where new ideas arise, with new methods, a new theory, and a new worldview which creates a revolution. The revolution encompasses a paradigm shift that formulates a new world order with words that express the changed thoughts, the different view of the world, the different feelings for how it works, the different phenomena and puzzling of difficulties, and the new ways of interacting (Kuhn, 1962). As a result of the revolution, there is a change in meaning within the researchers themselves, which is demonstrated by a change in theory.

\section{Trauma-Informed Care}


Critical Recognition of the Experiences of Therapeutic Behavioral Strategists in Addressing Student Trauma

In a historical account of psychological trauma and societal responses, the SAMHSA's

Center for Substance Abuse Treatment (2014) describes the origins of trauma conceptualization in the United States. They describe how ideas about trauma launched from literature on war veterans in the 1860 s who returned home with physical and emotional stress from their experiences in combat. Early literature attributed such reactions to "moral weakness" (i.e., personal deficits on the part of the individual experiencing the distress) or "battle fatigue" (i.e., needing respite from the war environment). To address such conditions, talk therapy and physical rest were espoused as clinically appropriate treatments. Over a century later, in the 1980s, the American Psychiatric Association formally recognized posttraumatic stress disorder as a clinical diagnosis, marked by the experience of a specific tragic event and subsequently resulting in impaired functioning (McCarty et al., 2014). While individual treatment and clinical methods were long seen as the most effective approach to addressing trauma and posttraumatic stress disorder, newer ideas began to emerge about the utility of empowerment and psychosocial models in the treatment of trauma-affected individuals (McCarty et al., 2014). For example, peer support became a strong supplemental treatment approach to aid individuals who had experienced catastrophic events. Eventually, as societal consciousness began to focus on the overwhelming plight of many marginalized and vulnerable populations in the United States, trauma's definition began to expand to include interpersonal forms of violence as well as perceived threat or harm. Aiding in the development of this new definition, research began to illuminate the prevalence of such adverse events, particularly among young people. This emergence of focus on youth is partially due to the work of Felitti et al. (2010), who found that more than $50 \%$ of adults in their study experienced at least one form of traumatic stress during childhood. They also found that these childhood experiences were positively correlated with 
Critical Recognition of the Experiences of Therapeutic Behavioral Strategists in Addressing Student Trauma

significant health challenges later in life (Felitti et al., 2010). Today, childhood trauma is identified as "America's hidden health crisis", as youth trauma has risen to the forefront of the trauma landscape. This work shed light on the importance of preventing childhood trauma and also recognizing and addressing the needs of youth exposed to adverse events prior to their journey into adulthood. This research, in the fields of medicine and mental health services, along with the needs expressed by those receiving services, informed initial ideas about ways in which service agencies could better serve their clients through practices and policies that were sensitive to their traumatic histories (McCarty et al., 2014). These ideas, now termed "trauma-informed care," include a number of key features that are supported and promoted at the national level. For example, SAMHSA's trauma-informed approach includes acknowledging the prevalence of trauma, recognizing the impact of these experiences on all individuals, utilizing trauma-sensitive practices and policies, and avoiding practices that may retraumatize (McCarty et al., 2014). In a review of trauma-informed care across various organizations, three core components of traumainformed care emerged: (a) workforce/professional development, (b) organizational changes, and (c) practice changes (Maynard et al., 2019). Such trauma-informed approaches have become widely adopted in many public service sectors (e.g., mental health, child welfare) and have now come to the attention of schools and education authorities. In response to this emerging area of trauma-informed practice in schools, an abundance of resources and frameworks have been developed to address the needs of trauma-affected youth in schools, as described next.

The resource literature places a strong emphasis on using new knowledge to employ empathetic responses to students who are trauma-exposed and avoiding approaching students from a deficit perspective when they exhibit behavior that is considered problematic or disruptive. One widely cited resource (Thomas et al., 2019), developed by Western Washington 
Critical Recognition of the Experiences of Therapeutic Behavioral Strategists in Addressing Student Trauma

University and Washington Superintendent of Public Instruction, provides six principles for compassionate instruction and discipline in the classroom: (a) always empower, never disempower; (b) provide unconditional positive regard; (c) maintain high expectations; (d) check assumptions, observe, and question; (e) be a relationship coach; and (f) provide guided opportunities for helpful participation (Wolpow et al., 2009). The focus in this resource shifts educator perspectives from viewing students' undesirable behaviors (e.g., avoidance, aggression, disengagement) as inherently bad or oppositional toward viewing each student as having been affected in some way by their experiences.

\section{Shifting Perspectives}

Using a trauma lens when handling difficulties with students means shifting the question from "what is wrong with you?" to "what is happening with you?" While some specific Tier II and III school trauma interventions address trauma symptoms explicitly, the literature places greater importance on creating and maintaining a school environment where everyone is treated with compassion and understanding and is empowered and validated in who they are as students and educators. This includes intentionally building and sustaining meaningful relationships between staff and administrators, staff and students, and among the students themselves.

\section{Self-Care for Educators}

Educators working with students who are exposed to trauma can experience secondary traumatic stress. This stems from learning about students' trauma exposure, feeling empathetic yet having limited ability to change their students' situations. The resources emphasize the importance of maintaining self-awareness of secondary or vicarious trauma symptoms and engaging in self-care practices - a trauma-informed approach is a process and not a product- 
Critical Recognition of the Experiences of Therapeutic Behavioral Strategists in Addressing Student Trauma

thereby not overemphasizing all the potential impacts/outcomes particularly as it relates to the universal strategies that support a trauma-informed environment in schools for all students and staff. In the large varied landscape of resources, a formally agreed upon approach and practices rooted in evidence should be promoted. Still, this approach should give specific attention to the health and well-being of teachers and other school staff, as they navigate the challenging roles they face with students.

Through trauma-informed care, educators must also recognize their role and accept their responsibilities to ameliorate the consequences of trauma on youth (Thomas et al., 2019). Educational researchers along with school-based practitioners must incorporate pioneering research occurring in neuroscience, psychology, and social work to better inform their research and practice agendas (Thomas et al., 2019). It is important to encourage researchers outside of education to position teachers, and, specifically, teaching, as well as the other adults in schools (i.e., professional school counselors, teaching assistants, and bus drivers) and their activities more prominently in their research agendas. Advocating for a true systems-wide discussion in service of a research-informed practices approach that results in actionable recommendations and respect for all individuals and components of the system with explicit attention to schools is imperative (Thomas et al., 2019). Since school-based practitioners confront the impacts of trauma in the lives of students on a daily basis, it is important that trauma informed care practices move forward expediently with prevention and recovery at every level of the system in mind.

\section{Trauma-Informed Schools and Trauma}

As a result of research regarding the impact trauma has on children, and subsequently adult physical and mental health and well-being, national organizations have formed initiatives 
Critical Recognition of the Experiences of Therapeutic Behavioral Strategists in Addressing Student Trauma

to recognize and address trauma symptoms and provide appropriate interventions to support the healing of traumatized youth in order for them to become healthy, productive citizens. For example, SAMHSA, the National Center for Trauma-Informed Care (SAMHSA, 2015a), National Council for Behavioral Health (2015), National Child Traumatic Stress Network (NCTSN) (Ko et al., 2008), and the Ohio Department of Mental Health and Addiction Services (Kasich \& Plouck 2016), advocate for the implementation of Trauma-Informed Care professional development (TIC PD) to create an informed workforce capable of addressing the multifaceted needs of traumatized individuals within a trauma-sensitive organization. The advocacy is founded on trauma-survivor stories, research, including the outcomes of the ACE Study (Felitti \& Anda, 2010) and advances in neuroscience, indicating the prevalence and long-term impact of childhood trauma on cognitive and physical functioning, as well as the impact trauma has on brain development, social-emotional well-being, learning, and behaviors (Perry, 2001). "In turn these neurodevelopmental effects may result in significant cost to the individual, their family, community and, ultimately, society. In essence, childhood maltreatment alters the potential of a child and, thereby, robs all of us" (Perry, 2001, p. 15).

Harris (2001) advocate for the use of trauma theory to develop service systems that meet the needs of all individuals. A trauma-informed organization has a safe and inviting climate, educated workforce, and supports the needs of the whole-person; a TIC organization does not have to provide trauma therapy (Evans \& Coccoma, 2014). Within a trauma-informed system, the focus is on understanding the whole individual rather than the troubling symptoms or behaviors so that individuals can regain control and autonomy (Harris \& Fallot, 2001). SAMHSA, an agency within the U.S. Department of Health and Human Services, spearheads the national effort to improve the behavioral well-being of individuals within the U.S., and 
Critical Recognition of the Experiences of Therapeutic Behavioral Strategists in Addressing Student Trauma

influences federal efforts to encourage the implementation of a trauma-informed approach to behavioral health care and social service systems (SAMHSA, 2015c). "Trauma informed care is an approach to engaging people with histories of trauma that recognizes the presence of trauma symptoms and acknowledges the role that trauma has played in their lives" (SAMHSA, 2015a, para. 10).

A TIC approach includes the following understandings and reactions (SAMHSA, 2015d):

- the pervasive impact of trauma and avenues for recovery;

- identification of signs and symptoms of trauma in all organizational stakeholders, including children and adults; • behaviors are coping strategies and outcomes of trauma;

- trauma-related knowledge is assimilated into policies, procedures, everyday practices, and organization culture;

- the environment and interactions are physically and psychologically safe for students and employees;

- communications and procedures are trustworthy, just, and transparent;

- staff actively endeavor to resist re-traumatization of students and employees (e.g., isolating a neglected student);

- stakeholders within the school community collaborate (i.e., power and decision making is shared);

- school personnel empower students, give them a voice and choice, build upon student strengths, and believe in student resiliency and capacity for healing; 
Critical Recognition of the Experiences of Therapeutic Behavioral Strategists in Addressing Student Trauma

- eliminates stereotypical and biased beliefs to provide supports that meet individual needs.

The SAMHSA Center for Mental Health Services began funding the National Center for Trauma-Informed Care (NCTIC) in 2005 to provide resources, consultation, education and technical support to service organizations and K-12 education (SAMHSA, 2015a). SAMHSA (2015a) frames its concept for trauma around three "E's": “event(s), experience of the event, and effect" (para. 11). SAMHSA is a leader in the efforts to develop and encourage the use of trauma-specific interventions. The principles that guide SAMHSA's trauma-informed approach can be used "for analyzing social policy and guiding advocacy efforts" (Bowen \& Murshid, 2016, p. 223). A key goal of the agency is to promote recovery from trauma and build resiliency amongst trauma victims.

The National Child Traumatic Stress Initiative (NCTSI) was reauthorized in 2013 by congress as an acknowledgment of the dire impact trauma has on the mental health of children (SAMHSA, 2015b). The goal of NCTSI is to provide PD, develop and implement interventions to reduce the negative impact of trauma on youth, and improve treatment and access to community-based mental health care services for trauma victims. As a result of this initiative, SAMHSA representatives and other agency experts formed the NCTSN, made up of 70 treatment and research organizations, whose mission is to improve trauma-informed practices and access to services, as well as establishing collaborative networks between schools and agencies (Ko et al., 2008). Regardless of the noted advantages of becoming a trauma-informed school, few states or school districts are implementing the approach. For example, California is in the beginning stages of implementing school-related initiatives to counteract the impact that trauma has had on student academic achievement, misbehaviors, and health (Adams, 2013). 
Critical Recognition of the Experiences of Therapeutic Behavioral Strategists in Addressing Student Trauma

Teachers in some areas of Washington, Massachusetts, and Wisconsin are receiving whole-school TIC PD so that they can recognize the behavioral symptoms of trauma-induced stress, gain an understanding of the scientific research behind TIC, and acquire trauma-informed approach skills to manage traumatized student behaviors (Cole et al., 2013). Jaycox et al. (2006) and the OhioMHAS recommend that agencies and schools implement trauma-informed interventions and approaches. The overarching goal of a school-based TIC approach is to "reduce emotional and behavioral problems related to trauma exposure and to foster resilience in students for the future" (Jaycox et al., p. 9). The goal of care within a trauma-informed school is to help students overcome difficulties (Mayeroff, 1995), to thrive despite challenges, and to build resiliency (Brendtro \& Longhurst, 2005).

The fact that the number of students who are exposed to trauma is increasing each day demonstrates the need for researchers to know the best way for teachers to be prepared to provide a trauma informed teaching approach so that they can support students as they learn to operate in their neo-cortex. (Jones, 2013, p. 111) Although resilience is a universal human trait, humans need encouragement and positive relationships to thrive (Brendtro \& Longhurst, 2005). According to Lazarus and Folkman, the problems faced by individuals start with stress: "a state of physical and psychological arousal that signals some challenge or difficulty" (as cited in Brendtro \& Longhurst, 2005, p. 53). Effective interventions recommended by the NCTSN can be implemented in schools with a trained workforce: teaching students skills to manage stress and emotions, assisting students in clarifying feelings and perceptions about traumatic events in a manner that does not re-traumatize and amends inaccurate or unhealthy mindsets, utilizing journaling or the arts to articulate traumatic events and empower resiliency; and including parents in providing supports (OhioMHAS, 2016e). 
Critical Recognition of the Experiences of Therapeutic Behavioral Strategists in Addressing Student Trauma

In addition, NCTSN (2008) advocates for the implementation of academic

accommodations and modifications regardless of whether the traumatized student qualifies for special education services. Potential accommodations and modifications include shortened homework assignments, additional time to complete classwork, a plan for students to leave class when feeling overwhelmed to meet with a staff member in a safe place, and assistance with executive functioning skills, such as remembering and organizing school work. To mitigate the negative impact of trauma on children, teachers can provide students with empathetic support, and teach students strategies for mindfulness and remaining calm during difficult situations (Bethell et al., 2014). Cook et al. (2005) expounded upon the six core components of complex trauma intervention:

- improvement of personal and environmental safety;

- improvement of self-regulation capabilities following emotional, behavioral, physiological or cognitive dysregulation;

- improvement of executive functioning, such as planning and decision making, and selfreflection of past and present experiences;

- development of coping skills to manage traumatic memories and experiences, including mourning without debilitating results;

- improvement in interpersonal relationship skills, such as assertiveness, cooperation, perspective-taking, setting limits and appropriate boundaries, empathy, and the ability to appropriately engage in physical and emotional intimacy with others; 
Critical Recognition of the Experiences of Therapeutic Behavioral Strategists in Addressing Student Trauma

- improvement in affect, including a greater sense of self-worth, competency, and achievement, creativity, experiencing happiness, engaging in the community, and ability to plan for the future.

Bethell et al. (2014) found that children, ages six to seventeen, who learned resiliency strategies such as remaining calm and in control when faced with difficulties were able to ameliorate the negative effect of childhood trauma and increase engagement in academics.

\section{Safe, Calm, Supportive, and Healing Environment}

According to Stevens (2012), trauma-sensitive schools and trauma-informed classrooms are perceived as safe, supportive and caring. School safety encompasses more than crisis plan implementation (Ko et al., 2008) or ALICE (Alert, Lockdown, Inform, Counter, Evacuate) training. In addition to the fear caused by trauma that occurs outside of the confines of the school, negative or violent experiences at school can cause students to be scared. Being called on to give a speech in class, harassment from peers or adults, feeling that nobody cares, having no one to play with, or anticipating or enduring a physical attack may make school feel unsafe for students (Bluestein, 2001). Also, receiving threats, being taunted regarding race, sexual orientation, or disability, and verbal insults may make students feel unsafe (Harris, 2000).

These behaviors occur in all areas of the school facility, including hallways, restrooms, and playgrounds, and often go unnoticed (Harris, 2000). All school personnel possess dispositions toward students and are responsible for the success of schools. The ancient African proverb, "it takes a village," used by Hillary Rodham Clinton in the 1996 book It Takes a Village, rings true. According to Hattie's (2012) review of 913 meta-analyses, the teacher had the largest effect size $(d=0.47)$ on student academic achievement. However, teachers cannot do it alone: "Schools must develop systems to assist them" (Sitler, 2009, p. 122). Classified 
Critical Recognition of the Experiences of Therapeutic Behavioral Strategists in Addressing Student Trauma

employees interact with students in the hallways, cafeteria, classrooms, during recess, upon

arrival and dismissal from school, and on the school bus; therefore, classified staff have the potential to negatively impact student behaviors that may impede learning or provide adult supports to facilitate feelings of safety and care (Cole et al., 2013). Students who have experienced traumatic events may live with toxic stress, and therefore view the world through a lens of potential threat and danger. A safe, calm and supportive environment is critical as "academic work is viewed as secondary to recognizing warning signs of impending trouble" (Harris, 2000, p. 6).

School safety includes academic safety, emotional safety, social safety, and physical safety (Bluestein, 2001). Adults within the school setting can help students perceive that they are physically and psychologically safe and cared for, and that the adults will help them through traumatic experiences by effectively using a trauma-informed approach (OhioMHAS, 2016d). The NCTSN (2008) suggest that educators support students in maintaining routines during or after traumatic experiences to help students feel safe and to imply that life continues to move forward. Providing choices may help students feel that they control their life in the school setting, as they may lack control of their life or live in chaos outside of school. Schools can also designate an adult to support and encourage traumatized students. School personnel should communicate clear limits for appropriate and inappropriate behaviors and implement logical consequences rather than issue reprimands and punitive consequences. Additionally, NCTSN (2008) suggests that schools communicate that it is appropriate for students to talk to educators within the school setting and establish a time and safe place for students to discuss feelings and incidents leading to trauma. During these discussions, educators should provide simple and realistic responses to student questions, explain misconceptions and rectify distorted thinking 
Critical Recognition of the Experiences of Therapeutic Behavioral Strategists in Addressing Student Trauma about traumatic events. Educators should proactively address potential triggers or vulnerabilities in the environment that may re-traumatize or escalate negative feelings or behaviors. 
Critical Recognition of the Experiences of Therapeutic Behavioral Strategists in Addressing Student Trauma

\section{Chapter 3:}

\section{Methodology}

This project examines the experiences of six therapeutic behavioral strategists (TBS) by listening to their authentic voices as they describe their work with traumatized students. TBS are mental health professionals who provide comprehensive behavioral support services to students, school staff, and parents, to address mental health related behavioral challenges that limit a student from receiving the full benefit of their educational experience. I will highlight the importance of critically recognizing the role of TBS in working with traumatized students in order to learn how to redistribute resources in servicing these students properly. This project utilizes the lenses of critical consciousness (Freire, 2000), transformative learning theory (Mezirow, 1997), and paradigm shift (Kuhn, 1962) complemented by trauma-informed care (Walkley \& Cox, 2013) in examining the experiences of TBS in assisting traumatized students. This dissertation is important because it helps understand the stories, experiences, perspectives, and roles of TBS in addressing the needs of traumatized students. After prompting participants to engage in open-ended storytelling of their experiences working with traumatized students. I used a semi-structured, open-questioning protocol to interview participants. Themes emerged from participants" "storytelling" and responses to questions are identified as evidence described by Cresswell and Poth (2017) as lived experiences of TBS working in schools. Once I identify these themes, they will affirm theories of trauma-informed care and the best professional practices in responding to traumatized students, while also responding to the research questions: How does TBS work with students who have experienced trauma? What do TBS's view as challenges in the school setting for children who have experienced trauma? What recommendations can TBS 
Critical Recognition of the Experiences of Therapeutic Behavioral Strategists in Addressing Student Trauma

provide in order to help school sites better serve students who have experienced trauma?

Gathered data will increase the efficacy of TBS's in serving traumatized students appropriately.

\section{Research Design}

The goal of this project is to talk to therapeutic behavioral strategists (TBS) about their experiences and best practices, and how that maps onto existing practices of trauma informed care. The lenses of critical consciousness (Freire, 2000), transformative learning theory (Mezirow, 1997), and paradigm shift (Kuhn, 1962) complemented by trauma-informed care (Walkley \& Cox, 2013) in examining and analyzing the experiences of TBS in assisting students with trauma, will create the theoretical foundation underlying this goal. Clandinin (2016) states: "it is because we all live out narratives in our lives and because we understand our own lives in terms of the narratives that the form of narrative is appropriate for understanding the actions of others." (p. 197). The work of these researchers provides the inspiration for choosing the method of narrative inquiry to best reach this goal. Each participant participated in three, 45-minute interviews using the attached interview protocol. I conducted semi-structured, open interviews with interviewing techniques that encourage open dialogue pertaining to participant experience in their work with traumatized students. As TBS stories are told and recalled from memory, themes emerged through theoretical exploration and interpretation of data sets (Conle, 2001). From these, I obtained rich data to be analyzed through the constructed lens of critical consciousness, transformative learning theory, and paradigm shift, to identify relevant themes to be synthesized and attached to established theories of trauma-informed care practices.

\section{What is Narrative Inquiry and Why is it Used?}


Critical Recognition of the Experiences of Therapeutic Behavioral Strategists in Addressing Student Trauma

The first decision I made was whether to address the research questions from a quantitative or qualitative paradigm. The critical aspect that led to making this decision is the fact that the perception of participants is of the most critical interest in this work. Because of this, I made the decision to approach my inquiry through a qualitative lens. The next question I addressed was which qualitative path to take to best address my research questions. To best answer this, I turned to the book of Creswell and Poth (2017) in their book Qualitative Inquiry \& Research Design: Choosing Among Five Approaches. The following paragraphs briefly describe the defining characteristics of narrative inquiry and support the case for why narrative inquiry is the most appropriate fit for my study.

The primary purpose of narrative research is to tell the individual story of the subjects being studied. The stories that are collected tell the individual experiences of participants in a specific place or situation and focus on descriptions of "physical, emotional, and social situations" (Cresswell \& Poth, 2017, p. 69). I chose to utilize narrative inquiry because I will be telling the stories of therapeutic behavioral strategists as they describe their work with students that have been exposed to trauma. I want to be able to capture the experiences of TBS as they work with students, administrators, teachers, and families while also being able to understand how they feel physically, emotionally, and how they may respond to various social situations to help students that have been exposed to trauma.

Through narrative inquiry, data can be gathered in the form of interviews, observations, documents, or pictures (Creswell \& Poth, 2017). I decided to use narrative inquiry because I will be gathering data through the forms of interviews. Conducting interviews with therapeutic behavioral strategists will allow me to understand their stories, experiences, and perspectives through their authentic voices as they describe their work with traumatized students. Data can 
Critical Recognition of the Experiences of Therapeutic Behavioral Strategists in Addressing Student Trauma

then be analyzed thematically, structurally, or dialogically, focusing on values, plot, significance, or character mapping and time (Creswell \& Poth, 2017). Another reason I chose to utilize narrative inquiry was because it provides opportunities to analyze my data thematically and focus on values, plot, and significance. Analyzing my data thematically helped identify themes that affirm the theories of trauma-informed care and the best professional practices in responding to traumatized students.

The stories that are written to describe these narratives contain turning points, specific tensions, or interruptions in which meaning is made "related to similarities, differences, change, or coherence" (Cresswell \& Poth, 2017, p. 69). Narrative inquiry was an appropriate fit for my study because TBS stories were written to describe specific tensions regarding differing viewpoints of mental health professionals and educational professionals. The emerging themes will help explain appropriate responses to best serve students that have been exposed to trauma. According to Creswell and Poth (2017) this path of inquiry requires the researcher to select "one or more individuals who have stories or life experiences to tell and spend considerable time with them gathering their stories” (p. 71). Another reason narrative inquiry was chosen for my dissertation was because I selected six therapeutic behavioral strategists who all have stories and life experiences to share regarding their work with traumatized students, and I spent 135 minutes with each of them to gather their stories, experiences, and perspectives. The hope through these efforts was to identify themes among the responses that weave together a cohesive framework tied to the previously mentioned theories of learning with specifics of what is currently known to be effective when working with students experiencing trauma.

\section{Narrative Inquiry}


Critical Recognition of the Experiences of Therapeutic Behavioral Strategists in Addressing Student Trauma

I will highlight the importance of critically recognizing the role of TBS in working with traumatized students to learn how to redistribute resources in servicing these students properly. The educational value of this dissertation is accentuated by the roles of TBS in addressing the needs of traumatized students. The lenses of critical consciousness (Freire, 2000), transformative learning theory (Mezirow, 1997), and paradigm shift (Kuhn, 1962) complimented by traumainformed care (Walkley \& Cox, 2013) in examining and analyzing the experiences of TBS's in assisting students with trauma will create the theoretical foundation underlying this goal.

Through narrative inquiry, TBS's stories are told and recalled from memory, and themes will emerge through theoretical exploration and interpretation of data sets (Conle, 2001). From these, I obtained rich data to be analyzed through the constructed lens of "Critical Consciousness," "Transformative Learning Theory," and "Paradigm Shift," to identify relevant themes to be synthesized and attached to established theories of trauma informed care practices. As elaborated upon further later in this work, once themes were created, they were taken back to participants to determine if my interpretation matched the participants' perspective on how to appropriately work with students experiencing trauma. As illustrated clearly, there are direct ties between the conceptual framework and the utilization of narrative inquiry. The conceptual framework plays a significant role in identifying relevant themes that will be synthesized and attached to the established literature of trauma informed care through the use of narrative inquiry. As I explain in later chapters of this work the emerging themes also have a direct connection to the lenses of critical consciousness, transformative learning theory, paradigm shift, and trauma-informed care.

Narrative inquiry is used to study, understand and reconstruct experiences while staying within narrative modes of expression throughout this process (Conle, 2005). Narrative inquiry 
Critical Recognition of the Experiences of Therapeutic Behavioral Strategists in Addressing Student Trauma

describes the phenomenon of personal experiences and is rooted in circular dimensional practice of inquiry and discovery (Conle, 2001). The aim of narrative inquiry is to bring understanding and clarity to a particular phenomenon through the telling of lived experiences (Connely \& Clandinin, 1990). As the stories are told, and recalled from memory, themes emerge through theoretical exploration and interpretation of data sets (Conle, 2001). Furthermore, Conle, (2001) described that truth claims can be verified through theoretical discourse, as narrative inquiry may assist with clarifying lived values and to determine what may be good for a particular society or culture. In other words, understanding the experiences of therapeutic behavioral strategists in their work with traumatized students will bring clarity, and help understand how to determine the most appropriate way to work with students that have experienced trauma.

Narrative inquiry can be undertaken individually, but is best practiced collaboratively. It takes its contents from the subjective realms of emotion and imagination, as well as from the experience of events and situations in the "lifeworld" (Schutz 1962; Schutz and Luckman 1973; Habermas 1984, 1987). A narrative inquiry is a story- told from individuals who have experience or are focal to the phenomenon studied. These stories go beyond the data. They tell why and how the phenomenon took place or is happening in the present. Connelly and Clandinin (2006) described narrative inquiry as a social construct where, people shape their daily lives through stories that describe who they are, and how they view themselves in the environment that surrounds them, through their stories, experiences, and perspectives. Story, in the current idiom, is a portal through which a person enters the world and a means by which they interpret their experience of the world and make meaning.

Narrative inquiry, is the study of experience within a story (Connelly \& Clandinin, 1990). Stories allow us to see how humans experience the world around them; thus the 
Critical Recognition of the Experiences of Therapeutic Behavioral Strategists in Addressing Student Trauma phenomenon becomes the story, while the inquiry becomes the narrative. In other words, TBS will share their stories describing their work with traumatized students. As TBS share their stories describing their work with traumatized students, they will begin to share their experiences not only with students, but with teachers, administrators, and families as they all play vital roles for students that have experienced trauma. The stories that TBS share regarding their work with traumatized students is the phenomena, while their experiences working with students, teachers, administrators, and families become the narrative. Narrative inquiry is often used in the discipline of education as "Education and educational research is the construction and reconstruction of personal and social stories; learners, teachers, and researchers are storytellers and characters in their own and other's stories" (Connelly \& Clandinin, 1990, p. 2).

It is paramount for narrative inquiry researchers to understand the context of voice when writing a narrative- whose voices are we hearing, and whose voices are we not hearing? A silent voice also tells a story (Bakhtin, 1981). Voice has two components which are not mutually exclusive. The first is the voice as an individual accomplishment. Individuals who speak with their own voice have taken ownership of who and what they are. They are able to express a sense of self, or a true self in terms of what they claim to be. This voice is informed, influenced, and shaped by cultural factors which allows TBS to express their own experiences through a TIC lens (Sperling \& Appleman, 2011).

\section{$\underline{\text { Positionality }}$}

I am a 31-year-old Asian American male from a low-income single parent background. As a child I experienced domestic violence, exposure to family drug use, frequent meetings with police, separation from mother, fatherlessness, eviction, and homelessness. My father was 
Critical Recognition of the Experiences of Therapeutic Behavioral Strategists in Addressing Student Trauma

incarcerated and deported to the Philippines when I was 17 years old. All of these traumatic experiences happened from sixth through twelfth grade. My exposure to trauma significantly impacted my experience in school. It became difficult to focus on academics after I had witnessed my father assault my mother on numerous occasions, after being evicted from our home, after watching the police handcuff my father for drug use and physical assault, after realizing that my father was in prison knowing that I would never see him again, and after knowing that our only option to sleep at night was in a car because we exhausted all of our options with family and friends. Focusing on my academics was the last thing on my mind. My thoughts would always rewind back to all the traumatic events that I had been exposed to, which prevented me from concentrating in the classroom. Feeling of sadness, anxiety, fear, defeat, and anger were negatively affecting my behavior. I was always inflicting the anger I was feeling towards other people in school and at home. I would lash out at my family, classmates, and teachers. Whenever I was considered a behavioral problem I was always sent to detention, or was asked to attend Saturday school as punishment for my behaviors in the classroom. I felt like I was always being punished when I was in school, rather than receiving support from them. Not once did a teacher ask me if I was okay, or care to ask what was the reason for my behavior. I felt that my school could have been a better support system, and help link me to resources that my family and I desperately needed at the time. I did not have any teachers, counselors, or administrators, to help support me throughout those challenging times in my life. I did not feel like I had built a strong enough relationship with any of the school staff to share how vulnerable I was during that time.

As I reflect on my experience with trauma during grade school it was clear that I needed support from my schools. I felt like they did not possess awareness in understanding what I was 
Critical Recognition of the Experiences of Therapeutic Behavioral Strategists in Addressing Student Trauma

going through even when I displayed erratic behavior in the classroom. They did not possess any

feelings of compassion or empathy of understanding what I was going through outside of school.

The staff at my school did not take the time to build a relationship with me at all. My teachers

possessed traditional practices of providing punishment for my behaviors which retraumatized

me, and embedded my trauma even further. This explains why my behaviors in the classroom

were happening frequently. I would have had a better educational experience if my school

received professional development on trauma informed care and promoted safety, resilience,

trauma awareness, and choice/empowerment. If my school was informed about trauma, I feel

like I would have been linked to resources that would have benefitted my family and I during those challenging times. My immediate needs were never addressed during grade school which made my experience transitioning into young adulthood extremely difficult as well.

As a lost and confused young adult I spent 7 years at a community college learning about mental health and how my mental health significantly impacted my life. I attended Saddleback College for my Associate's degree, California State University Fullerton for my undergraduate degree, and the University of Southern California for my master's degree in clinical social work. I have been an educator for six years and have been in classified management in education for two years in urban elementary, middle, and high schools in San Bernardino County. As a mental health professional for students in the K-12 setting, I have taught psychoeducation to high school, middle school, and elementary students. As classified management, I am a therapeutic behavioral strategist. As a therapeutic behavioral strategist I recognize student challenges that are related to trauma, and provide support for those students to become successful. My main role as a TBS facilitator is to provide psychoeducation to students, families, and staff. As a TBS facilitator I deliver services that integrate and synergize therapeutic and educational 
Critical Recognition of the Experiences of Therapeutic Behavioral Strategists in Addressing Student Trauma

interventions. I am on the student's interdisciplinary social emotional treatment team, and I collaborate on the implementation of evidence-based strategies, and teach adaptive skills to increase functioning and reduce or extinguish interfering behaviors. I am responsible for teaching social emotional learning (Anger Management, Grief \& Loss, Social Skills, SelfRegulation, and Self-Empowerment) to students, parents, and school staff. As classified management, I am responsible for making sure students are receiving social emotional learning services before students are suspended/expelled by school administration.

\section{Acknowledging Potential Bias}

The importance of positionality and its role in acknowledging potential bias may cause concern for trustworthiness in this project. Building in tools to prevent potential bias helped ensure trustworthiness throughout this study. A social identity map is a tool that will be used to help prevent potential bias and ensure trustworthiness for this project. A social identity map is a reflexivity tool for practicing explicit positionality in critical qualitative research (Jacobson \& Mustafa, 2019). When utilizing a social identity map, researchers can explicitly identify and reflect on their social identity to address the difficulty that many critical qualitative researchers experience when trying to conceptualize their social identities and positionality (Jacobson \& Mustafa, 2019). The social identity map is not meant to be used as a rigid tool but rather as a flexible starting point to guide researchers to reflect and be reflexive about their social location (Jacobson \& Mustafa, 2019). The map involves three tiers: the identification of social identities (Tier 1), how these positions impact our lives (Tier 2), and details that may be tied to the particularities of our social identity (Tier 3) (Jacobson \& Mustafa, 2019). With the use of this map as a guide, the aim is for researchers to be able to better identify and understand their social locations and how those locations may pose challenges and aspects of ease within the qualitative 
Critical Recognition of the Experiences of Therapeutic Behavioral Strategists in Addressing Student Trauma

research process (Jacobson \& Mustafa, 2019). Being explicit about our social identities allows us (as researchers) to produce reflexive research and give our readers the tools to recognize how we produced the data (Jacobson \& Mustafa, 2019). Being reflexive about our social identities, particularly in comparison to the social position of our participants, helps us better understand the power relations imbued in our research, further providing an opportunity to be reflexive about how to address this in a responsible and respectful way (Jacobson \& Mustafa, 2019).

Below is an illustration of my personal social identity map. I had on opportunity to identify my social identity (middle class, United States citizen, able, 31 years old, Filipino, heterosexual, CIS, and male). Once I was able to identify my social identity it revealed my current social location and how my social locations can pose challenges to my research project. When I look at my social location in terms of class, I have more resources to learn about trauma compared to others who may not be as fortunate as I am. Due to my middle-class status I am able to provide shelter and at times take tend to take this for granted. However, if I were to fill out this social identity map as a twelve-year-old-boy, my social location would be totally different. This social identity map has taught me to look at both sides of the coin. I want to be explicit about my social location in the past, and where my social location is now. Being explicit about my past and current social location will help readers understand how I produced my data, and where I am coming from when I explain my analysis. My view of trauma as a twelve-year-old-boy is much different compared to my view of trauma as a thirty-one-year-old man. As a thirty-one-year-old Asian male from a middle-class background I have found my self in positions where I have caught myself taking things for granted. However, when I reflect back to when I was a twelveyear-old-boy I found myself being more appreciative about things that I take for granted now. Utilizing this social identity map enabled me to become more reflexive and practice where my 
Critical Recognition of the Experiences of Therapeutic Behavioral Strategists in Addressing Student Trauma

positionality stands in my qualitative research. This social identity map has really helped me

identify and reflect on my own social identity to address the difficulty that I have been having when trying to conceptualize my personal social identity and positionality.

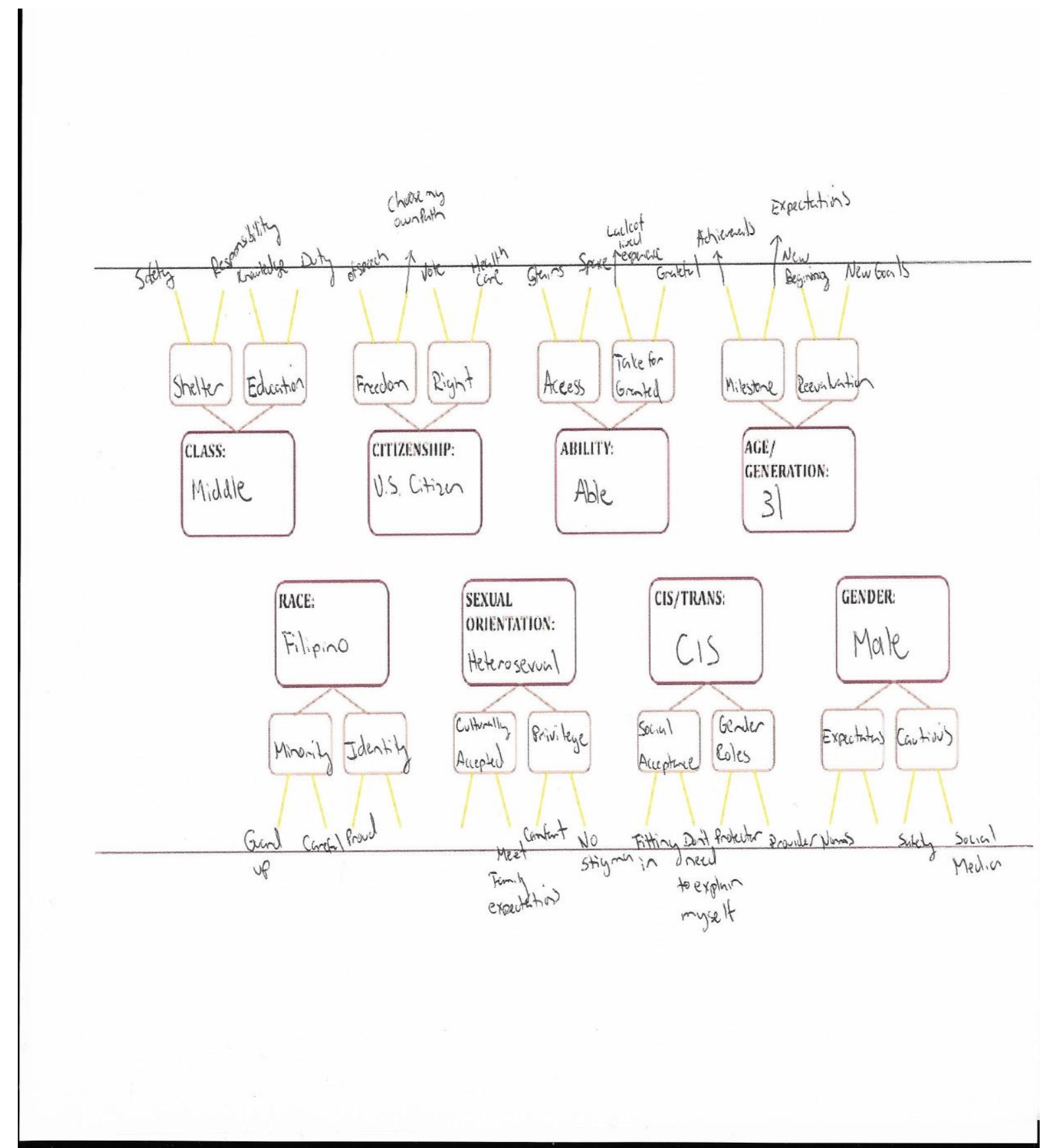

Figure: 5 
Critical Recognition of the Experiences of Therapeutic Behavioral Strategists in Addressing Student Trauma

\section{Population and Sample}

The therapeutic behavioral strategists (TBS) were recruited to participate in the study because they are mental health school district employees who work with traumatized students on a daily basis. I used purposive sampling to highlight the important experiences of the targeted population (Etikan et al., 2016). To gain access to TBS's contact information for recruitment, I retrieved their information through the Rialto unified school district website page located in the student services staff section. In the student services staff section of the directory, I obtained the TBS phone numbers, emails, and mailing address to their district office location. I obtained contact information for recruitment by communicating with TBS via telephone, email, or through recruitment letters. TBSs who were recruited were then referred to by an alphanumeric system, which identifies the participants by a combination of alphabetic and numeric characters to keep their identities private. This process is beneficial to connect information to TBS while keeping their identities private and protected.

\section{Protection of Participants}

During all interviews, audiotaping of the participants was completed with the individualized consent and approval from the participants to ensure the accurate transcriptions of their voices, to ensure the data collected and analyzed was accurate, and that there was a direct reflection of the inherent meaning. I utilized a dedicated device for voice recording of the interview. I then assigned alphanumeric codes to all the interviews to ensure protection of the participants' identities during interviews and audiotaping. When discussing the findings and reporting data, only the alphanumeric codes will be used. Alphanumeric system identifies the 
Critical Recognition of the Experiences of Therapeutic Behavioral Strategists in Addressing Student Trauma

participants by a combination of alphabetic and numeric characters. For example: Participant $1=$ P1, Participant 2= P2 and so on.

As the principal investigator, I obtained informed consent from all participants through the University of Redlands Consent to Participate in a Research Study agreement. All participants read and signed the consent to participate form prior to any interviews. Children were not enrolled as subjects in this study, as the primary focus is on the therapeutic behavioral strategist's experiences, challenges, and recommendations when working with traumatized students. The informed consent includes information regarding the purpose of the study, how data will be collected, the expected time of participation, the possible risks associated with participation, the possible benefits to participation, any compensation, the process of maintaining confidentiality, the fact that participation is voluntary, the fact that participants may leave the study at any time, and contact information for the researcher. Additionally, Consent to Participate agreements contained contact information for mental health services, which participants could utilize should interviews bring up any unresolved emotional responses related to working with students in marginalized communities. A copy of the Consent to Participate in a Research Study form has been attached. All participants are over the age of 18. All participants in the study were volunteers. Since face to face meetings cannot be conducted due to the public health crisis, informed consent will be collected via email. I chose to email the informed consent document to all participants. Once participants have received the informed consent document and agreed to participate in the study, they were asked to sign the consent form, and scan their signed documents to the principal investigator's email.

The primary investigator will destroy all the data collected. The hardcopy will be shredded and the digital data will be destroyed, which will completely eliminate all of the 
Critical Recognition of the Experiences of Therapeutic Behavioral Strategists in Addressing Student Trauma

electronic data files. Data will be destroyed after the completion of the dissertation and the

related articles are composed, or after five years, whichever is longer. In addition, all data will be destroyed using the guidelines that have been established by the university institutional policies and the state laws.

\section{The Setting}

In a time of unprecedented change and disruption due to COVID-19, I was faced with unique opportunities and challenges (Lobe, Morgan, \& Hoffman, 2020). Public health mandates and social distancing measures are restricting my ability to carry out my investigations (Lobe, Morgan, \& Hoffman, 2020). I have been forced to transition from face-to-face data collection to utilizing the google meet virtual platform (Lobe, Morgan, \& Hoffman, 2020). Some of the challenges I faced conducting interviews virtually was making sure that the privacy of participants, confidentiality of data, and data security privacy were kept safe (Lobe, Morgan, \& Hoffman, 2020). It was a challenge trying to find out what the privacy, confidentiality, and data collection policies were for various virtual platforms and services (Lobe, Morgan, \& Hoffman, 2020). Another challenge was the inconsistent internet connection. During, one of my interviews I had a difficult time understanding what my participant was saying because our internet connection was insufficient. I had to set up another interview meeting with that participant to clean up the data, and make sure I was able to understand their experiences clearly.

However, I did experience some benefits while conducting interviews virtually. Scheduling interviews was smooth. Most of my participants had been working from home, so I was able to schedule interviews back-to-back without walking to separate office spaces. I also felt that participants were more at ease knowing that interviews were being conducted from 
Critical Recognition of the Experiences of Therapeutic Behavioral Strategists in Addressing Student Trauma

home rather than conducting interviews on district campuses. Due to Covid-19, as a researcher I

felt much safer conducting interviews virtually rather than meeting with the participants face to face as the rise of corona virus cases have been increasing in San Bernardino county. Therapeutic behavioral strategist district employees were interviewed through the google meet virtual platform. Virtual interviews happened after the school day, in quiet places that were free from distractions.

\section{Instrumentation}

A dedicated device for voice recording was utilized to record the interviews. All interviews were assigned alphanumeric codes to ensure protection of the participants' identities during interviews and audiotaping. When discussing the findings and reporting data, only the alphanumeric codes were used. Alphanumeric system identified the participants by a combination of alphabetic and numeric characters. For example: Participant $1=\mathrm{P} 1$, Participant $2=\mathrm{P} 2$ and so on.

\section{Data Collection and Analysis}

Cresswell and Poth (2017) state the importance of a purposive participant sample size remaining small and manageable in order to obtain deep experiential data when conducting narrative research. Six total participants were interviewed for this project. Each participated in three, 45-minute interviews using the attached interview protocol. The resultant semi-structured, open interviews will be captured using a dedicated device for voice recording, transcribed using rev.com, then analyzed using NVivo qualitative data analysis software. The data transcriptions were uploaded into the NVivo software program which organized and categorized data into themes. To make sure I was not too distant from my analysis, I transcribed, reviewed, and hand 
Critical Recognition of the Experiences of Therapeutic Behavioral Strategists in Addressing Student Trauma

coded the data. After hand coding the data, I uploaded the data into NVivo, and compared my commonalities and themes with the NVivo commonality and themes. My commonalities and themes were similar to the NVivo commonality and themes. NVivo was helpful because I was able to store data and locate data all at a central location. NVivo also helped me manage data from the 18 interviews, and conduct data searches such as word queries, and helped display my data into themes and categories. Below is a graphic that explains which participants were interviewed, how many times each participant was interviewed, and the length of time for each interview.

\begin{tabular}{|c|c|c|c|}
\hline Participants & $\mathbf{1}^{\text {st }}$ Interview & $\mathbf{2}^{\text {nd }}$ Interview & $3^{\text {rd }}$ Interview \\
\hline P1 & 45 Minutes & 45 Minutes & 45 Minutes \\
\hline P2 & 45 Minutes & 45 Minutes & 45 Minutes \\
\hline P3 & 45 Minutes & 45 Minutes & 45 Minutes \\
\hline P4 & 45 Minutes & 45 Minutes & 45 Minutes \\
\hline P5 & 45 Minutes & 45 Minutes & 45 Minutes \\
\hline P6 & 45 Minutes & 45 Minutes & 45 Minutes \\
\hline & & & \\
\hline
\end{tabular}


Critical Recognition of the Experiences of Therapeutic Behavioral Strategists in Addressing Student Trauma

The collection of data started during the last week of November 2020. All data was collected through the Google-Meet virtual platform. The data collection protocol consisted of the following: 1. The researcher gave the criteria for participants to the superintendent: The superintendent used prior knowledge of participants and the district data system. 2. Participants were contacted by the superintendent for permission. The superintendent provided the IRB approved consent form and collected the signed forms from all six participants. 3. Participants were asked to participate by the superintendent and were given my letter of introduction and IRB participant consent form. 4. Participants who were interested were given my name and email address and were invited to contact me for more information. The superintendent worked with me to set interview dates and times with participants through the google-meet virtual platform. At each agreed upon date and time, the superintendent asked the lead agent of special education to call participants by telephone to remind them of their scheduled interviews through the google-meet virtual platform that day. I began the interview protocol and audio-recorded each of the interviews. I used member checking at the end of the final interview. All six participants approved the transcripts. I met 3 times with 6 participants, and each interview was 45 minutes in length. I recorded each interview for accuracy. I first transcribed each interview for all six participants from the audio-recording, and then I coded the data using the following steps from Creswell (2013): 1. I went line by line through each transcript and used open coding to identify words (point of view/mindset) and phrases (wearing two different lenses). 2. I then used the axial codes to create analytical themes that address the research questions within the conceptual framework. Axial codes help make meaning to the relationship between categories and concepts. 
Critical Recognition of the Experiences of Therapeutic Behavioral Strategists in Addressing Student Trauma

For example, all participants stated how educators and mental health professionals had a different approach when working with students exposed to trauma. According to participant responses educators provide punishment for problem behaviors, while mental healthprofessionals seek to understand where the behavior stems from in order to provide resources to support those students. Later in the paper you will see how these different concepts develop into one of the emerging themes. I also followed the methods of Strauss and Corbin (1990) to determine the core phenomenon: 1 . While coding I looked for causal conditions - what caused the phenomenon to occur? I looked for specific events in the narrative, particularly the phenomena of understanding TBS participant experiences when working with students that have been exposed to trauma. 2. While coding, I looked for strategies the participants used to respond to the events that occurred. 3. While coding I looked for intervening conditions - what factors contributed to the participants having that response? 4. I then looked for the consequences of those responses in terms of outcomes. 5. I then created propositions from the categories by thematically analyzing the narratives. 6. Finally, I conducted a conditional matrix (Strauss \& Corbin, 1998) where I looked at how critical consciousness, transformational learning, and paradigm shift can be used to make staff aware of the importance of the problem, the desired outcomes of the professional development and how to reach the goal of a fully embedded trauma informed care framework within the school district culture (Burns, 1978) which surrounds the conditions that will help improve the core phenomenon (traumatized students). I then uploaded the data into the NVivo computer software program. The computer program allowed me to store data, organize and review the data, code data, analyze data (Creswell, 2013)

\section{Summary}


Critical Recognition of the Experiences of Therapeutic Behavioral Strategists in Addressing Student Trauma

The narrative inquiry methodology gave voice to six TBS mental health professionals as they told their stories about their experiences working with their students in school, in addressing the impact of trauma to students who are in the primary and secondary level of public education. These six participants were each interviewed three times over the course of one month through the google-meet virtual platform. Using the questions from the data protocol, I transcribed 12 transcripts and both hand-coded each transcript and used the computer software program, NVivo, to code the data into themes and categories. The confidentiality of all participants was significant throughout this study. No identifying data was stored with transcripts and every effort was made to ensure the anonymity of the participants as they participated in this study. All six participants were given the opportunity to review the transcripts and ask or answer follow-up questions, in addition to adding or deleting parts of the transcript so that it accurately represented what they were trying to say. The participants were given the debrief letter, with my name and contact information, after all interviews were concluded. 
Critical Recognition of the Experiences of Therapeutic Behavioral Strategists in Addressing Student Trauma

\section{Chapter 4: Findings}

\section{Purpose}

As mentioned above, children exposed to trauma encounter a plethora of challenges which could include learning deficits, emotional regulation problems, and inter-personal issues with teachers, other staff, and peers. The goal of this project is to talk to therapeutic behavioral strategists (TBS) about their experiences and best practices, and how those map onto existing practices of trauma-informed care. Once themes are identified, they will affirm or oppose the theories of trauma-informed care and the best professional practices in responding to traumatized students. Critically recognizing therapeutic behavioral strategist voices will shed light on how to appropriately work with students experiencing trauma and examine the necessary recommendations needed to best support traumatized students in a school setting. The intention was to assemble suggestions that could also be scaled to other, similar communities in an attempt to work toward a more just and equitable educational system for children that have been exposed to trauma.

\section{Participants}

The participants were all mental health professionals working in the same school district. Six therapeutic behavioral strategists (TBS) made up the representative sample of TBS participants. The TBS' were recruited in the spirit of Cresswell and Poth's (2017) notion of purposive sampling specifically because they are individuals that work with traumatized students every day in their line of work. All participants worked in the elementary, middle, and high school levels. Two of the participants came to the school district as former professionals in probation with minor youth. One participant was working at the child and welfare department for 
Critical Recognition of the Experiences of Therapeutic Behavioral Strategists in Addressing Student Trauma

the district before taking the position as a TBS. Another participant was working in a school district in the high desert as a campus director of safety before taking their position as a TBS.

The other participant was working for SELPA in the high desert before their current position as a TBS. The last participant was working for a community based mental health organization before taking their current position as a TBS.

\section{P1}

This participant had been working in the juvenile probation department for sixteen years before their current role as a therapeutic behavioral strategist. In their role as a juvenile probation officer the participant experienced many opportunities working with minors that had experienced various forms of trauma. P1 also mentioned developing empathy and compassion for students experiencing trauma, because they had been exposed to trauma themselves growing up in south central Los Angeles.

\section{$\mathbf{P 2}$}

This participant had been working in the school district's child and welfare office for 15 years before their current role as a therapeutic behavioral strategist. In their role as a child and welfare office worker, the participant experienced many opportunities to witness unique circumstances from students and their families where they had experienced trauma. P2 also mentioned developing awareness and possessing the ability to reflect on situations for students experiencing trauma because of the difficult challenges they faced in their own life.

\section{P3}


Critical Recognition of the Experiences of Therapeutic Behavioral Strategists in Addressing Student Trauma

P3 previously worked in community-based mental health where push in services were provided to students through prevention and early intervention programs for five years. In this role as a community-based mental health provider they have worked with many students that have been exposed to different forms of trauma. Many of the students that they worked with deal with parent divorce, parental drug abuse, or any kind of abuse that can caused students to have issues concerning their mental health. P3 was able to develop awareness of trauma based on their professional and life experiences overtime.

\section{P4}

$\mathrm{P} 4$ previously worked for an alternative program through probation in the juvenile hall department for ten years. During their previous role as a juvenile probation worker they would work to make sure kids were maintaining their goals in order to get released from probation early. P4 has worked with a plethora of children that have been exposed to various forms of trauma. Through their line of work P4 was able to develop empathy for students and developed trauma awareness in their previous positions as they worked in juvenile probation for several years.

\section{P5}

Before working for Rialto unified school district as a therapeutic behavioral strategist, this participant worked for a school district in the high desert as a school safety coordinator, responsible for making sure students were provided with safety throughout all campuses of the district. P5 had the opportunity to work with many students that exhibited concerning behavior stemming from different forms of trauma. P5 worked with a high population of at-risk students that were expelled from previous schools and overly suspended. Based on their work experience 
Critical Recognition of the Experiences of Therapeutic Behavioral Strategists in Addressing Student Trauma

P5 was able to develop empathy, compassion, and awareness of trauma through their professional experience for ten years.

\section{P6}

P6 had been working in the mental health realm for about 9 years. P6 worked for a school district through an organization called SELPA. P6 served the Apple Valley and high desert region working at two different school districts delivering preventative and early preventative intervention services. Working in the mental health realm for nine years, P6 had many opportunities working with children that have experienced trauma in their lives. Through their professional experience in mental health, P6 was able to gain empathy and compassion while also developing trauma awareness for students facing adverse childhood experiences.

\section{Narratives}

\section{P1}

P1 was the first to respond to my recruitment efforts. This individual was very supportive and enthusiastic to participate in this project right from the beginning of the process, as demonstrated by their quick response to all emails concerning the interview appointment. Upon arrival for our first meeting, there was a very kind and obliging impression present in the virtual Google-Meet platform. As the interview began, statements like "I am willing to do anything to help students" and "hopefully, your project can make positive changes to help students I work with" demonstrated that there was a sense of passion and commitment on the part of this therapeutic behavioral strategist (TBS). P1 explained that while they have been working in the realm of mental health for a long time, their confidence working in a school setting was different 
Critical Recognition of the Experiences of Therapeutic Behavioral Strategists in Addressing Student Trauma

due to "the different barriers" as they put it. P1 also stated that their early experience working with students experiencing trauma within the school district was a struggle. They mentioned that there is a clear distinction between the way mental health providers view students, and how educators view students, specifically for those students who have experienced trauma. As the interview proceeded, this person began to warm up and spoke of their experience with traumatized students.

The value of this person's response in our conversation was in their insight as to what was transformative to their beliefs, and their subsequent practices regarding how to appropriately work with students experiencing trauma. They plainly stated that many teachers and administrative staff have difficulty working with students displaying behaviors due to trauma that students experience outside of school. Below, I will lay out the specifics of what all participants provided in the way of themes through various figures. This first participant was a heavy contributor to every theme that was developed in creating these. Their most profound impact on this work overall was in their statements that helped build the theme of developing rapport/relationships with students. Creating a relationship and building rapport with students was very helpful when identifying students with trauma. A powerful example of this came in the statement: "You look at things differently when you work in mental health. When you work with kids in a juvenile hall setting, those kids do not get to go home. Since those kids are not able to go home, I had the privilege of observing and trying to build a relationship with these kids, and you start to notice different cues that help me dig deeper to investigate whether these kids have suffered through trauma in some point in their lives. If I have a student who may not be verbally aggressive, or may not be participating in class and seems to be a little stand offish that is when I notice that there may be something going on with this particular student which lets me know that 
Critical Recognition of the Experiences of Therapeutic Behavioral Strategists in Addressing Student Trauma

I may need to do further investigation to really understand what this student may have been going through. But you can only get valuable information from the student if you build a relationship with the student. Kids have to be able to trust you, and if they do not trust you, they are not likely to open up to you in any kind of way."

Throughout the conversation with this TBS participant, this concept of building relationships and creating rapport was heavily emphasized in our conversation. P1 stated how valuable building relationships can be when working with kids in the primary, middle school, and highs school levels. "Once you build relationships with these students, naturally you will become invested to helping these children. When you observe these students you will notice their big reactions to small things. I'll see plenty of students who have quick reactions when they feel like they are being threatened. They go from zero to one hundred miles per hour over the door slamming or someone looking at them wrong because they do not understand how to process that."

P1 provided another example: "We have the students who are aggressive, and if they get bumped into accidentally by their peers they instantly try to start fights with them. It feels like these students have some sort of stress response system. So when students display big reactions to small things that is an indicator of how to identify students with trauma." This participant was then able to discuss their role as a therapeutic behavioral strategist and what their job description entails when working in a school setting. "Because this position is so new, and because we are a very new program we get confused with social worker/emotional health therapist on campus, but we are a totally different program. As a therapeutic behavioral strategist we play a very unique role because we kind of fill in the gap with what is missing in the school, specifically in the area of social emotional learning. There is a huge disconnect between behavior and how schools 
Critical Recognition of the Experiences of Therapeutic Behavioral Strategists in Addressing Student Trauma

govern the discipline at their school site. When I work with students' I want to make sure students receive the right supports they need so that they can be successful. I wear a lot of different hats. I make sure students are triaged to appropriate services. When students are triaged into the service which I provide I teach students skills in a group or even a one on one setting based on the student need. I teach life skills that may not have been taught at home to their circumstance at home. I teach students how to ask for help appropriately, how to start a conversation, how to make friends, how to give compliments, how to deal with losing games. These are some examples of skills that I am teaching students every day."

As this participant explained their work in the school setting, the mention of building relationships was highlighted once again. "A big part of our role as TBS is to really connect and build relationships with our students. When I work with these kids in a group or one on one setting I form strong relationships, especially with students who might have had early neglect or abuse, and so you might be seeing the reactive attachment, and there's a lot of highs and lows and push and pull." This participant then went on to explain how "poverty' seemed to be a trend that they noticed from students experiencing trauma. "I think some of the experienced trauma might be due to students' socioeconomic backgrounds. If kids live in a bad or rough neighborhood where there's a lot of violence. I mean, kids experience trauma by seeing things, guns going off, police all the time, just not feeling safe. I don't think that matters, necessarily, if you're white, black, Hispanic. If you live in a rough environment you are more likely to experience trauma."

TBS participant one then went on to discuss recommendations when addressing students experiencing trauma appropriately. "Well there is a huge disconnect between my TBS staff and professional educators. Because of the work experience of TBS we have worked in environments 
Critical Recognition of the Experiences of Therapeutic Behavioral Strategists in Addressing Student Trauma

where children experiencing trauma was always the norm so we view their behaviors differently compared to a school teacher. There needs to be some kind of universal approach where teachers and administrative staff can receive training on trauma informed care or even a training on implicit bias. In the field of mental health, when you are able to look at things through a trauma informed care lens you address behaviors differently because you become more aware of the circumstances that a student may be going through which is causing them to act a certain way. You won't be able to pick out random students who experience trauma, there isn't a flashing sign above their head that says they are experiencing trauma. But recognizing that a universal approach where school staff are trauma informed would be beneficial for all students, particularly beneficial for kids who've experienced trauma."

\section{P2}

P2 was interviewed directly after the first participant on the same day, through the google meet virtual platform. Similar to the first participant, this participant was very excited and eager to help with this project. This person has been working for the Rialto Unified School District for fifteen years and possessed great confidence with their new role as a therapeutic behavioral strategist. Early in the conversation, this TBS stated "I have been working in the child welfare department since 2005, and my previous department was considered the hub of student services. I have had the opportunity to witness very unique circumstances from students and their families. Many of the students and families that I came into contact with have had exposure to trauma. Working in the district for so long I was able to notice how much trauma negatively impacted the students' experience in school." 
Critical Recognition of the Experiences of Therapeutic Behavioral Strategists in Addressing Student Trauma

P2 then went on to explain their role as a therapeutic behavioral strategist, stating: As a therapeutic behavioral strategist we may get referrals from teacher, principals, school counselors, and so on. Once I receive that referral that is when I get involved and do my research on the student. I check to see the demographic of the students, their grades, their report cards, and all the information I can gather so that I am make sure to triage the student to the most appropriate service. Once I am able to gather all my information, and understand that a particular student will benefit from my service, it is most important for me to make sure I build a relationship with the student. Building a relationship is the most important thing you can do before providing any kind of support or service. Before someone can be comfortable with you they have to be able to feel like they can trust you. When you are able to build a foundation of trust with students, they will be more open to working with you because those students feel like you have their best interests. Once I am able to build that trust with a student I either work with them in a group or individual setting where I teach social emotional learning skills. While I am working with these students' I am also always in constant communication with the students teachers and their families, and I communicate with them to make sure we are all on the same page, and provide them with updates on the kinds of skills we work on every time I meet with their child.

This participant then went on to discuss the types of challenges they come across for students who may be experiencing trauma. "Building relationships is crucial and if teachers or admin do not take the time to establish any kind of relationship with students it can be difficult to identify whether students are experiencing trauma or not. When you build relationships with students you become more invested into their success. When you become more invested you are more likely to observe students and understand where behaviors stem from, understanding why some students have difficulty maintaining relationships with their peers, or even why some 
Critical Recognition of the Experiences of Therapeutic Behavioral Strategists in Addressing Student Trauma

students appear to be very guarded. Some of those social cues can give you ideas to whether a student may be experiencing trauma outside of school, but trauma can be difficult to identify if relationships are not built with students. When you start to observe a student you may recognize that the student may have relationship difficulties with peers. One of the things I noticed are the lack of social skills students don't have because of the exposure to trauma. The lack of social skills can become barriers that negatively impacts a child's ability to build relationships and friendships, which often leads to a lack of connection with peers. A lot of the times I will see students who are going through a difficult time, and make an attempt to reach out to someone to try and be a friend, but unconsciously they do it in a way that comes off disrespectful, so their peers or even teachers may view that behavior differently. But they want to make friends, and they're trying, they just don't know how to do it because of certain challenges that have impacted their life. Maybe they never had a chance to learned how to approach people appropriately. Most of the time those kids want to make friends, but it doesn't go very well. This is why our role as TBS is important because we are able to help teach them those skills to become successful. One of the other things that I find difficult is providing consistency for the student both at home and at school. A lot of the times families can be very busy, and we all try our best to communicate with families on the types of skills we are working on at the moment. So if there is a lack of communication between home and school it can be difficult because of the inconsistencies that may arise."

This participant then explains some of the trauma trends that they notice with students experiencing trauma "I do notice that when there is no consistency in a child's life they tend to be more quiet, and they keep to themselves because those students are trying to internalize what is going to happen before it even happens. For example, I work with a lot of foster youth and 
Critical Recognition of the Experiences of Therapeutic Behavioral Strategists in Addressing Student Trauma

they have to be separated from their families, they are always moving to different places, switching schools all the time, and all those things can be very difficult for them to process because there is just no stability in their lives. A lot of the times these students fall through the cracks because they are not necessarily a behavioral issue, but they are experiencing enormous amounts of trauma. A lot of the times students are only recognized by school staff when they are a behavioral issue, but a lot of the times the quiet ones are going through a lot of trauma as well, and it is terrible that that those are the kids that fall through the cracks sometimes."

This participant then went on to explain some of the recommendations that they would provide to school sites to help better serve traumatized students appropriately "Teachers wear many different hats, but their primary focus is academics. I think that teachers need more support from their staff. There should be more connections between counselors, TBS workers, and teachers. We need to help bridge the gap for those teachers because they see the students for a majority of the time. We need to teach schools how to possess more awareness when it comes to trauma. When things are looked through a trauma-informed care lens its almost like there is a change of point of view. So if we could provide some kind of training where everyone is more informed about trauma, and the impact it can have on students I think that would be very helpful moving forward." This statement really emphasized the need for school staff to become more educated on trauma-informed care approaches.

\section{P3}

P3 had a great sense of confidence in terms their role as a mental health professional in the school district, professional presence, and quality of thoughtful responses to the inquiry that I presented. This participant helped to build all themes discussed later in this work through their 
Critical Recognition of the Experiences of Therapeutic Behavioral Strategists in Addressing Student Trauma

very thorough responses. This participant then went on to explain some of their professional experiences before working for Rialto unified school district: I worked in community based mental health where we provided push in services to where we serviced kids through prevention and early intervention. In this work we have worked with many students that have been exposed to different forms of trauma. Many of the students that I have worked with deal with parent divorce, parental drug abuse, or any kind of abuse that can cause them to have issues that concern their mental health. Trauma plays a big role in the school environment. From my perspective, a lot of times teachers teach from an authoritative perspective, and when kids have been traumatized it can be very difficult for students to receive information that way because they are already on edge. Students that have experienced trauma may feel like the world is against them because of some of the things that they have experienced, but unfortunately sometimes our school system is just set up for our kids to sit and learn, and just do as they are told and it doesn't really foster an environment for students to explore their feelings or even explore who they are as a person.

This participant then went on to discuss their role as a therapeutic behavioral strategist for Rialto unified school district: I go into the schools and provide social emotional wellness groups. I have 3 different schools that I am assigned to, and typically I conduct 5 social emotional learning groups per day. Walking into school sites there lots of pressure on us because we are seen as the front line of defense when it comes to student behaviors that have issues with discipline. Through my groups I teach various skills where we discuss topics like anger management, social skills, grief and loss, and self-empowerment. After all of my groups and one on one meetings are complete I make sure that all of my paperwork is well documented. 
Critical Recognition of the Experiences of Therapeutic Behavioral Strategists in Addressing Student Trauma

This participant then explained some of the difficulties they possess working as a

therapeutic behavioral strategist: I would say that the educational field and mental health are like co-parents that do not get along. I paint that picture because some educators see things very black and white where mental health professionals are able to really look at the whole child. Often times educators, they just do not see it. From my perspective some teachers have an agenda, they are taught to come into work follow the lesson plan, and its very rigid. But in mental health we are able to pick up on social cues. We are able to understand why a student always has his hoodie on or why is this student not showing eye contact, and I think that we are programed to read a persons verbal and non-verbal communication cues. I think that educators really need to understand the whole child because this is a significant problem that I see. If you have a student that is always chatty, and then all of a sudden that student is quiet, that is a red flag. Or if you have a student that is quiet and then all of a sudden they are chatty that can be a red flag. As a mental health professional we look out for those types of signals. Where teachers may just be trying to get through their lesson plan, and miss out on opportunities to recognize that this student may be exposed to trauma outside of school, and it's unfortunate because the system is set up that way. It doesn't really give teachers room to explore what students are actually going through. On top of that those teachers may have like thirty plus kids that they are working with, where we as TBS are able to recognize that one kid that may feel like they are out of place or we see that there may be different issues that are going on with them. But because teachers plates are so full they have no choice but to solely focus on the academic piece. So this is a systematic problem that doesn't really allow teacher to see the needs of all students.

The participant then explained some of the barriers they notice when working with students that have been expose to trauma: I feel like in most organizations there is this invisible 
Critical Recognition of the Experiences of Therapeutic Behavioral Strategists in Addressing Student Trauma

hierarchy or like this invisible red tape, and that is a huge barrier that I think hurts students. I

have been doing this line of work for a very long time and I know how to work with students appropriately but there is a game of politics that you have to play before you can actually help a child. There are things that I can do in the immediate moment that can really benefit a student, but because of laws, or funding, or different politics I am not able to best serve the child because of the limitations that we have working in a school setting. As a mental health professional you have the passion, you have the heart, you have the right intensions but you can get in trouble if you do things outside of traditional practices.

After discussing the barriers as a TBS professional, this participant then went on to explain recommendations they would provide to best serve students experiencing trauma. "I think that the entire school district would need to change their mindset and approach when working with students. I do not think that educators are educated on trauma and the significant impact that it can have on students. In the field of mental health we are taught to look at things through a trauma informed care lens. In Leyman's terms trauma-informed care means to treat people the way you would want to be treated. School need to have humility and recognize that everyone is human. School need to build awareness and self-reflect on biases they may have. They need to become more conscious of what their students are going through so that they can approach their students in a way that is more open so that they can meet the need of students. In order to make changes happen I would create a proposal to pitch to the superintendent because this kind of approach has to come from the top down. I would do a soft rollout of training for all staff for about six months to a year to really educate them on trauma. I would really focus on the staff first because we really need to help them and meet their needs first. We need to develop a culture where the entire school is on board with utilizing this trauma informed care approach. 
Critical Recognition of the Experiences of Therapeutic Behavioral Strategists in Addressing Student Trauma

When we teach staff to treat ourselves with kindness, and teach staff to treat their peers with

kindness it will be culture that permeates the entire district, and that is the kind of approach that we need to have as an entire district. And once we establish this culture within the staff, it will be comfortable to begin to roll this approach onto our students because it should be an approach that comes naturally. The head of the district would have to buy in to this trauma informed care approach so that all staff can buy-in. It starts at the top. So the first year would be training staff regarding universal trauma informed care approaches. After that first year is completed and we start to utilize trauma informed care practices naturally, then we will be able to roll this approach out to our students. That is how I would start things up to help students that are suffering from trauma." This statement really emphasizes the importance of educating school staff on trauma informed care practices, and utilizing those practices amongst themselves before rolling trauma informed care approaches onto students.

\section{P4}

The next TBS participant was gracious and expressed their gratitude to participate in this project stating "I'm so appreciative you are taking the time to hear our voices." Upon arrival for our first virtual meeting, there was a very kind and warm presence that was displayed from this participant. As the interview began, statements like "Thank you for hearing our voices" and "hopefully our TBS insight through your project can make positive changes to help students that have suffered through trauma" demonstrated that there was a sense of humility on the part of this therapeutic behavioral strategist (TBS). This participant was also a significant contributor to every theme that was developed. As the conversation went on the participant began to discuss their experience working with children who have suffered through trauma "I have been working with children since 2010, where I was working in probation generally with kids who were 
Critical Recognition of the Experiences of Therapeutic Behavioral Strategists in Addressing Student Trauma

considered to be at risk. In that job I was really able to help these kids from a therapeutic position. I worked in alternative program through probation, so when kids were released from probation/juvenile halls they would come into our center to actually work on their program in hopes to have an early release. Through my program once they completed counseling, they would get a certificate that stated they completed therapy. The whole purpose of the program I was working at was to have different phases of therapy where the kids were involved with different clinicians, have family therapy with family members so that they could create a cohesive environment when they come back home. I also worked in the department of children of family services where I was a program manager of a transitional shelter program. Children would come into my program for 72 hours before being placed in a home or residential program. When children were being pulled away from their home, my role was to give them a safe place to come too while there is constant engagement with staff $24 / 7$ so that the kids can have a roof over their head. When I was working in that position I would hear so many storied where children ages 6-18 years old would be exposed to so many different forms of trauma. Young girls were being sex trafficked at a very young age, many of their parents were incarcerated, a lot of the kids were suffered through a lot of trauma and would make a lot of poor decisions because of their circumstances." This statement really displayed the depth of experience the participant had working with children that have suffered through trauma.

After the participant explained their previous work experience the participant then discussed what their new role as a therapeutic behavioral strategist entailed "The most important thing in my new position as a therapeutic behavioral strategist is building relationships with these students. These students are looking for someone to look up too. Many of these students have been exposed to trauma, and all of the kids come to school to be loved. When you build a 
Critical Recognition of the Experiences of Therapeutic Behavioral Strategists in Addressing Student Trauma

trusting relationship with students it's amazing to feel how much your presence is felt just by being there with them. When I am attuned and deeply listening to these students stories I feel for them because many of the traumatic experiences they are going through I can relate to. There is a sense of empathy that you feel for other people, especially if you have gone through similar situations yourself. The fact that I am able to help students who are going through the same challenges I was gong through is just a blessing, because I know I can help these kids. There has to be some kind of empathy and compassion so that these kids can receive that beacon of hope. When I work with kids, once I build a relationship I hope to have relationships with these kids even when they become adults. My goal is to try my best to make sure these kids can be successful despite their circumstance. So I would say the most important part of this job is creating relationships." This statement shows the importance of relationship building, especially for students experiencing trauma. With all the policies and procedures that job duties entail, this participant really highlighted the importance of forming relationships with students.

After the participant explained their job duties as a therapeutic behavioral strategist, the participant went on to discuss some of the challenges they encounter "It can be really difficult to explain the impact of trauma to some teachers because I feel like we are wearing 2 different lenses. When I meet with a student and I'm getting to know their story, I want to know if they have experienced any kind of trauma that might explain why, for instance, a fifteen-year-old is doing some things that's more typical of a five year- old. Maybe something happened to that student and because their brain development was disrupted, they were not able to learned coping skills to help navigate through a difficult time. It can be frustrating because a lot of educators do not see it that way. They only see the behavior that is in front of them, and do not realize the true impact that trauma has had in their life. Rather than punishing students for their behaviors we 
Critical Recognition of the Experiences of Therapeutic Behavioral Strategists in Addressing Student Trauma

need to provide help for these kids that are going through a difficult time. It is also frustrating because some educators do not create opportunities to build relationships with students. From what I see, there are so many instances where teachers lose trust from their students within seconds. For example, kids do not like to be put on blast in front of their peers. When teachers remind students of a bad experience there are facing at home, they can lose trust in who you are as a person. If a student is suffering through trauma at home, and a teacher sparks that traumatic experience again in a school environment, that student has lost all trust in you. We have to change the culture within our schools otherwise there is always going to be this underlying problem." This statement really magnifies the difference in perception between mental health professionals and educators, especially when discussing student trauma.

Soon after the participant described the challenges in their position, they went on to discuss the recommendations needed to better serve students experiencing trauma. "The first recommendation I would make is to implement a mandatory implicit and explicit bias training with all staff. Not just teachers, but the entire staff. This will really help individuals reflect and become more aware about themselves. Many people do not take the time to understand themselves, and they think that whatever they have been doing for so many years has always been right. They really need to take a step back to reflect and be more aware of themselves. Individuals need to understand how to look at things from a different perspective, and the only way they can do that is if all staff critically reflect on themselves and become more aware of their own personal biases. Once people are able to reflect on themselves maybe they can reflect and become more aware on what other people may be going through because of the challenges that they have gone through in life. So the very first recommendation I would make is to implement a mandatory implicit and explicit bias training. The next thing I would do is conduct a 
Critical Recognition of the Experiences of Therapeutic Behavioral Strategists in Addressing Student Trauma

training on ACES scores. Understanding ACES scores is another layer of trauma that even as adults we didn't know that were are part of the ACES situation. Even as adults, our ACES scores could have been through the roof and we would have never even known. Once we understand ACES scores I would then make sure to have quarterly synergies with all schools to check in to see if we are truly implementing practices that are more trauma informed. We would need to make these synergies mandatory so that we can make sure all schools are promoting practices that are geared more towards students that have suffered through trauma. If we are able to accomplish those three things, we have now created a nice layer that is very difficult to penetrate. It does not matter what school you go to, no matter what teacher you talk to, no matter what administrator you talk to they are all implementing practices that are more trauma informed." This statement emphasizes the importance of a paradigm shift from traditional practices to a more trauma centered approached to really help students experiencing trauma.

\section{P5}

The fifth TBS participant was delighted and willing to participate in this study stating "I'm thrilled to help out with this project." Upon arrival for our first virtual meeting, there was a very warm presence that was displayed from this participant. As the interview began, statements like "I'm glad to help anyway I can" and "hopefully our experiences and point of view through your project can really help our students" demonstrated that there was a sense of passion on the part of this therapeutic behavioral strategist (TBS). This participant was also a significant contributor to every theme that was developed. As the conversation went on the participant began to discuss their experience working with children stating: Before working for Rialto unified, I worked for a school district in the high desert where I worked with elementary, middle, and charter high schools. I was the school safety coordinator, so I was in charge of making sure I 
Critical Recognition of the Experiences of Therapeutic Behavioral Strategists in Addressing Student Trauma

was providing safety for all school campuses. I worked with teachers custodians, and I supervised all the proctors and kitchen staff. That position actually molded more into the shape of discipline. I always ended up being the person who had to interview students that were having disciplinary and behavioral issues. My heart would always tell me how can I help these children not exhibit these behaviors, or help me understand what is driving these kinds of behaviors, and how I can support this student and their teachers so that I can help them be more successful. I had the opportunity to work with a lot of students that had behavioral concerns that stemmed from different forms of trauma. We had a high population of at-risk students. Students that were expelled from previous schools, those that had been overly suspended, were students that I would mostly serve. In time I ended becoming the campus director, in the role of campus director I ended up doing a lot of intervening with students that were more inclined to being suspended. Typically the school was enforcing a zero tolerance policy, but we have to do something different because there is a reason why students may be acting a certain way. I never thought that a zero-tolerance policy worked because if we just let them go, how are we really benefitting the student. Obviously they have been cut loose already so what can we do to make things different. So I really helped develop a system where we could counsel and work with these students in a way that hopefully can help them flip the script. This statement shows the vast experience this participant has when working with students experiencing trauma. The statement also explains that in order to make positive changes, different alternatives need to occur in order to get different outcomes.

Once the fifth TBS participant was able to explain their previous work experience, they went on to explain their current role as a therapeutic behavioral strategist "As a TBS it is a lot of interface work with our students, teachers, family members, and school administrators. Our main 
Critical Recognition of the Experiences of Therapeutic Behavioral Strategists in Addressing Student Trauma

focus is to teach students skills that will enable them to have the kinds of behaviors that are appropriate not only for them in school, but skills that they can also use for the rest of their lives. We are teaching them how to cope in situations that can be challenging, and we give students examples of how they can utilize skills in very difficult situations." This statement really highlights the importance of collaboration that needs to be maintained for the students' success, and also captures the importance of teaching skills not just in school, but for everyday life.

After the fifth TBS participant discussed their role as TBS, they then went on to explain the kinds of challenges endured throughout their work "The difficulty is the mindset that some of the adults have in the school setting. Most of the time adults are so focused on solely academics, and making sure that the lesson planned is being followed. A lot of the times those adults also have such a demanding caseload that it can be overwhelming to handle for them. So if a handful of children in their class of 30 students is going through a difficult time outside of school, that can be difficult for an educator to attend to the students needs at the moment because they have a lot of other things on their plate. There are some teachers that try to attend to all of their students in the best way that they can, but overall they are just inundated with the task of achieving a specific goal in terms of how many students they have to grade, or are progressing at a certain level in order to recognize if they are a sufficient teacher." This statement highlights that some teachers are not able to attend to all student needs, and some teacher must shift some of their focus to addressing the child's needs rather then solely focusing on academics, especially if a student is suffering from trauma outside of school.

After the participant explained their difficulties as TBS, they then went on to explain the recommendations they would provide in order to appropriately work with traumatized students "The first recommendation I would provide is to make it mandatory for every staff person to be 
Critical Recognition of the Experiences of Therapeutic Behavioral Strategists in Addressing Student Trauma

trained on trauma informed care. Every staff member whether its nutrition services, office staff, teacher aides or custodians. All staff will receive this training. The purpose of training in trauma in formed care training is to reflect outside of your own perspectives/biases and try to focus more on the lens of what a student and their family may be going through. The second recommendation I would make would be to provide an assessment to make sure that the training was beneficial, and that they actually learned something new. The third recommendation I would ask if any kinds of procedures need to change, is the current procedure we are practicing most appropriate for students to become successful. Step four would be to make sure that we implement what we have learning in our trauma informed training, and use these practices on the school campuses. The hope is to make these trauma-informed care practices the new culture of what every school needs to look like. There may be some difficult conversations when these trainings are provided, but we need to have these tough conversations so that we could do better, and provide the best practices for students to become successful." This powerful statement really captures the importance of shifting the mindsets of all school campuses, and practice a philosophy that is centered toward trauma informed care practices so that we can work with traumatized students appropriately.

\section{P6}

The sixth TBS participant was energetic and willing to participate in this study stating "I'm excited to be a part of this project: Upon arrival for our first virtual meeting, there was a very spirited and vigorous presence that was displayed from this participant. As the interview began, statements like "I've been looking forward to having this interview" and "It is a pleasure to be able to help share my experiences and point of view through your project. I know projects like these are designed to really help students, so I'm glad to be a part of this process" 
Critical Recognition of the Experiences of Therapeutic Behavioral Strategists in Addressing Student Trauma

demonstrated that there was a sense of passion on the part of this therapeutic behavioral strategist

(TBS). This participant was also a significant contributor to every theme that was developed. As

the conversation went on the participant began to discuss their experience working with children stating: I have been working in the mental health realm for about 9 years now. I worked for a school district and the organization was called SELPA. I served the Apple Valley and high desert region. During that time I worked at two different school districts and delivered preventative or early preventative intervention programs. In that work I conducted a lot of groups, classroom presentations, and discussed topics like bullying, and working with these kids hands on so that we could improve their behavioral skill sets so that they could be successful. I also worked for an agency where I worked as a TBS worker providing in home services. I provided behavioral supports to children and families. I also worked at an intensive unit, and also worked in schoolbased programs where I did the same kinds of things, but specialized in their own way especially when behaviors were considered to be more intensive. I would provide in home services about three to four hours a day providing non-stop interventions to help the families. Prior to that I also worked at a juvenile placement center where I worked as a social worker and eventually become a director of that agency where I oversaw 36 bed units of kids that were on probation. I was in charge of overseeing all the daily operations of that unit, which consisted of their behavioral needs, clothing needs, school components, their mental health, and even their family integration plan. That was a brief overview of the last fifteen years of my work experience." This statement explains depth of experience this participant has had working in mental health, particularly with children that have been exposed to trauma.

After the participants work experience was explained, they then discussed their current role as a therapeutic behavioral strategist in the school district stating "Through our work as 
Critical Recognition of the Experiences of Therapeutic Behavioral Strategists in Addressing Student Trauma

therapeutic behavioral strategists we really focus on identifying certain students who are

struggling with certain skill sets and being able to provide them with behavioral modifications so that they have higher chances of being successful. Our process really involves receiving a referral. Referrals can come from school staff, parent, and from there we follow up with those students conduct some level of assessment which we determine what level of services would be appropriate for the student. We offer a different range of services form group services, one on one services, classroom services, and so on. Our services can last from 10 weeks, some last 18 weeks, some services last until the end of the school year. Some of the group services we provide are ART groups which consists of aggression replacement training, we also provide stress reduction techniques, we provide our social emotional learning curriculum which extends all the way to the end of the school year. The SEL curriculum consists of four different modules. Selfregulation, self-esteem, social skills, and grief and loss are the four modules that make up our social emotional learning curriculum. Through a combination of providing services and working with our treatment team, we try our best to make sure we identify kids, place them in the right program, and monitor them in that process to get them into a place where they can be successful." This statement really provides insight to the type of work therapeutic behavioral strategists do on an everyday basis. This statement also gives insight to various services provided by TBS staff, and gives information on the types of behaviors that students display due to possible trauma experienced outside of school.

After this participant explained their current role as a therapeutic behavioral strategist, they then went on to explain some of the challenges they face in their TBS role stating "The problem is there is not enough training on trauma for professional educators. As great as educators are, they are programed to really limit themselves to the educational component of our 
Critical Recognition of the Experiences of Therapeutic Behavioral Strategists in Addressing Student Trauma

student achievement levels. Many of the interventions that teachers utilized are more focused towards their academics, but not necessarily addressing the behaviors that may be occurring. Not recognizing that trauma may be the biggest culprit of why the student is not succeeding, so I think in order for them to really get on board in terms of closing that gap. There is a huge distinction between the work mental health professionals provide, and the work that educators provide. At the end of the day there is this dilemma that educators may feel like addressing student behaviors may not be part of their job description. They also may be more nervous about approaching difficult behaviors because they do not feel like they have the expertise in that area, and they may be reluctant to try something different. We need to do a better job of providing educators with entry level skills where they are able to center their minds to a more trauma aware based framework. Without those kinds of changes, it will continue to be difficult to help students reach their full potential. I still believe that there are some people who do not believe in mental health. I still see a lot of adults who use mental health as an excuse. Unless the needs of a child are met both mentally and physically it will be very difficult for that child to succeed. So, the mindset for some people just has to change." This powerful statement explains the difficulties the participant faces when professional educators are not aware of the impact that trauma can have on students.

Once the participant addressed the challenges they encounter, they then went on to explain the connecting themes for students that have experienced trauma "Trauma impacts students differently. Generally speaking trauma can bring out aggression, levels of depressive symptoms, self-esteem can be impacted, bullying behavior can arise, not social connecting with their peers in school. All of those things connect hand in hand when it comes to students that experience trauma. I also think that some students do not have good communication skills as a 
Critical Recognition of the Experiences of Therapeutic Behavioral Strategists in Addressing Student Trauma

result of their trauma. They have been suppressed to some degree, so when the student has an opportunity to talk about what is going on with them, those opportunities are missed because they do not know how to seek help and they do not know how to explain what they need if they were to get someone to listen. Communication skills are broken in homes where trauma exists, so being able to rewire those things to give students confidence and empower them is important because I think that all of these things are being impacted by what they see and what they have to deal with on a day to day basis. I think more educators need to have more empathy for what some of these students go through." This statement explains the types of behaviors that are exhibited form students once they are exposed to trauma. This statement may also give insight to the type of approach that would be more appropriate for educators to utilize when serving students experiencing trauma.

After the participant explained the connecting themes they found in students experiencing trauma, they then went on to explain the recommendations needed in order to best serve those students appropriately "Possessing a trauma based approach is a framework that would definitely our school district. The more an individual is able to learn about trauma, the more you are able to provide help. Students do not display behaviors just because, there is a reason why students are displaying certain types of behaviors. Once we are able to understand the whole child, and understand what the child may be going through we start to think of that behavior differently. We have to make school aware that trauma is a real situation. Trauma is not something that is make believe, its not something that only a few students go through. I think that at some point in everybody's life they go through at least some form of trauma. So it has to start form the top. We can't just use trauma informed care practices on our students, we also have to practice trauma informed care with our staff. We all have gone through things, and it is important that we all 
Critical Recognition of the Experiences of Therapeutic Behavioral Strategists in Addressing Student Trauma

have a framework to feel comfortable to talk about those things. We should have support groups

for our faculty so that they feel supported. It would be great to have some level of support group

for our teachers and staff to be able to go to so that they can deal with their own trauma but then

also be able to more informed about dealing with behaviors appropriately at the student level.

This type of training and support needs to be ongoing and should be a topic of discussion all year long. Maybe we can tie trauma informed care practices into our PBIS framework, I think there are many different ways we can implement trauma informed care practices into our school district. Creating a universal trauma informed care framework will help provide preventatives through classroom presentations on every level, and being able to address difficult conversations. Just being able to provide kids with the power to express some of their concerns, and have that be something that can be normalized within the district so that they do not feel like they are isolated. If we do that, and continue to have those trainings, and continue to provide preventative care we can create an environment where trauma is recognized as a real thing. Even as adults, when adults get impacted by trauma, they themselves may not realize the self-defenses that they put up on a day to day basis to prevent themselves from being vulnerable. For example, if I went through trauma and I was let down, and I now am guarded, that guard is going to be seen as missed opportunities to connect with students. So these are some of the recommendations that I would make to better serve traumatized students appropriately." This statement really highlights the importance of utilizing a trauma informed care framework within the school setting. The statement also captures the benefits that staff and students could benefit from utilizing a trauma informed care framework.

All participants in this study brought their own unique perspective to the conversations that were conducted in order to better understand their experiences in addressing student trauma. 
Critical Recognition of the Experiences of Therapeutic Behavioral Strategists in Addressing Student Trauma

I have made my best attempt at capturing their stories in the above narratives. In following up with all participants to analyze the original interview transcripts, all participants were satisfied with the capturing of the conversations. My contribution to the work is in my best description of the unspoken communication and overall atmosphere of the virtual environment that we shared in discussing what they experienced. What follows is a deeper dive into the specifics of what crafted the emergent themes, followed by implications for practice. In other words, I will attempt to answer why anyone would want to read this work and what the world can gain from its efforts.

\section{Data Analysis}

\section{Process}

I used the following process to organize the data collected from the 6 participants.

1. Data organization- organizing the 6 transcripts into data files.

2. Reading and memoing- read through each of the 6 transcripts to do initial codes and make notes in the margins and memos.

3. Describing the data into codes and themes- Describe the story of each participant chronologically.

4. Classifying the data and codes into themes- Identify themes and categories in the stories.

5. Interpreting the data- Determine the meaning of data

6. Using NVivo analysis as a tool- upload data into computer software program. 
Critical Recognition of the Experiences of Therapeutic Behavioral Strategists in Addressing Student Trauma

7. Representing, visualizing the data into tables per theme describing the themes, categories, and elements of trauma informed care and TBS practices and providing evidence from the data to support critical consciousness, transformative learning theory, and paradigm shift.

8. Organize the story of each of the 6 Participants in chronology of when the interviews took place.

9. I wrote the 6 narratives to describe each of the participants and their unique experiences as a therapeutic behavioral strategist for Rialto Unified School District. Each narrative was framed in the context related to the conceptual framework.

\section{Findings}

The first two themes began surfacing instantly when the responses were paraphrased sentence by sentence, and those were the themes of empathy and compassion, specifically the importance of displaying empathy and compassion in their position. Responses such as: "The fact that I am able to help students who are going through the same challenges I was going through is just a blessing, because I know I can help these kids. These kids need that beacon of hope." highlighted compassion and empathy as a point of emphasis throughout the entire interviewing process. During this phase it was also becoming evident that TBS utilize a unique approach in their field of work.

The next themes that emerged were the significance of reflection and awareness. Responses such as "Communication skills are broken in homes where trauma exists, so being able to rewire those things to give students confidence and empower them is important because I 
Critical Recognition of the Experiences of Therapeutic Behavioral Strategists in Addressing Student Trauma

think that all of these things are being impacted by what they see and what they have to deal with on a day-to-day basis captured the importance of utilizing reflection and awareness as a TBS.

The themes that stood out immediately were the themes of relationships and trustspecifically the significance of building relationships and trust in the role of therapeutic behavioral strategists. Responses such as: "The most important thing in my new position as a therapeutic behavioral strategist is building relationships with these students. These students are looking for someone to look up too. Many of these students have been exposed to trauma, and all of the kids come to school to be loved. When you build a trusting relationship with students it's amazing to feel how much your presence is felt just by being there with them, suggested that building relationships and trust with students is a key component when working with students experiencing trauma.

During this phase, it was also becoming evident that there was significant difference in the way therapeutic behavioral strategists viewed student behaviors related to trauma compared to educators. This helped to solidify my decision to name this theme "Point of View/Mindset." Responses such as: "I would say that the educational field and mental health are like co-parents that do not get along. Totally different mindset. I paint that picture because some educators see things very black and white where mental health professionals are able to really look at the whole child highlight "mindset" as a point of emphasis throughout the entire interviewing process.

The underlying knowledge of the literature base of trauma-informed care provided important foundational themes which emerged from the data. Fundamental tenets of Critical Consciousness (Friere, 1974) and Transformative Learning Theory (Mezirow, 1978) posit that 
Critical Recognition of the Experiences of Therapeutic Behavioral Strategists in Addressing Student Trauma

people are becoming critically conscious when they start to reflect and the develop some form of awareness. When an individual is able to develop awareness of their own biases, that awareness will help transform the way they build trust and relationships while also learning to collaborate and empower the trust and relationships with students they work with (McKnight, 2004;

Sakamoto \& Pitner, 2005). This was demonstrated in the data in responses such as: "Building relationships is crucial and if teachers or admin do not take the time to establish any kind of relationship with students it can be difficult to identify whether students are experiencing trauma or not. When you build relationships with students you become more invested into their success." These responses really highlight building "trust and relationships" as a point of emphasis throughout the entire interviewing process.

The next theme that began to emerge upon paraphrasing the responses sentence by sentence was the theme of utilizing a "trauma-informed care" lens. Some examples that reflected this are: "We need to do a better job of providing educators with entry level skills where they are able to center their minds to a more trauma aware based framework. Without those kinds of changes, it will continue to be difficult to help students reach their full potential" and "In the field of mental health, when you are able to look at things through a trauma-informed care lens you address behaviors differently because you become more aware of the circumstances that a student may be going through which is causing them to act a certain way." This constant theme of "trauma-informed care" solidified the thought that providing professional development for school staff regarding trauma-informed care is crucial to the success of students experiencing trauma.

\section{Themes and Categories}


Critical Recognition of the Experiences of Therapeutic Behavioral Strategists in Addressing Student Trauma

What follows below are graphical representations of excerpts of analyzed data, displaying how the raw data of responses funneled into the paraphrase phase of the first round of coding and how these connected to the literature of Freire (1974), Mezirow (1978), Kuhn (1962), and Hopper, Bassuk, \& Olivet (2010). These scholars represent the theoretical underpinnings and consequent mindset framing of criticality in the analysis phase of this work. A stated goal of this work was to identify how to redistribute resources and attention in servicing traumatized students properly, and examine whether therapeutic behavioral strategists (TBS) experiences and their practices map onto existing practices of trauma informed care. The results of this work appear to iterate toward a delicate balance of attaching to existing literature while at the same time deviating enough so that new knowledge is developed. The constructed themes stand separate but also similar to the scholars upon whose theories they build. 
Critical Recognition of the Experiences of Therapeutic Behavioral Strategists in Addressing Student Trauma

\begin{tabular}{|c|c|c|c|}
\hline Theme & TBS Practices & TIC Practices & Textual Evidence \\
\hline $\begin{array}{l}\text { Empathy \& } \\
\text { Compassion }\end{array}$ & 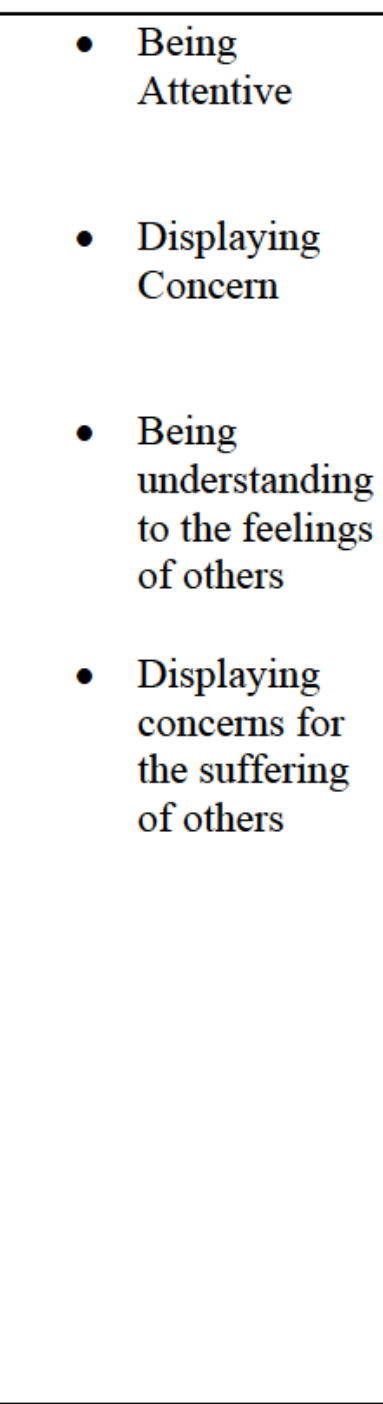 & 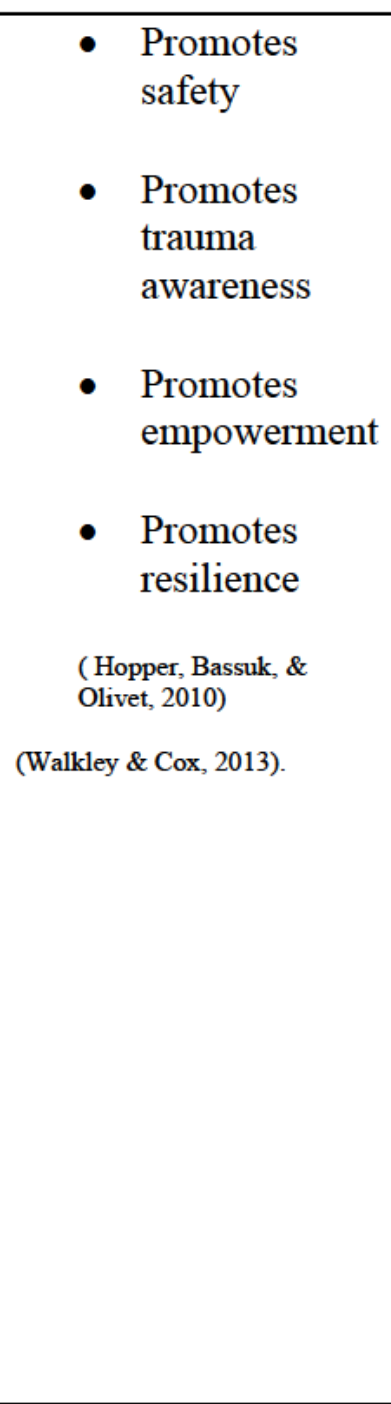 & 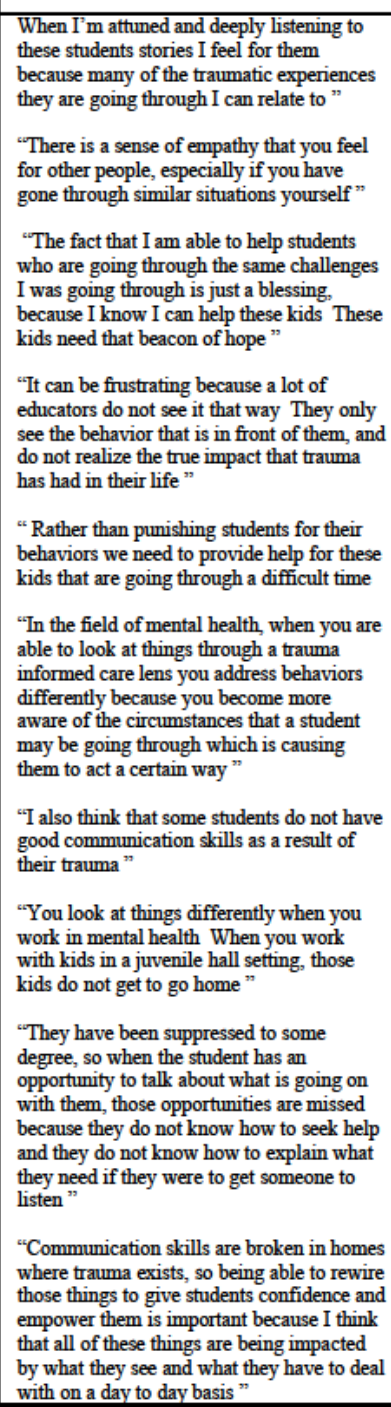 \\
\hline
\end{tabular}

Figure: 7 
Critical Recognition of the Experiences of Therapeutic Behavioral Strategists in Addressing Student Trauma

\begin{tabular}{|c|c|c|c|}
\hline Theme & TBS Practices & TIC Practices & Textual Evidence \\
\hline Awareness & $\begin{array}{l}\text { - } \begin{array}{l}\text { Displaying } \\
\text { concern }\end{array} \\
\text { - Rapport } \\
\text { Building } \\
\text { - Recognizing } \\
\text { Personal Bias } \\
\text { - Recognizing } \\
\text { what others } \\
\text { are going } \\
\text { through }\end{array}$ & $\begin{array}{l}\text { - } \begin{array}{l}\text { Promotes } \\
\text { safety }\end{array} \\
\text { - } \begin{array}{l}\text { Promotes } \\
\text { trauma } \\
\text { awareness }\end{array} \\
\text { - } \begin{array}{l}\text { Promotes } \\
\text { empowerment }\end{array} \\
\text { - Promotes } \\
\text { resilience }\end{array}$ & 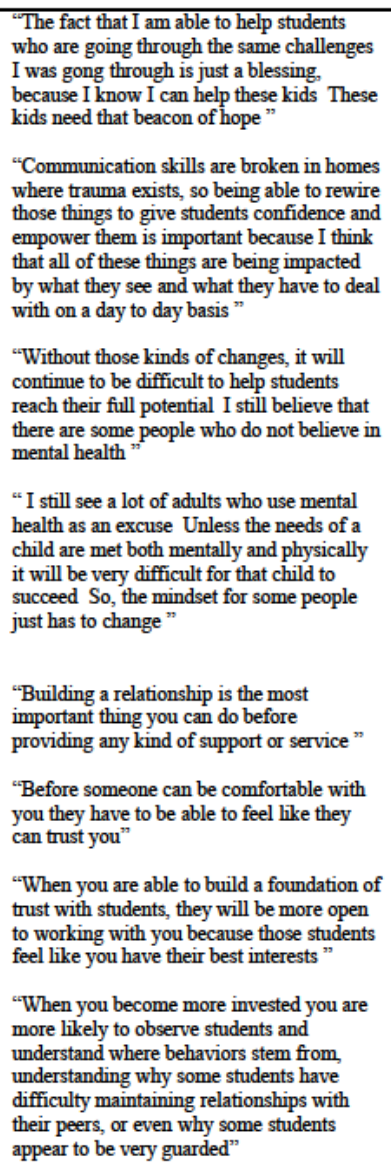 \\
\hline
\end{tabular}


Critical Recognition of the Experiences of Therapeutic Behavioral Strategists in Addressing Student Trauma

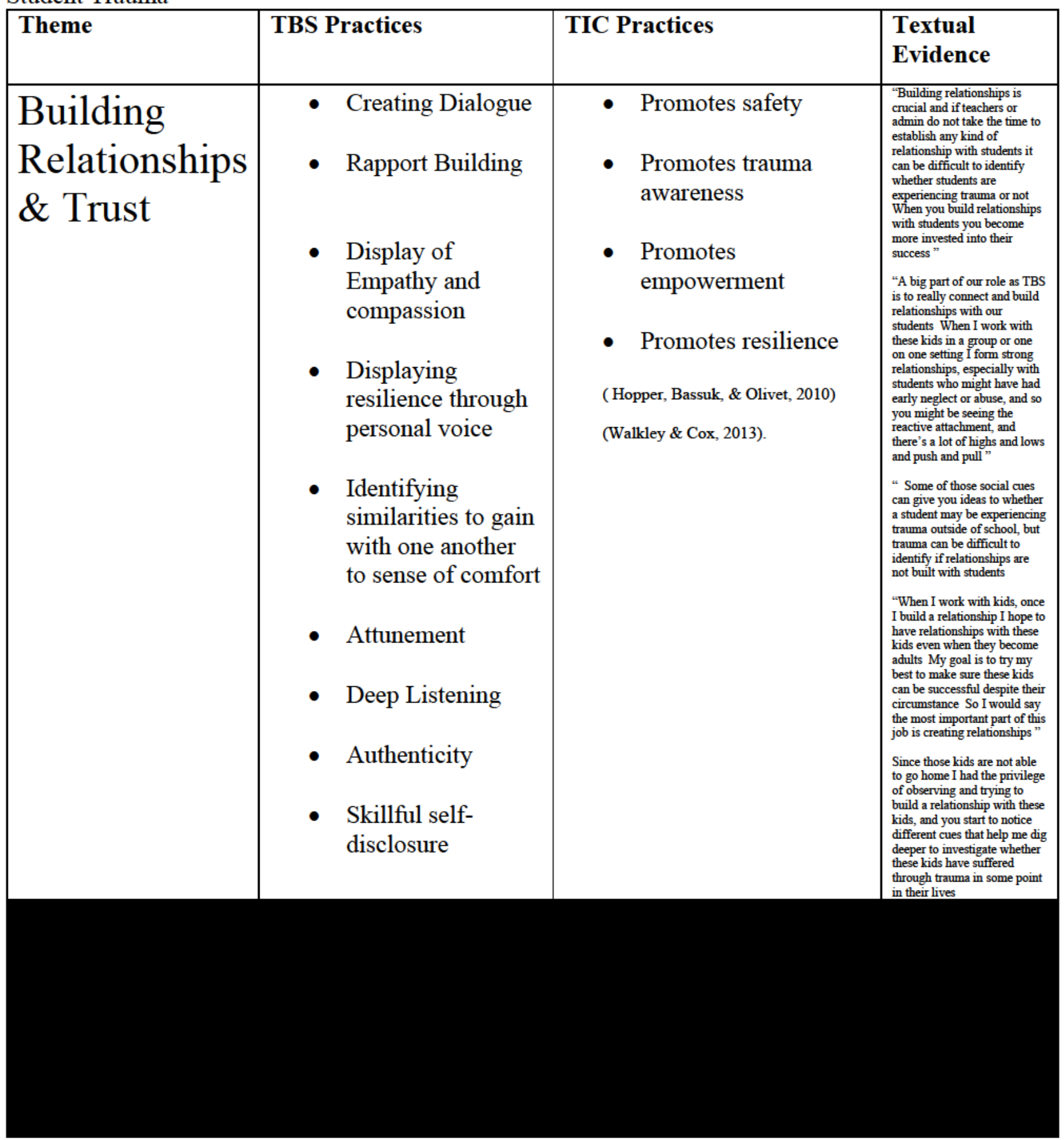


Critical Recognition of the Experiences of Therapeutic Behavioral Strategists in Addressing Student Trauma

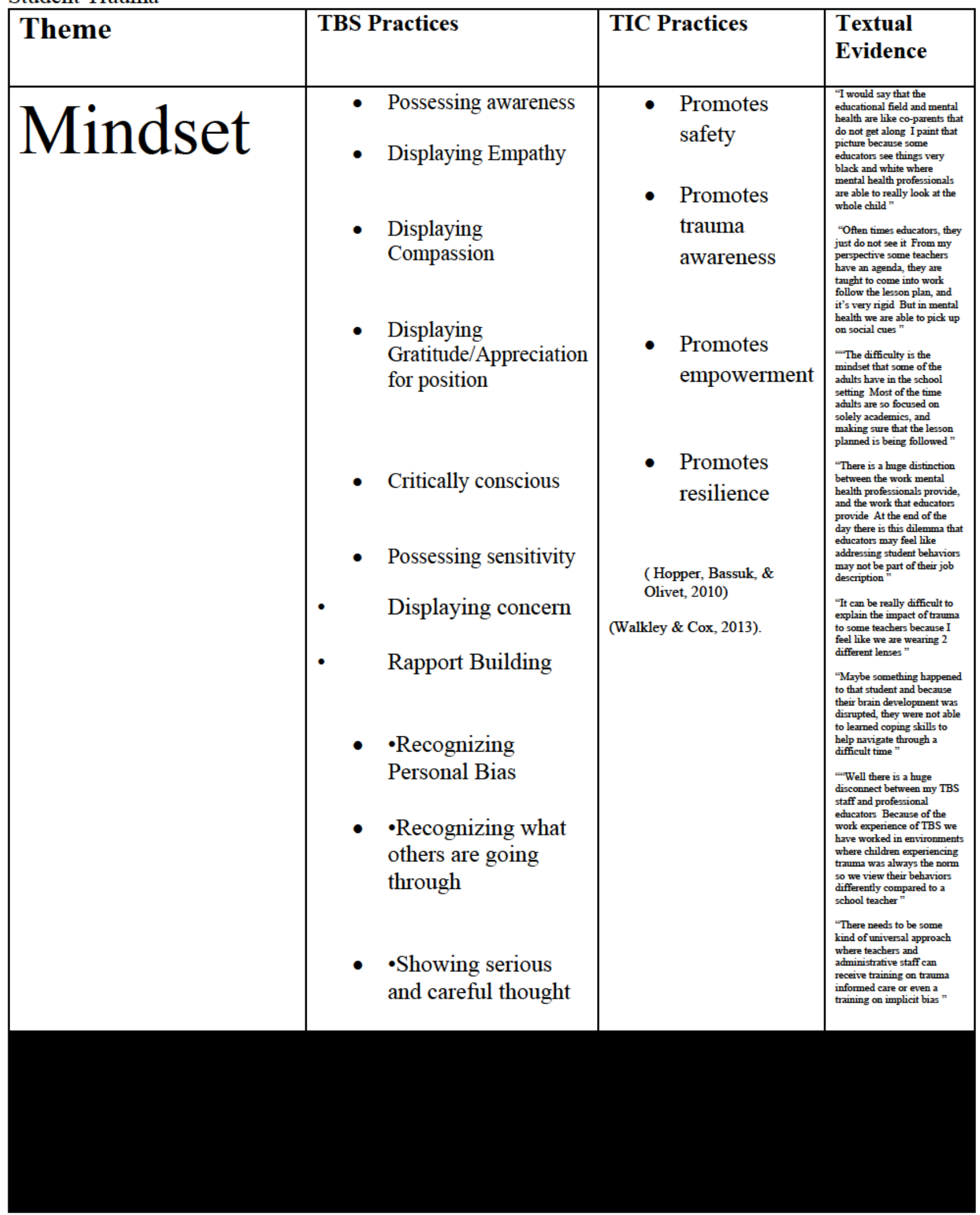


Critical Recognition of the Experiences of Therapeutic Behavioral Strategists in Addressing Student Trauma

\begin{tabular}{|c|c|c|c|}
\hline Theme & TBS Practices & TIC Practices & $\begin{array}{c}\text { Textual } \\
\text { Evidence }\end{array}$ \\
\hline $\begin{array}{c}\text { Trauma Informed } \\
\text { Care }\end{array}$ & $\begin{array}{l}\text { - Possessing awareness } \\
\text { - Displaying Empathy } \\
\text { - Displaying } \\
\text { Compassion } \\
\text { - Displaying } \\
\text { Gratitude/Appreciation } \\
\text { for position } \\
\text { - Critically conscious } \\
\text { - Possessing sensitivity } \\
\text { Promoting } \\
\text { empowerment to } \\
\text { encourage personal } \\
\text { voice }\end{array}$ & $\begin{array}{l}\text { - } \begin{array}{l}\text { Promotes } \\
\text { safety }\end{array} \\
\text { - } \begin{array}{l}\text { Promotes } \\
\text { trauma } \\
\text { awareness }\end{array} \\
\text { - Promotes } \\
\text { empowerment } \\
\text { - Promotes } \\
\text { resilience } \\
\text { (Hopper, Bassuk, \& } \\
\text { Olivet, 2010) } \\
\text { (Walkley \& Cox, 2013) }\end{array}$ & 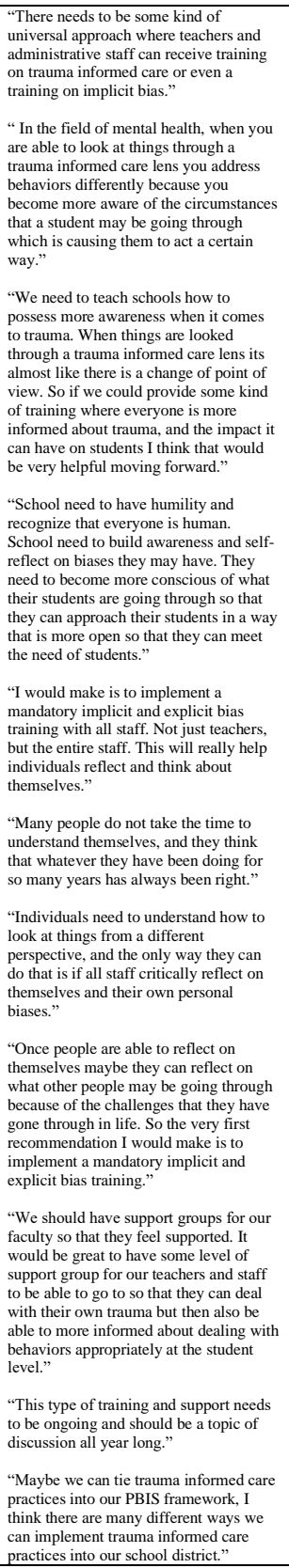 \\
\hline
\end{tabular}


Critical Recognition of the Experiences of Therapeutic Behavioral Strategists in Addressing Student Trauma

Making Meaning of Emerging Themes

As mentioned earlier, the conceptual framework was used as a guide in seeking answers to my research questions. All of the themes that emerged throughout the data analysis phase of this work connect to each element of my conceptual framework. In order to make meaning of the themes that emerged I will rearticulate my questions and use that as a way of organizing my analysis. The first research question asks- How does TBS work with students who have experienced trauma? Hearing the participant responses helped me understand that their job duties were not the most important aspect of their job. Rather it was their approach they possessed going into their job duties that was far more important. The participants explained that their main job duty throughout the day is to conduct one on one or group sessions where they teach elements of social emotional learning. However, the participants explained that their work cannot be effective unless they utilize a trauma informed care approach. Participants explained that there were prerequisites that had to take place before performing their job duties. It was imperative for participants to be reflective and aware of the students they work with. It was imperative for participants to show empathy and compassion for students they serve. It was important for participants to make sure that they were able to build trust and relationships with their students. All of these actions need to take place before performing their job duties, otherwise their work would not be effective.

As I reflect on my experience as a student experiencing trauma, I did not feel connected or engaged in the classroom unless I was able to form a relationship with the instructor. I had a very difficult time having relationships with adults due past trauma with my father. My basketball coach was the only adult I respected mainly because he took the time to get to know what my circumstance was outside of school. I remember during basketball practice I was 
Critical Recognition of the Experiences of Therapeutic Behavioral Strategists in Addressing Student Trauma

feeling angry because my family and I had just gotten evicted from our home the day before. As my coach was correcting me after I had forgotten a play on the court, I started cursing out my coach for no reason because I was so angry with the unfortunate events that were coming my way. Instead of the coach punishing me for cursing him out in front of my teammates, he pulled me aside after practice and asked me what was wrong. When the coach asked me what was wrong, I started crying because no one had asked me that question before. He was the first person within my school campus to ask what was going on with me to make me act out this way. When I understood that he was willing to understand what I was going through, I was able to become vulnerable with him.

I share that story because it connects to the work that TBS practices when working with traumatized students. TBS works with students by making sure they display empathy and compassion with their students. This means that they make it a priority to show concern and understanding for the sufferings or misfortunes of the students they work with. They are able reflect and become aware of how student trauma can impact the way they behave in the classroom. Some of the participants explained how they were able to reflect on their own misfortunes from their past and recognize how they were able to get through those challenges, and share their success in order to promote resilience for students that have been exposed to trauma. It was a priority to make sure that TBS built trust and relationships with students. Building trust and relationships with students allowed their job duties to become more effective because students are more willing to listen to people they have built a relationship with, rather than listening to someone who knows nothing about them.

Without empathy and compassion, without reflection and developing awareness, without building trust and relationships with students it will be difficult to possess the right mindset 
Critical Recognition of the Experiences of Therapeutic Behavioral Strategists in Addressing Student Trauma

going into their job duties. Behind every student behavior, there is a story behind it. My coach could have just punished me for embarrassing him, because I cursed him out in front of my teammates. Instead, he was willing to understand my underlying issues that made me behave that way. From that point on I was able to trust him, and I felt safe whenever I was in his presence because I felt like he cared about me. The way my coach was able to build a relationship with me by becoming aware of my circumstance, and displaying empathy for my circumstances is the kind of work that TBS conducts when they work with students experiencing trauma.

The second question asks- what do TBS's view as challenges in the school setting for children who have experienced trauma? As I was listening to the participant responses it was clear that the biggest challenge TBS had when working with traumatized students was working with school teachers and administrators. There was a constant collide in the approach and mindset between TBS staff and most teachers/administrators when dealing with traumatized students that were misbehaving in the classroom. Based on the participant responses there was a lack of relationship, empathy, and compassion that school staff had with their students. When school staff provide punishment to traumatized students, those punishments only re-traumatize them and embed their trauma even further. TBS would try to explain how punishment would not be appropriate at a certain time especially if formed relationships, empathy, and compassion were lacking. Based on TBS responses educational professionals were very firm with how they conducted things, and there was no room to shift things to help tailor the needs of students experiencing trauma. TBS explained how students would express their frustration regarding the relationships they had with teachers and administrators.

Once I was able to build a solid relationship with my basketball coach I never felt retraumatized when he would punish me when I forgot a play during practice. Coach would punish 
Critical Recognition of the Experiences of Therapeutic Behavioral Strategists in Addressing Student Trauma

his players by making them run laps or do a certain amount of push-ups if you did something wrong. Since my coach built a relationship with me, and I knew that he cared about me because he took the time to build a relationship, I always listened to him. I listened to him because I did not want to let him down. This is the same approach that educators need to make when addressing students that have experienced trauma. Punishment cannot be provided unless a solid foundation is built between the student and educator. If punishment is provided and there is a lack of trust/relationship between an educator and student, that punishment only becomes a disservice for the student. TBS must continue making an effort to help educators understand the importance of building rapport with students before providing punitive measures. TBS must also to continue to help educators learn how to address the meaning behind student behavior. Understanding the meaning behind student behavior can help shift the approach of school staff.

The last research question states- what recommendations can TBS provide in order to help school sites better serve students who have experienced trauma? After reviewing participant responses it is clear that recommending professional development, specifically in the area of trauma informed care, will help TBS and school staff work together and better serve students that have experienced trauma. As we reflect on critical consciousness, transformative learning theory, paradigm shift, and trauma informed care they all make connections to the themes that emerged throughout this study. Unless school staff become more informed about the impact that trauma can have on a student, it will be difficult to reflect and gain awareness, it will be difficult to display empathy and compassion, it will be difficult to build relationships with students, and it will be difficult to possess the appropriate mindset when working with students experiencing trauma. Through TBS responses, all of them explained how training on trauma informed care 
Critical Recognition of the Experiences of Therapeutic Behavioral Strategists in Addressing Student Trauma

really helped shift the way they viewed students, and allowed them to understand themselves as they all experienced hardships during their childhood.

As I reflect on my personal experience there were hardly any adults on school campus that were aware of trauma. When I was a student in grade school, I always viewed myself as a troubled student because that was what the adults had labeled me as. But as I started to learn more about myself through a trauma informed care training in graduate school, I started to understand why I was exhibiting behaviors. Punishments never served justice for me, it only angered me more knowing that the punishment was being provided from a stranger. However, when there were adults that showed me that they cared about me and took the time to build a relationship with me, I always felt safe around them and did not feel the need lash out at people. Trauma informed care needs to be utilized as a universal approach for all school staff so that we can all serve traumatized students appropriately. 
Critical Recognition of the Experiences of Therapeutic Behavioral Strategists in Addressing Student Trauma

\section{Chapter 5: Conclusion}

\section{Summary of Study}

Chapter 1 of this work set the stage for why this study matters. In chapter 1 , I discussed the significant impact that trauma has on students and how traumatic experiences can shape student lives indefinitely. As previously stated, there is not much reliable data to measure the problem of trauma in our schools, however there is a general sense among educators, communicated through their associations, that trauma and trauma-related behavioral issues have reached crisis levels in classrooms across the country. I discussed how trauma affects brain development in children and explained how trauma-related behaviors observed in schools, are increasing the urgency within the education profession to find practical approaches that can help classrooms and communities. Chapter 1 also discussed the difficulties of forming trustful relationship for students experiencing trauma due to their inability to regulate emotions. I also mentioned ways in which educators risk re-traumatizing students unconsciously, and are more likely to expose traumatized students to secondary trauma. Chapter 1 also explained the conceptual framework that was used to guide my research. The conceptual framework focuses on the issue of trauma in schools and is framed around critical consciousness theory, transformative learning theory, paradigm shift theory, and elements of trauma-informed care (TIC). I discussed each theory in depth and explained how the conceptual framework was used as a guide in seeking answers to the research questions. In the last section of Chapter 1, I explained my reasoning, and clarified how and why the entire study revolves around these particular research questions. 
Critical Recognition of the Experiences of Therapeutic Behavioral Strategists in Addressing Student Trauma

Chapter 2 worked through the relevant literature pertaining to the problems and the methods used to address them, as presented in Chapter 1. I outlined a historical background of trauma as an area of study, the various forms of trauma, the significant impact trauma can have on student behaviors, and the impact trauma can have on relationships. From this historical background, the discussion pivoted to surface level investigation of most appropriate approaches when working with students experiencing trauma, that exist in the literature before transitioning into a discussion of what methodology would best address the research questions guiding this work. I then include a brief discussion of my reasoning for choosing qualitative methods, followed by a justification for choosing narrative inquiry to capture the deep, lived experiences of the TBS participants as they share their experiences working with students experiencing trauma. After this discussion, I addressed the current empirical literature that underlies the constructed conceptual lens of Critical Consciousness (Freire, 1970), Transformative Learning Theory (Mezirow, 1978), Paradigm Shift (Kuhn, 1962), in order to bring the reader's attention to the identifying changes needed to shift away from traditional practices when working with students experiencing trauma. Next the concepts of trauma-informed care (Hopper et al., 2010), was discussed to complete the other half of the critical framework, and discussion of the current empirical literature section with the work in the field of trauma-informed care was explained in detail.

In the methods section of Chapter 3, I discussed the research design of this study, followed by a more in-depth discussion of the history and philosophical origins of the narrative inquiry method. I discussed the different strands of narrative inquiry and made the case for why I took a thematic narrative inquiry approach for the purposes of this study. Beyond this, I discussed the purposive sampling technique used to choose the six therapeutic behavioral 
Critical Recognition of the Experiences of Therapeutic Behavioral Strategists in Addressing Student Trauma

strategists (TBS) participants, followed by the setting in which the data collection took place, and a brief discussion of characteristics of the participants. Next followed a positionality statement in which I gave my brief background description and insight into the lens with which I view the world. I also acknowledged the potential bias that may cause concern for trustworthiness in this project due to my positionality. I discussed the necessary tools to prevent potential bias and ensure trustworthiness throughout this study. Finally, I described some of the finer points that were used to obtain institutional review board approval, such as gatekeeper permission from the participating district, the consent form that was used, potential risks to participants, instruments used to collect data, and the data analysis process.

Chapter 4 took us into the new knowledge that this work helped develop, and it brought to light some of the answers to how therapeutic behavioral strategists work with students who have experienced trauma, what TBS view as challenges in the school setting for children who have experienced trauma, and what recommendations TBS would provide in order to help school sites better serve students that have experienced trauma. I reviewed the purpose of the study and follow that with a thorough description of the data analysis process that helped describe the methods in enough detail that the study could be replicated if desired. The findings were then discussed in detail in which the five identified themes of empathy/compassion, reflection/awareness, building trust/relationships, mindset, and trauma informed care were first introduced and explained. Finally, to conclude Chapter 4, I provided a more thorough description of the participants, accompanied by a brief description of their contributions to the data set.

Finally, here in Chapter 5, I bring together the study and summarize in as succinct a manner as possible the efforts that were undertaken over the course of nearly three years to complete this endeavor. As the reader can see upon the conclusion of reading this paragraph, a 
Critical Recognition of the Experiences of Therapeutic Behavioral Strategists in Addressing Student Trauma

research discussion precedes a discussion of implications of this study in which I offer

recommendations for future professional practices to best work with students experiencing

trauma. To complete this work, I take the reader through a brief conclusion, followed by the

limitations that this project experienced, and ending with suggestions for future research.

\section{Research Questions Discussion}

How do TBS work with students who have experienced trauma, and what do therapeutic behavioral strategists (TBS) view as challenges in the school setting for children who have experienced trauma? Both of the first two research questions were addressed at the same time during the data analysis phase of this project. As can be concluded from the tables and discussion

provided in Chapter 4, this research study has narrowed down the thoughts of the six participants on how and why TBS practices are most effective when working with traumatized students compared to traditional education practices, and how similar TBS practices are compared to trauma-informed care practices, creating the five identified themes of:

\section{- Empathy/Compassion}

- Awareness/Reflection

- Building Trust/Relationships

- Mindset

\section{- Trauma Informed Care}

After multiple passes of extensive coding of participant responses, these themes best describe what all participants felt were the most appropriate practices when working with students experiencing trauma. As made evident in the figures from Chapter 4, there were many responses in the data that solidified these themes as the most salient elements to both therapeutic behavioral 
Critical Recognition of the Experiences of Therapeutic Behavioral Strategists in Addressing Student Trauma strategist practices (TBS) and trauma informed care (TIC) practices. The deep questioning and examination of the TBS participants' voices through amplifying their responses helped lead to the conclusion of these five as the themes best representative of their experience.

New Take-Aways from This Process- There were a couple of things I learned from these interviews that I was not aware of before.

1. School sites need to become more informed about trauma as there is still a huge disconnect in approach between educators and mental health professionals.

2. More school districts need mental health professionals to promote trauma awareness.

3. I understand how important this work is to both teachers and administrators who are not trained in trauma informed care and how beneficial it can be for them to embrace trauma informed care and therapeutic behavioral strategists on their school campuses.

Participants expressed their frustration in the way some teachers and administrators approach the behaviors of traumatized students. Displaying empathy and compassion, and building trust and relationships appears to be a difficult thing to do for individuals who are not informed about trauma. For mental health professionals I believe they may need get back to the fundamentals and help educators understand the proper steps of how to build relationships with students. Building relationships is not an easy task, so mental health professionals need to spend more time helping educators understand the appropriate steps to build relationships with students. Students are more likely to be engaged and listen to someone who they have built a relationship with. According to participant responses building relationships is one of the most important parts of their work. 
Critical Recognition of the Experiences of Therapeutic Behavioral Strategists in Addressing Student Trauma

As I was listening to participant responses they mentioned that each of them have a caseload of 170 students or more, and that more than half of those students have been exposed to trauma. Rialto Unified school district is the only district in San Bernardino County that has a program specific to help students experiencing trauma. There is a need for TBS in the district as I have understood the significant impact these mental health professionals have for those students that have experienced trauma. As I reflect on my experience as a traumatized student, I would have benefitted from TBS services. As a student I had difficulty expressing my emotions appropriately, my social skills and brain development were disrupted each time I experienced a traumatic event. TBS would have helped restore my social emotional development, and help me cope with challenging situations more appropriately. After high school there were many opportunities where I could have easily followed the footsteps of my father and turn to drugs in order to escape the pain I was feeling. If I had TBS as a resource when I was in school, I know my opportunities to turn to drugs would be much smaller than they were after I graduated high school. As a community we should want our future generations to become successful, and now that we understand that nearly half of our students are exposed to trauma by the time they reach seventeen years old, it is clear that more school districts need to hire mental health professionals to address the needs of students experiencing trauma.

After listening to participant responses, I understand how important this work is to both teachers and administrators who are not trained in trauma informed care and how beneficial it can be for them to embrace trauma informed care and therapeutic behavioral strategists on their school campuses. TBS was not just brought to the district to teach only students, TBS was also brought into the district to educate school staff on the significance that trauma can have a student. TBSs work experience has been centered around trauma for most of their careers, and 
Critical Recognition of the Experiences of Therapeutic Behavioral Strategists in Addressing Student Trauma

based on their responses they have the same goals that teachers want for their students, and that goal is for all of their students to be successful. School staff and TBS should be in constant communication discussing any concerns that they have for their students. If school staff is having difficulty with behaviors in the classroom TBS is there to consult with them or provide recommendations that would help the student succeed rather than just providing punishment for them. I hope that people reading this work who were not informed about trauma before are able to understand that TIC approaches and TBS approaches are similar and are effective for students experiencing trauma. Creating a culture that promotes safety, resilience, empowerment, and awareness will help traumatized students feel safe while they are in school.

What recommendations can TBS provide in order to help school sites better serve students that have experienced trauma? As is expanded upon further below, the results of this study provide exciting recommendations about what can done to improve professional practices when working with students experiencing trauma. In the following implications section, I present recommendations to guide the development of future professional practices; I then expand upon it in detail, outlining recommendations for optimal developmental considerations.

\section{Implications}

\section{Buy-in from District Leadership}

My first suggestion when designing a trauma-informed care proposal in a school setting, is to establish district leadership buy-in by critically recognizing therapeutic behavioral strategist voices. Once district leadership is able to critically recognize therapeutic behavioral strategist voices, the themes of reflection and awareness will take place. As was unpacked earlier in this work in describing the theme of reflection and awareness, the two provide an interconnected 
Critical Recognition of the Experiences of Therapeutic Behavioral Strategists in Addressing Student Trauma

positive influence toward a paradigm shift to trauma-informed care practices. One of the practical recommendations to receive buy-in from district leadership is to set up a meeting to propose the implementation of trauma informed care practices for all school districts. Setting up a meeting to propose the implementation of trauma informed care as a universal approach will help district leaders understand the perspectives of TBS strategies. This meeting will allow district leaders to listen to the types of language TBS uses, understand their specific concerns, and the opportunities that they see to strengthen the way they work with students experiencing trauma. Another practical step to gain leadership buy-in would be to assign ownership of various elements of trauma informed care to different people that make up the leadership team. When you assign district leaders ownership of various elements of trauma informed care, those leaders will be able to examine the elements of trauma informed care that they have ownership of, and as they examine trauma informed care, this will allow more opportunities for district leadership to consider using trauma informed care as a universal approach. After district leadership has had opportunities to utilize trauma informed care approaches in their everyday work, the next step would be to hold regular meetings to discuss how the approach has been working for them in their work with school staff. Once they are able to recognize how a TIC approach is effective for adults, they will start to understand why a TIC approach is the most appropriate when creating an environment that feels safe for all students.

\section{Professional Development}

In order to make this shift to trauma-informed care practices, all school staff must participate in mandatory professional development on trauma, implicit \& explicit bias, and building relationships with students. The implication of professional development will create opportunities for individuals to reflect on themselves and the environment that surrounds them. 
Critical Recognition of the Experiences of Therapeutic Behavioral Strategists in Addressing Student Trauma

Being able to reflect and gain awareness as an initial step in the process of any paradigm shift is

crucial. Once this foundation of reflection and awareness is created through professional development in areas of trauma, implicit and explicit bias, and building relationships, then the implementation of utilizing trauma informed care practices can begin.

Providing professional development for school staff will help fulfill the goal of using a trauma informed care approach, which not only provides tools to cope with extreme situations but to create an underlying culture of respect, support, resilience, choice \& empowerment, and safety. This research has shown the benefits of practicing trauma-informed care and continuing education on trauma-informed care. The practical implications also emphasized the important TBS skills of building relationships, reflection and awareness, possessing empathy and compassion, shift of mindset, addressing barriers to conduct trauma informed care practices. In order for the rest of the school staff to develop these same attributes, providing professional development in the areas of trauma, implicit \& explicit bias, and building relationships will help create that first step of implementing trauma-informed care practices. These particular implications reflect the lenses of critical consciousness, transformative learning theory, paradigm shift, and trauma-informed care.

\section{Instituting Trauma-Focused Programs in School Districts}

During the interviews, it was clear that therapeutic behavioral strategists played a significant role when working with students experiencing trauma. Therapeutic behavioral strategists provide comprehensive behavioral support services to students, school staff, and parents to address mental health related behavioral challenges that limit a student from receiving full benefit from their educational experience. As described in the emerging themes sections of 
Critical Recognition of the Experiences of Therapeutic Behavioral Strategists in Addressing Student Trauma

this work therapeutic behavioral strategists mirror the same practices of trauma informed care, and the trust and relationships that are built with their students help them embody choice \& empowerment, awareness, resilience, and safety, which are the main four elements of trauma informed care practices. Participant voices highlighted how students feel safe with and will seek help from adults who embody the foundation of trauma-informed care practices. This evidence demonstrates the need for more school districts to institute more trauma focused programs to help students that are exposed to trauma.

\section{Conclusion}

Throughout this long and arduous process, the elegant goal has remained the same: to create something of tangible value that helps improve people's lives. The hope was to examine the role of therapeutic behavioral strategists (TBS) in addressing the impact of trauma to students in public education. Academic and behavioral expectations can be challenging to meet for students in school, and those expectations become nearly impossible to meet for students who have suffered from trauma. Trauma informed teaching is not usually fostered in schools, and most public schools are not trauma-informed. Unfortunately, the reality is that trauma impacts nearly fifty percent of students in public education. Rather than address this fact and work to deconstruct this inequity, I chose to embrace this reality and study methods for improving the way schools work with students experiencing trauma. This study examines the experiences of six therapeutic behavioral strategists (TBS) by listening to their authentic voices as they describe their work with students experiencing trauma. The power of these stories helped the five themes to emerge as the identified catalysts for change in utilizing a trauma-informed care approach in the school setting. In order for significant change to occur, critically recognizing TBS voices through the lenses of critical consciousness, transformative learning theory, complimented with 
Critical Recognition of the Experiences of Therapeutic Behavioral Strategists in Addressing Student Trauma

trauma-informed care need to take place in order to make a paradigm shift in the way we approach students experiencing trauma. The implications of this are that we recognize the voices of professionals that utilize trauma-informed care practices, receive buy-in from district leadership, provide professional development for all school staff, institute trauma-centered programs for more school districts, and implement trauma-informed care as a universal, districtwide approach.

\section{Limitations}

A major limitation for student researchers is the stringent requirements of the institutional review board (IRB), regarding working with minor participants. Studies that may be interested in learning from the experiences of student participants are avoided due to strict requirements. This study may have endeavored to study the voices of the students in regarding how school staff addresses trauma, but this goal was quickly curbed in order to be able to meet IRB requirements in a timely manner.

If the study were designed again, another twist to the design may have been to arrange a time where all participants could have participated in a roundtable discussion together in the same space. The hope for this would be twofold: first, I'd anticipate that a group discussion would massage the memory of all participants, allowing them to remember elements that they would struggle to remember on their own. The second reason for the group discussion would be to study some of the team dynamics in action when presenting their thoughts in a public setting. It would have been interesting to see if the same candor would be in place as in the individual interviews. 
Critical Recognition of the Experiences of Therapeutic Behavioral Strategists in Addressing Student Trauma

As a human I have inherent biases and make assumptions: therefore, the data is processed through my personal lens which may not be generalizable to the majority of therapeutic behavioral strategists. In conclusion, there is a lot of work to be done with students who have experienced trauma. This study gave insight into the challenges these participants experience when working with students in school, as well as ways in which therapeutic behavioral strategists address those challenges. Going forward, it will be important to educate school staff about trauma and trauma-informed care so that students who have experienced trauma are not overlooked or dismissed.

\section{Future Research}

As tends to be the case with many paths of inquiry, the work set forth in this project opens up curious paths of future inquiry. To begin with, any of the six identified themes could be expanded upon and merit substantial study on their own. Narrowing these six down to the most foundational theme of building trust and relationships, I would like to study this theme more extensively in the future. It would be worthwhile to study what conditions foster the best practices of building trust and relationships. Through the TBS participant voices it was evident that school staff had the most difficulty building trust and relationships with their students, as examined through the lens of critical consciousness. Findings show the challenges and barriers for school therapeutic behavioral strategists and also show the need for intervention. There are several points which could be researched further for more information. For example, one could research efficacy of different models of trauma-informed care. Other areas of study could include school satisfaction for children who have experienced trauma or comparison between schools implementing a trauma-informed care model and schools who are not; such schools are likely to 
Critical Recognition of the Experiences of Therapeutic Behavioral Strategists in Addressing Student Trauma

have differing rates of disciplinary actions including detention and suspension, as well as

graduation rates. 
Critical Recognition of the Experiences of Therapeutic Behavioral Strategists in Addressing Student Trauma

\section{References}

Adams, Z. W., McCart, M. R., Zajac, K., Danielson, C. K., Sawyer, G. K., Saunders, B. E., \& Kilpatrick, D. G. (2013). Psychiatric problems and trauma exposure in nondetained delinquent and nondelinquent adolescents. Journal of Clinical Child \& Adolescent Psychology, 42(3), 323331.

Avey, J. B., Luthans, F., \& Jensen, S. M. (2009). Psychological capital: A positive resource for combating employee stress and turnover. Human resource management, 48(5), 677-693.

Bass, B. M., \& Riggio, R. E. (2010). The transformational model of leadership. Leading organizations: Perspectives for a new era, 2, 76-86.

Bandura, A. (1989). Regulation of cognitive processes through perceived self-efficacy. Developmental psychology, 25(5), 729.

Barbuto, J. E. (1997). Taking the charisma out of transformational leadership. Journal of Social Behavior and Personality, 12(3), 689-697.

Beavers, A. (2009). Teachers as learners: Implications of adult education for professional development. Journal of College Teaching \& Learning (TLC), 6(7).

Bell, H., Limberg, D., \& Robinson III, E. M. (2013). Recognizing trauma in the classroom: A practical guide for educators. Childhood Education, 89(3), 139-145.

Berg, A. E. (2017). Trauma in schools: Identifying and working with students who have experienced trauma. 
Critical Recognition of the Experiences of Therapeutic Behavioral Strategists in Addressing Student Trauma

Bethell, C. D., Newacheck, P., Hawes, E., \& Halfon, N. (2014). Adverse childhood experiences:

assessing the impact on health and school engagement and the mitigating role of resilience. Health Affairs, 33(12), 2106-2115.

Blitz, L. V., Anderson, E. M., \& Saastamoinen, M. (2016). Assessing perceptions of culture and trauma in an elementary school: Informing a model for culturally responsive trauma-informed schools. The Urban Review, 48(4), 520-542.

Blodgett, C., \& Lanigan, J. D. (2018). The association between adverse childhood experience (ACE) and school success in elementary school children. School Psychology Quarterly, 33(1), 137.

Bloom, S. L., \& Farragher, B. (2013). Restoring sanctuary: A new operating system for traumainformed systems of care. Oxford University Press.

Bluestein, J. (2001). Creating emotionally safe schools: A guide for educators and parents. HCI.

Brendtro, L. K., \& Longhurst, J. E. (2005). The resilient brain. Reclaiming children and youth, 14(1), $52-60$.

Centers for Disease Control and Prevention. (2018). US Department of Health, and Human Services.(2013). REPORT-Antibiotic Resistance Threats in the United States, 1-114.

Clandinin, D. J. (2016). Engaging in narrative inquiry. Routledge.

Cook-Sather, S. D., Viola, L., Zur, K. B., Rubin, B. Y., \& Riou, B. (2012). Case scenario: perioperative administration of tocotrienols and green tea extract in a child with familial dysautonomia. The Journal of the American Society of Anesthesiologists, 117(3), 639-645. 
Critical Recognition of the Experiences of Therapeutic Behavioral Strategists in Addressing Student Trauma

Conle, C. (2000). Narrative inquiry: Research tool and medium for professional development. European journal of teacher education, 23(1), 49-63.

Conle, C. (2001). The rationality of narrative inquiry in research and professional development. European journal of teacher education, 24(1), 21-33.

Connelly, F. M., \& Clandinin, D. J. (1990). Stories of experience and narrative inquiry. Educational researcher, 19(5), 2-14.

Corbin, J. M., \& Strauss, A. (1990). Grounded theory research: Procedures, canons, and evaluative criteria. Qualitative sociology, 13(1), 3-21.

Coulter, C., Michael, C., \& Poynor, L. (2007). Storytelling as pedagogy: An unexpected outcome of narrative inquiry. Curriculum Inquiry, 37(2), 103-122.

Cranton, P. A. (2002). Teaching for transformation. New directions for adult and continuing education, 93, 63-71.

Cranton, P., \& King, K. P. (2003). Transformative learning as a professional development goal. New directions for adult and continuing education, 98, 31-37.

Creswell, J. W., \& Poth, C. N. (2017). Qualitative inquiry and research design: Choosing among five approaches.[online] Sage publications.

Crosby, S. D. (2015). An ecological perspective on emerging trauma-informed teaching practices. Children \& Schools, 37(4), 223-230.

Crozier, J. C., \& Barth, R. P. (2005). Cognitive and academic functioning in maltreated children. Children \& Schools, 27(4), 197-206. 
Critical Recognition of the Experiences of Therapeutic Behavioral Strategists in Addressing Student Trauma

Darling-Hammond, L., Wei, R. C., Andree, A., Richardson, N., \& Orphanos, S. (2009). Professional learning in the learning profession. Washington, DC: National Staff Development Council, 12.

De Zulueta, F. (2007). The treatment of psychological trauma from the perspective of attachment research. In Responses to traumatized children (pp. 105-121). Palgrave Macmillan, London.

de Zulueta, F. (2014). Post-traumatic stress disorder and attachment: possible links with borderline personality disorder. Clinical Topics in Child and Adolescent Psychiatry, 41.

Dirkx, J. M. (2006). Engaging emotions in adult learning: A Jungian perspective on emotion and transformative learning. New directions for adult and continuing education, 109, 15-26.

Dixon, L. B., McFarlane, W., Hornby, H., \& McNary, S. (1999, April). Dissemination of family psychoeducation: The importance of consensus building. In Schizophrenia Research (Vol. 36, No. 1-3, pp. 339-339). PO BOX 211, 1000 AE AMSTERDAM, NETHERLANDS: ELSEVIER SCIENCE BV.

Elkovitch, N., Latzman, R. D., Hansen, D. J., \& Flood, M. F. (2009). Understanding child sexual behavior problems: A developmental psychopathology framework. Clinical Psychology Review, 29(7), 586-598.

Evans, A., \& Coccoma, P. (2014). Trauma-informed care: How neuroscience influences practice. Routledge.

Felitti, V. J., \& Anda, R. F. (2010). The relationship of adverse childhood experiences to adult medical disease, psychiatric disorders, and sexual behavior: Implications for healthcare. The impact of early life trauma on health and disease: The hidden epidemic, 77-87. 
Critical Recognition of the Experiences of Therapeutic Behavioral Strategists in Addressing Student Trauma

Fecser, M. E. (2015). Classroom strategies for traumatized, oppositional students. Reclaiming Children and Youth, 24(1), 20.

First, M. B., France, A., \& Pincus, H. A. (2004). DSM-IV-TR guidebook. American Psychiatric Publishing, Inc.

Foltz, R. (2008). Medicating relational trauma in youth. Reclaiming Children and Youth, 17(3), 3.

Fox, B. H., Perez, N., Cass, E., Baglivio, M. T., \& Epps, N. (2015). Trauma changes everything: Examining the relationship between adverse childhood experiences and serious, violent and chronic juvenile offenders. Child abuse \& neglect, 46, 163-173.

Freire, Paolo. "Education for critical consciousness London." Sheed and (1974).

Friere, P. (2000). Pedagogy of the oppressed (30th Anniv.). New York: Continuum.

Fritz, G. K. (2017). The National Child Traumatic Stress Network. The Brown University Child and Adolescent Behavior Letter, 33(9), 8-8.

Gabowitz, D., Zucker, M., \& Cook, A. (2008). Neuropsychological assessment in clinical evaluation of children and adolescents with complex trauma. Journal of Child \& Adolescent Trauma, 1(2), 163-178.

Gerdes, K. E., Lietz, C. A., \& Segal, E. A. (2011). Measuring empathy in the 21st century: Development of an empathy index rooted in social cognitive neuroscience and social justice. Social Work Research, 35(2), 83-93. 
Critical Recognition of the Experiences of Therapeutic Behavioral Strategists in Addressing Student Trauma

Ghandour, R. M., Jones, J. R., Lebrun-Harris, L. A., Minnaert, J., Blumberg, S. J., Fields, J., ... \& Kogan, M. D. (2018). The design and implementation of the 2016 National Survey of Children's Health. Maternal and child health journal, 22(8), 1093-1102.

Giesecke, J., \& McNeil, B. (2004). Transitioning to the learning organization.

Giroux, H. A. (2014). When schools become dead zones of the imagination: A critical pedagogy manifesto. Policy Futures in Education, 12(4), 491-499.

Goodman, R. D., \& West-Olatunji, C. A. (2009). Applying critical consciousness: Culturally competent disaster response outcomes. Journal of Counseling \& Development, 87(4), 458-465.

Greeson, J. K., Briggs, E. C., Kisiel, C. L., Layne, C. M., Ake III, G. S., Ko, S. J., ... \& Fairbank, J. A. (2011). Complex trauma and mental health in children and adolescents placed in foster care: Findings from the National Child Traumatic Stress Network. Child welfare, 90(6), 91.

Gubi, A. A., Strait, J., Wycoff, K., Vega, V., Brauser, B., \& Osman, Y. (2019). Trauma-informed knowledge and practices in school psychology: a pilot study and review. Journal of applied school psychology, 35(2), 176-199.

Gurwitch, R. H., Messer, E. P., Masse, J., Olafson, E., Boat, B. W., \& Putnam, F. W. (2016). ChildAdult Relationship Enhancement (CARE): An evidence-informed program for children with a history of trauma and other behavioral challenges. Child abuse \& neglect, 53, 138-145.

Harris, C. (2000). You can't change what you can't see: How developmental stage influences transformative learning. In Challenges of practice: Transformative learning in action conference proceedings (pp. 217-222). The Center for Outreach and Innovation, Teachers College, Columbia University. 
Critical Recognition of the Experiences of Therapeutic Behavioral Strategists in Addressing Student Trauma

Hattie, J. (2012). Visible learning for teachers: Maximizing impact on learning. Routledge.

Hertel, R., \& Johnson, M. M. (2013). How the traumatic experiences of students manifest in school settings. Supporting and educating traumatized students: A guide for school-based professionals, 23-35.

Hinton, C., Miyamoto, K., \& Della-Chiesa, B. R. U. N. O. (2008). Brain research, learning and emotions: implications for education research, policy and practice 1. European Journal of education, 43(1), 87-103.

Hodgdon, H. B., Kinniburgh, K., Gabowitz, D., Blaustein, M. E., \& Spinazzola, J. (2013). Development and implementation of trauma-informed programming in youth residential treatment centers using the ARC framework. Journal of Family Violence, 28(7), 679-692.

Hsiao, K. L., Lu, H. P., \& Lan, W. C. (2013). The influence of the components of storytelling blogs on readers' travel intentions. Internet Research.

Jacobson, D., \& Mustafa, N. (2019). Social identity map: A reflexivity tool for practicing explicit positionality in critical qualitative research. International Journal of Qualitative Methods, 18, 16 Jaycox, L. H., McCaffrey, D., Eiseman, B., Aronoff, J., Shelley, G. A., Collins, R. L., \& Marshall, G. N. (2006). Impact of a school-based dating violence prevention program among Latino teens: Randomized controlled effectiveness trial. Journal of Adolescent Health, 39(5), 694-704.09406919870075.

Jensen, J. U., \& Lundgren, J. (2009). Procalcitonin monitoring in trauma intensive care patients: How helpful is it?. Critical care medicine, 37(6), 2093-2094.

Kasich, J. R., \& Plouck, T. J. (2016). Ohio Behavioral Health Housing Needs Assessment 2015. 
Critical Recognition of the Experiences of Therapeutic Behavioral Strategists in Addressing Student Trauma

Keysers, C. (2011). The empathic brain: How the discovery of mirror neurons changes our understanding of human nature. Lulu. com.

K Hopper, E., L Bassuk, E., \& Olivet, J. (2010). Shelter from the storm: Trauma-informed care in homelessness services settings. The Open Health Services and Policy Journal, 3(1).

Kitchenham, A. (2008). The evolution of John Mezirow's transformative learning theory. Journal of transformative education, 6(2), 104-123.

Klein, S., \& Merritt, D. H. (2014). Neighborhood racial \& ethnic diversity as a predictor of child welfare system involvement. Children and Youth Services Review, 41, 95-105.

Kose, B. W. (2009). The principal's role in professional development for social justice: An empiricallybased transformative framework. Urban education, 44(6), 628-663.

Ko, S. J., Ford, J. D., Kassam-Adams, N., Berkowitz, S. J., Wilson, C., Wong, M., ... \& Layne, C. M. (2008). Creating trauma-informed systems: child welfare, education, first responders, health care, juvenile justice. Professional psychology: Research and practice, 39(4), 396.

Kotsou, I., Nelis, D., Grégoire, J., \& Mikolajczak, M. (2011). Emotional plasticity: conditions and effects of improving emotional competence in adulthood. Journal of applied psychology, 96(4), 827.

Kouzes, J. M., \& Posner, B. Z. (2012). The leadership challenge: How to make extraordinary things happen in organizations. Panarchy, the collapse of the Canadian health care system, 124.

Kuhn, T. (1962). Kuhn’s Structure of Scientific Revolutions. Descargado Abril, 15, 2013. 
Critical Recognition of the Experiences of Therapeutic Behavioral Strategists in Addressing Student Trauma

Lahey, B. B., Rathouz, P. J., Keenan, K., Stepp, S. D., Loeber, R., \& Hipwell, A. E. (2015). Criterion validity of the general factor of psychopathology in a prospective study of girls. Journal of Child Psychology and Psychiatry, 56(4), 415-422.

Lobe, B., Morgan, D., \& Hoffman, K. A. (2020). Qualitative data collection in an era of social distancing. International Journal of Qualitative Methods, 19, 1609406920937875.

Lukens, E. P., \& McFarlane, W. R. (2004). Psychoeducation as Evidence-Based Practice: Considerations for Practice, Research, and Policy. Brief Treatment \& Crisis Intervention, 4(3).

Madera, J. M., Neal, J. A., \& Dawson, M. (2011). A strategy for diversity training: Focusing on empathy in the workplace. Journal of Hospitality \& Tourism Research, 35(4), 469-487.

Maynard, B. R., Farina, A., Dell, N. A., \& Kelly, M. S. (2019). Effects of trauma-informed approaches in schools: A systematic review. Campbell Systematic Reviews, 15(1-2).

McCarty, D., Braude, L., Lyman, D. R., Dougherty, R. H., Daniels, A. S., Ghose, S. S., \& DelphinRittmon, M. E. (2014). Substance abuse intensive outpatient programs: assessing the evidence. Psychiatric Services, 65(6), 718-726.

McInerney, M., \& McKlindon, A. (2014). Unlocking the door to learning: Trauma-informed classrooms \& transformational schools. Education Law Center, 1-24.

MEREDITH, D., \& WHITE-MCMAHON, B. A. K. E. R. (2016). Better behavior-positively!: Brainbased strategies and solutions. Lulu Publishing Services.

Merriam, S. B. (2007). Non-Western perspectives on learning and knowing. 
Critical Recognition of the Experiences of Therapeutic Behavioral Strategists in Addressing Student Trauma

Merriam, S. B., \& Bierema, L. L. (2013). Adult learning: Linking theory and practice. John Wiley \& Sons.

Mezirow, J. (1997). Transformative learning: Theory to practice. New directions for adult and continuing education, 1997(74), 5-12.

Mezirow, J. (1978). Perspective transformation. Adult education, 28(2), 100-110.

Milner IV, H. R. (2007). Race, culture, and researcher positionality: Working through dangers seen, unseen, and unforeseen. Educational researcher, 36(7), 388-400.

Moss, A. S., Wintering, N., Roggenkamp, H., Khalsa, D. S., Waldman, M. R., Monti, D., \&

Newberg, A. B. (2012). Effects of an 8-week meditation program on mood and anxiety in patients with memory loss. The Journal of Alternative and Complementary Medicine, 18(1), 48-53.

Nelson, M. L., \& Neufeldt, S. A. (1998). The pedagogy of counseling: A critical examination. Counselor Education and Supervision, 38(2), 70.

Newcomer, K. E., Hatry, H. P., \& Wholey, J. S. (2015). Conducting semi-structured interviews. Handbook of practical program evaluation, 492.

Norris, F. H., \& Stevens, S. P. (2007). Community resilience and the principles of mass trauma intervention. Psychiatry: Interpersonal and Biological Processes, 70(4), 320-328.

Ochs, E., \& Capps, L. (2009). Living narrative: Creating lives in everyday storytelling. Harvard University Press. 
Critical Recognition of the Experiences of Therapeutic Behavioral Strategists in Addressing Student Trauma

Oehlberg, K., Barg, F. K., Brown, G. K., Taraborelli, D., Stern, M. B., \& Weintraub, D. (2008).

Attitudes regarding the etiology and treatment of depression in Parkinson's disease: a qualitative study. Journal of geriatric psychiatry and neurology, 21(2), 123-132.

Overstreet, S., \& Chafouleas, S. M. (2016). Trauma-informed schools: Introduction to the special issue.

Patton, M. Q. (2002). Qualitative research and evaluation methods. Thousand Oaks. Cal.: Sage Publications.

Perfect, M. M., Turley, M. R., Carlson, J. S., Yohanna, J., \& Saint Gilles, M. P. (2016). School-related outcomes of traumatic event exposure and traumatic stress symptoms in students: A systematic review of research from 1990 to 2015. School Mental Health, 8(1), 7-43.

Perry, B. D. (2001). Bonding and attachment in maltreated children. The Child Trauma Center, 3, 1-17.

Rodgers, C. R., \& Raider-Roth, M. B. (2006). Presence in teaching. Teachers and Teaching: theory and practice, 12(3), 265-287.

Rossen, E., \& Cowan, K. (2013). The role of schools in supporting traumatized students. Principal's Research Review, 8(6), 1-8.

SAMHSA, Substance Abuse. "Mental Health Services Administration.(2011)." Key Substance Use and Mental Health Indicators in the United States: Results from the (2015).

Seidman, I. (1937). (2006). Interviewing as qualitative research: A guide for researchers in education and the social sciences.

Simonich, H. K., Wonderlich, S. A., Erickson, A. L., Myers, T. C., Hoesel, J., Wagner, S., \& Engel, K. (2015). A statewide trauma-focused cognitive behavioral therapy network: Creating an 
Critical Recognition of the Experiences of Therapeutic Behavioral Strategists in Addressing Student Trauma integrated community response system. Journal of Contemporary Psychotherapy, 45(4), 265274.

Sitler, H. C. (2009). Teaching with awareness: The hidden effects of trauma on learning. The Clearing House: A Journal of Educational Strategies, Issues and Ideas, 82(3), 119-124.

Sperling, M., \& Appleman, D. (2011). Voice in the context of literacy studies. Reading Research Quarterly, 46(1), 70-84.

Souers, K., \& Hall, P. (2016). Fostering resilient learners: Strategies for creating a trauma-sensitive classroom. ASCD.

Taylor, E. W. (2017). Transformative learning theory. In Transformative learning meets bildung (pp. 1729). Brill Sense.

Thomas, B., Scott, B., \& Pooler, D. K. (2015). Increasing the use of trauma-sensitive lens for school case managers: A training assessment. Journal of Adolescent and Family Health, 7(1), 4.

Thomas, K. (1962). The structure of scientific revolutions.

Thomas, M. S., Crosby, S., \& Vanderhaar, J. (2019). Trauma-informed practices in schools across two decades: An interdisciplinary review of research. Review of Research in Education, 43(1), 422452.

Valencia, R. R. (1997). Conceptualizing the notion of deficit thinking. The evolution of deficit thinking: Educational thought and practice, 19(1), 1-12.

Walkley, M., \& Cox, T. L. (2013). Building trauma-informed schools and communities. Children \& Schools, 35(2), 123-126. 
Critical Recognition of the Experiences of Therapeutic Behavioral Strategists in Addressing Student Trauma

Watts, R. J., Griffith, D. M., \& Abdul-Adil, J. (1999). Sociopolitical development as an antidote for oppression - theory and action. American journal of community psychology, 27(2), 255-271.

Woodbridge, M. W., Sumi, W. C., Thornton, S. P., Fabrikant, N., Rouspil, K. M., Langley, A. K., \& Kataoka, S. H. (2016). Screening for trauma in early adolescence: Findings from a diverse school district. School Mental Health, 8(1), 89-105.

White-McMahon, M., \& Baker, P. W. (2019). The Hopeful Brain: Neurotransactional Repair for Disconnected Children and Youth. Lulu Press, Inc.

Willis, C. (2009). Young children with autism spectrum disorder: Strategies that work. YC Young Children, 64(1), 81 .

Wolpow, R., Johnson, M. M., \& Hertel, R. (2009). The heart of learning and teaching. Olympia, WA: Office of Superintendent of Public Instruction (OSPI) Compassionate Schools.

Writer, L. A. W. Ohio Laws and Rules.(2015). Ohio revised code, 3301-35.

Zhang, W., \& Lu, J. (2009). The practice of affective teaching: a view from brain science. International Journal of Psychological Studies, 1(1), 35. 
Critical Recognition of the Experiences of Therapeutic Behavioral Strategists in Addressing Student Trauma

\section{Appendix A}
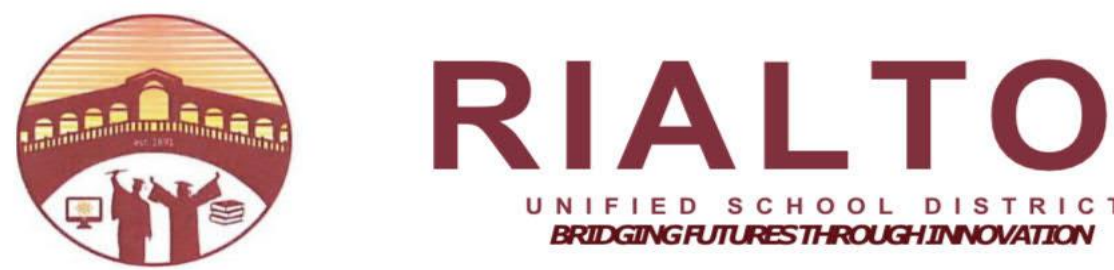

U N I F I E D S C H O O L D I S T R I C T BRIDGINGPUTURESTHROUGHINNOVATION

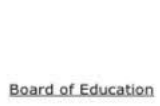

Nancy G. ם'Kelley President

Dina Walker Vice President

Joseph W. Martinez

Clerk

Joseph Ayala

Member

Edgar Montes

Member

Superintendent

Dr. Cuauhtemoc Avila
November 3, 2020

To Whom It May Concern:

The purpose of this letter is to inform you that I give Nathan Ambrosio permission to conduct the research entitled Critical Recognition of the Experiences of Therapeutic Behavioral Strategists in Addressing Student Trauma within the Rialto Unified School District. I understand that Nathan Ambrosio will send a request to Therapeutic Behavioral Strategists (TBS) of Rialto Unified School District to participate in this study.

Mr. Ambrosio will recruit six (6) participants to conduct interviews, using narrative inquiry methods, analyzing the collected data through the constructed lens of critical consciousness, transformative learning theory, paradigm shift, and elements of trauma informed care, then crafting a framework of the most effective practices possible when working with students experiencing trauma.

The following are the study procedures:

- The interviews will not take place during the work hours of the employees.

- The interviews will take approximately 60 to 120 minutes spaced over two to three separate interviews.

- The identity of the participants will not be reported in the research study.

- Results of the research study will be provided upon request to participants and interested parties via email/mail at the conclusion of the study.

- Participation in the study is voluntary and participants may withdraw from the study at any time.

Respectfully, Cuauhtemoc Avila, Ed.D. Superintendent 
Critical Recognition of the Experiences of Therapeutic Behavioral Strategists in Addressing Student Trauma

\section{Appendix B}

\section{Interview Question Protocol}

\section{Introduction}

- Thank you for taking the time to meet with me and for agreeing to participate in my study on critically recognizing therapeutic behavioral strategists' experiences in addressing student trauma. My name is Nathan Ambrosio, I am a doctoral student at the University of Redlands and this interview is part of the data collection process for my dissertation research project. This interview will last approximately $30-45$ minutes. I will be audio recording the interview to make sure I have all of the information you give me. I will also be asking you to review the transcript for the interview for accuracy once it has been transcribed.

- All information in the interview will be kept confidential. Your name will be changed in any report written regarding this study. If there are any questions you do not wish to answer, that is your choice and you may choose to end this interview at any time.

- If you are willing to participate, please state so.

- With your permission I would like to audio record this interview. The purpose of recording this conversation is because I will not be able to write as quickly as you speak. It is important that I get your responses in their entirety. If you consent to audio-recording please let me know.

- Please speak loud and clear so your entire responses will be recorded.

- Do you have any questions with what I have explained?

\section{General Background Information}


Critical Recognition of the Experiences of Therapeutic Behavioral Strategists in Addressing Student Trauma

- How long have you worked with children experiencing trauma?

- How does trauma impact students in school?

- How long have you worked in the field of education?

- Have you ever worked with students experiencing trauma in the school setting?

- How does your experience impact you as a mental health professional?

\section{Therapeutic Behavioral Strategist Experience}

- What is your role as a therapeutic behavioral strategist at the school district?

- As a therapeutic behavioral strategist (TBS), what are some of the things that you do when working with students experiencing trauma?

- What do TBS view as challenges in the school setting when working with students experiencing trauma?

- What are some of the connecting themes that you capture when working with traumatized students?

- What are some of the barriers you notice when working with traumatized students in the school setting?

- What recommendations can TBS provide in order to help school sites best serve students experiencing trauma?

\section{Closing}

- Is there anything you would like to add regarding your experience before I turn off the recorder?

- Thank you for participating in this interview. 
Critical Recognition of the Experiences of Therapeutic Behavioral Strategists in Addressing Student Trauma

\section{Appendix C}

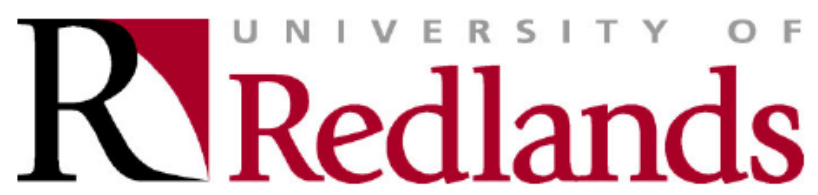

\section{Consent to Participate in a Research Study}

(For use with adult subjects only)

What follows is a consent form that explains what will be happening if you choose to participate in this research study. The first section (Investigator Information) should have been completed by the investigator. If this section is incomplete, do not continue with the study. Do not participate if this study has not been assigned an IRB approval number. The information you need to provide begins on Page 2 . Please read each section carefully.

\section{Investigator Information (to be completed by Principle Investigator)}

IRB approval number: 2020-51-REDLANDS

Title of project: Critical Recognition of the Experiences of Therapeutic Behavioral Strategists in Addressing Student Trauma

Name of principle investigator (PI): Nathan Ambrosio

Email of PI: Nathan_ambrosio@redlands.edu

Telephone number of PI:

Department or major of PI: Education 
Critical Recognition of the Experiences of Therapeutic Behavioral Strategists in Addressing Student Trauma

Position held by PI:

[] faculty

[ ] administrator/staff

$[\mathrm{X}]$ student

If $\mathrm{Pl}$ is a student or staff, complete the remainder of Investigator Information, otherwise go to next page.

Name of faculty or administrator sponsor: Dr. Jose Lalas

Department or office of sponsor: Education

Position held by sponsor:

$[X]$ faculty

[ ] administrator 
Critical Recognition of the Experiences of Therapeutic Behavioral Strategists in Addressing Student Trauma

General information about this study

You are being asked to participate in a research study. Whether you do is entirely up to you. You may refuse to participate, or you may stop participating at any time for any reason without any penalty.

The purpose of this inquiry is to recognize the impact trauma has on the primary and secondary level of public education through therapeutic behavioral strategist perspectives, and understand how to appropriately respond to students experiencing trauma. This dissertation critically studies and amplifies the voices of therapeutic behavioral strategists' (TBS) participants in the Rialto Unified School District using narrative inquiry methods.

You are being asked to participate in this study because you are a therapeutic behavioral strategist (TBS) at the Rialto unified school district (RUSD) working with students experiencing trauma. A total of 6 TBS's employees from RUSD will be interviewed for this project.

\section{How long this will take (i.e., duration of participation)}

If you choose to participate in this study, your involvement will take about $60-120$ minutes spaced over 2 -3 separate interviews.

\section{What will happen if you participate in this study}

If you choose to participate in this study you will be interviewed twice in semi-structured, open interviews lasting roughly $30-45$ minutes. The first interview will ask general questions related to your participation and experience working with students experiencing trauma. This interview will be transcribed and analyzed then brought back to you in the second interview where you will get a chance to clarify any responses and corroborate the themes that are identified. A third interview can be scheduled if there is considerable clarification and clean-up needed of the transcriptions upon the completion of the second interview.

\section{Audiotaping}

You will be audiotaped to be sure I capture all of the details of your perspective on working with students experiencing trauma. In this interview you will be identified as a TBS facilitator and assigned a number 
Critical Recognition of the Experiences of Therapeutic Behavioral Strategists in Addressing Student Trauma

based on when you are interviewed. Upon transcription and acceptance of this study as satisfactorily completed all audio recordings will be destroyed to protect your voice from dissemination and recognition.

\section{Protecting your privacy}

People who participate in this study will not be identified in any report or publication about this study. Although every effort will be made to keep the research records private, there may be times when federal or state law requires the disclosure of such records, including personal information. This is unlikely to happen, but if disclosure is required, the investigator will take whatever steps are allowable by law to protect the privacy of your personal information. In some cases, your information in this research study could be reviewed by representatives of the University of Redlands, research sponsors, or government agencies for purposes such as quality control or safety.

\section{What will happen if you experience any problems or discomforts during or after your participation}

It is possible that there are unknown risks or discomforts. Please report any problems immediately to the researcher.

Anything you do, including participating in research, carries with it some chance that something problematic or unwanted may happen. Although the researcher may direct you to medical, psychological, or other services, any costs related to such problems are your or your insurance company's responsibility.

\section{Questions about this study}

You may ask and have answered any question about the research. If you have questions or concerns, you should contact student Nathan Ambrosio at phone: email:

nathan ambrosio@redlands.edu advisor Dr. Jose Lalas at Jose lalas@redlands.edu.

\section{Questions or concerns about the investigators, staff members, and your participation in the study}

This study was approved by the University of Redlands Institutional Review Board (IRB). This board tries to ensure that your rights and welfare are protected if you choose to participate in the study. If you have 
Critical Recognition of the Experiences of Therapeutic Behavioral Strategists in Addressing Student Trauma

any questions about your role or how you were treated by the research personnel, you may contact the Chair of the IRB at Jessica Hehman@redlands.edu or by telephone at 909-748-8469.

\section{Participant's Agreement}

$\mathrm{I}$,

\section{Print Name Above}

have read the information presented above. I have asked all questions I had at this time. I voluntarily agree to participate in this research study.

\begin{tabular}{|l|l|}
\hline & \\
\hline Signature of Research Participant & Date \\
\hline
\end{tabular}

To be completed by researcher:

Print Name of Person Obtaining Consent 
Critical Recognition of the Experiences of Therapeutic Behavioral Strategists in Addressing Student Trauma

Signature of Person Obtaining Consent

Date 